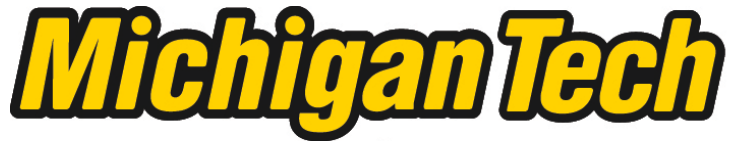 \\ Michigan Technological University Create the Future Digital Commons @ Michigan Tech
}

2012

\section{Lava discharge rate estimates from thermal infrared satellite data at Pacaya Volcano, Guatemala}

Hilary A. Morgan

Michigan Technological University

Follow this and additional works at: https://digitalcommons.mtu.edu/etds

Part of the Geology Commons

Copyright 2012 Hilary A. Morgan

\section{Recommended Citation}

Morgan, Hilary A., "Lava discharge rate estimates from thermal infrared satellite data at Pacaya Volcano, Guatemala ", Master's Thesis, Michigan Technological University, 2012.

https://doi.org/10.37099/mtu.dc.etds/335

Follow this and additional works at: https://digitalcommons.mtu.edu/etds

Part of the Geology Commons 
LAVA DISCHARGE RATE ESTIMATES FROM THERMAL INFRARED

SATELLITE DATA AT PACAYA VOLCANO, GUATEMALA

By

Hilary A. Morgan

A THESIS

Submitted in partial fulfillment of the requirements for the degree of MASTER OF SCIENCE

(Geology)

MICHIGAN TECHNOLOGICAL UNIVERSITY

2012

(C) 2012 Hilary A. Morgan 
This thesis, "Lava Discharge Rate Estimates from Thermal Infrared Satellite Data at Pacaya Volcano, Guatemala," is hereby approved in partial fulfillment of the requirements for the degree of MASTER OF SCIENCE in the field of Geology.

Department of Geological and Mining Engineering and Sciences

Signatures:

Thesis Advisor

Simon A. Carn

Committee Member

Andrew J.L. Harris

Committee Member

William I. Rose

Department Chair

Wayne Pennington

Date 


\section{Table of Contents}

List of Figures..................................................................................................................................

List of Tables .......................................................................................................................................6

Acknowledgements .......................................................................................................................7

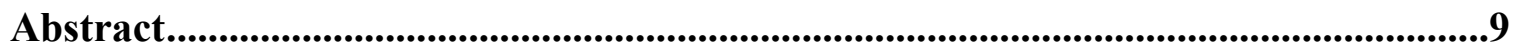

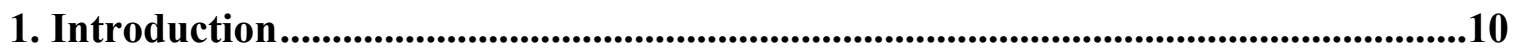

1.1 Geologic Background …………….............................................................10

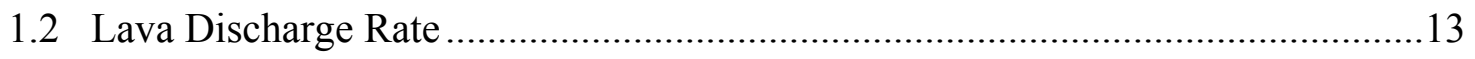

1.3 Satellite-Based Thermal Infrared Remote Sensing of Lava Flows.........................14

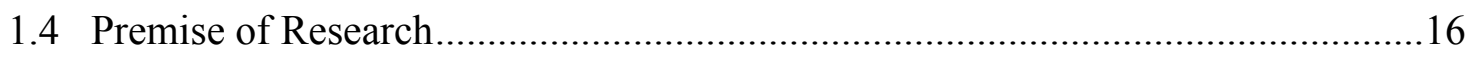

2. Methodology …...........................................................................................................................18

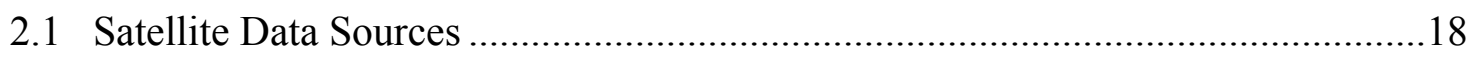

2.1.1 Moderate Resolution Imaging Spectroradiometer (MODIS) ...................18

2.1.2 Geostationary Operational Environmental Satellites (GOES)..................18

2.2 Data Acquisition and Image Processing ...............................................................19

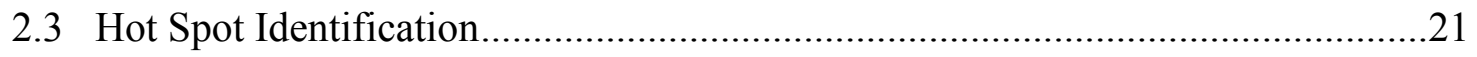

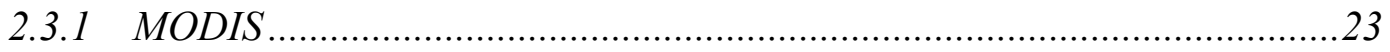

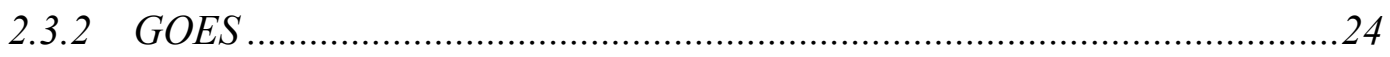

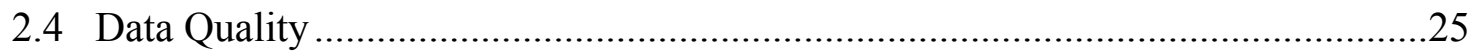

2.5 Time-averaged Discharge Rate Calculation ………..........................................27

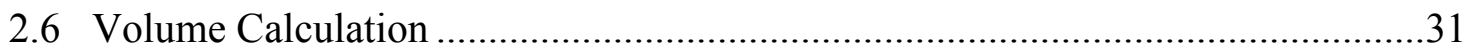

2.7 Two Methods of Determining Conversion Factor "M" ............................................32

2.7.1 Method 1: Best-Fitting................................................................................ 32

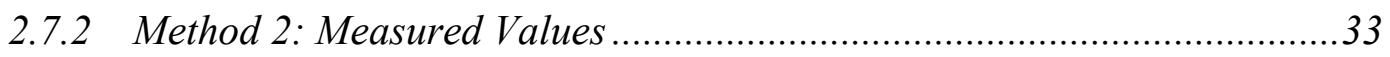

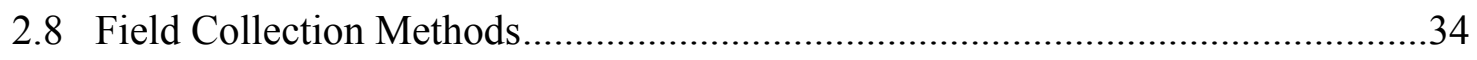

2.9 Measurement of Physical Properties.................................................................38

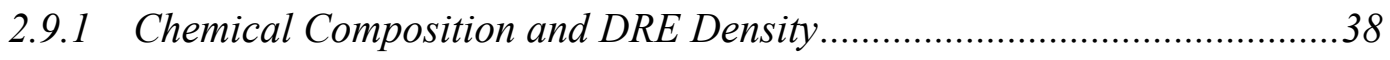

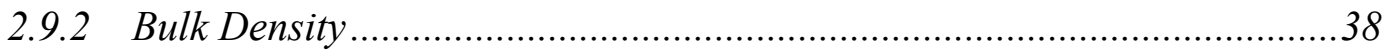




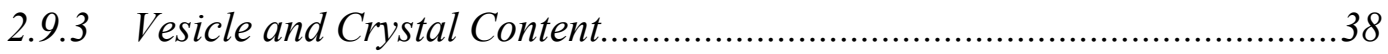

2.10 Long-term Magma Supply Rate.......................................................................39

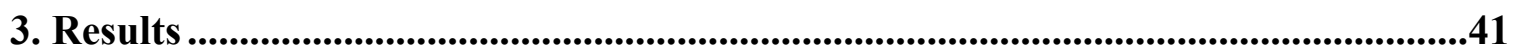

3.1 Satellite Data Quality and Temporal Coverage ..................................................41

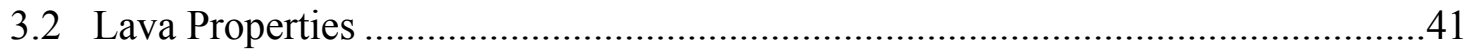

3.2.1 Chemical Composition and DRE Density .............................................41

3.2.2 Bulk Density and Measured Vesicularity …….........................................4

3.2.3 FOAMS Output (Vesicle and Crystal Content)........................................45

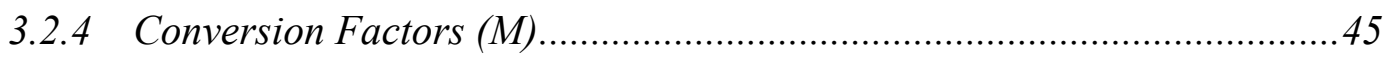

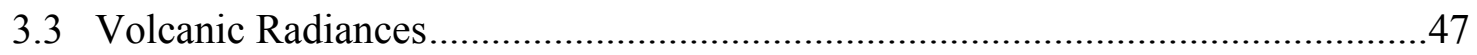

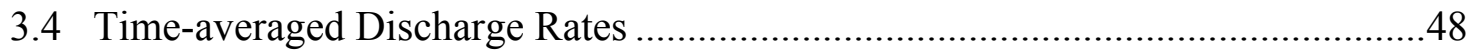

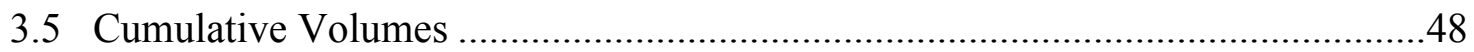

3.6 Down-flow Variation in the May 2010 and 2006-2008 Flows.............................48

3.7 Long-term Magma Supply Rate.........................................................................

4. Discussion ................................................................................................................................56

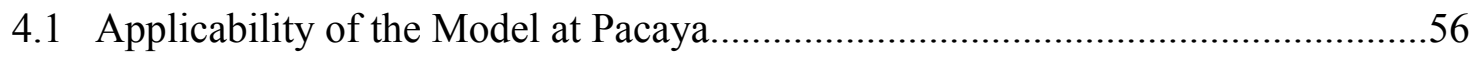

4.1.1 Comparison of MODIS and GOES Datasets ..........................................56

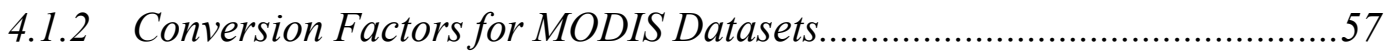

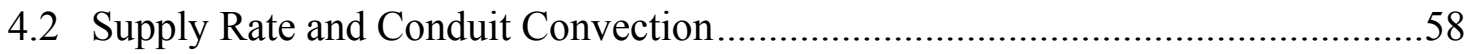

4.3 Implications for Hazard Mitigation ..................................................................6

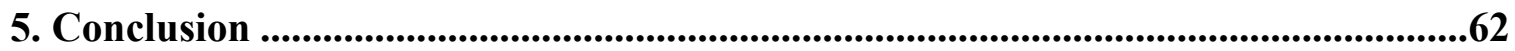

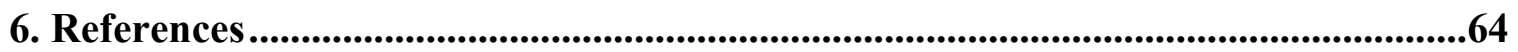

7. Appendices...................................................................................................................70

7.1 A: Examples of MODIS and GOES Hotspots .................................................70

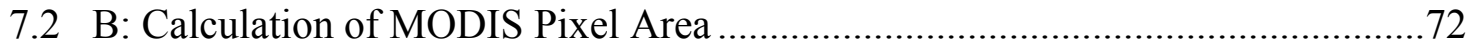

7.1 C: Major Element Compositions of Pacaya's Lavas and Calculated Densities.....73

7.1 D: Calendars Representing Satellite Data Coverage ...........................................76

7.1 E: TADR and Cumulative Volume Time Series Calculated via Method 2 ............78 


\section{List of Figures}

Figure 1.1 Map of the Central American Volcanic Arc ...........................................11

Figure 1.2 Google Earth image of the Pacaya volcanic complex .............................12

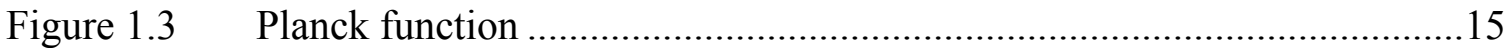

Figure 2.1 Representation of a single-pixel MODIS hot spot containing two thermal components ........................................................................21

Figure 2.2 Example of variation in hot spot size and relative intensity throughout the life of the 2004-2005 lava flow ...................................................23

Figure 2.3 Representations of unsaturated and saturated hot spots..........................24

Figure 2.4 Example of crust and core sampling locations in a lava flow...................35

Figure 2.5 Map of sampling locations from January 2012 fieldwork .........................36

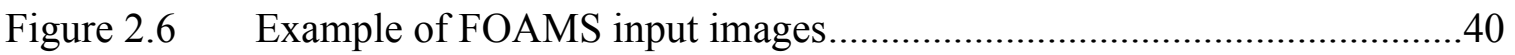

Figure 3.1 Average DRE densities for each of the four sampled flows ....................43

Figure 3.2 Average bulk densities for each of the four sampled flows......................44

Figure 3.3 Average vesicularities for each of the four sampled flows ......................44

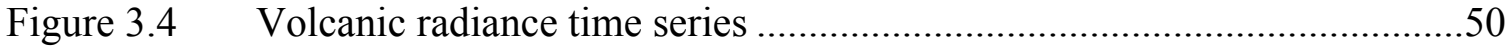

Figure 3.5 Time-averaged discharge rate and cumulative volume time series (Method 1) ..................................................................................51

Figure 3.6 Down-flow variation of bulk density in the 2010 flow.............................54

Figure 3.7 Down-flow variation of bulk density in the 2006-2008 flow ...................54

Figure 3.8 Long-term magma supply rate and cumulative volume over 20 years ......55

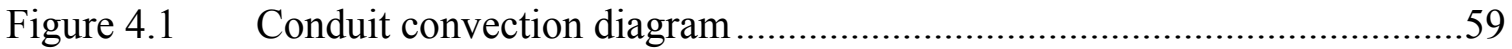

Figure $7.1 \quad$ Examples of MODIS and GOES hot spots ........................................ 70

Figure 7.2 Calendars representing satellite data coverage .....................................76

Figure 7.3 Time-averaged discharge rate and cumulative volume time series (Method 2) 


\section{List of Tables}

Table 2.1 Specifications for MODIS and GOES sensors …………………….........19

Table 2.2 All lava flows that occurred after the availability of MODIS data and

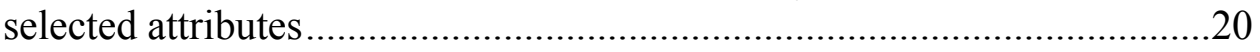

Table 2.3 Input parameters for the time-averaged discharge rate estimation

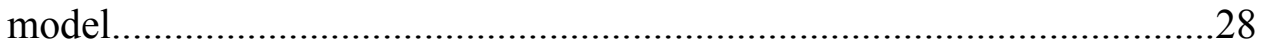

Table 2.4 Sample locations and analyses performed on each sample ........................37

Table 3.1 Major element chemical compositions for new Pacaya samples.................42

Table 3.2 Vesicles and crystal volume percentages calculated using FOAMS .........45

Table 3.3 Parameters used in the time-averaged discharge rate models for both methods 1 and 2 for MODIS datasets .......................................................46

Table 3.4 Parameters used in the time-averaged discharge rate models for both methods 1 and 2 for GOES datasets ......................................................... 47

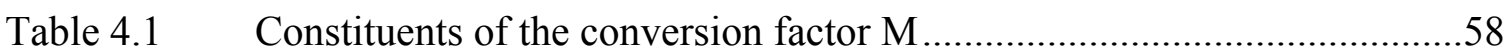

Table 7.1 Major element chemical compositions (weight \%) from Eggers [1971]...73

Table 7.2 Major element chemical compositions (weight \%) from Bardinzteff \& Deniel [1992] .............................................................................

Table 7.3 Major element chemical compositions (weight \%) from Matías [2009] ...75 


\section{Acknowledgements}

Completing a Master's degree through the new International Volcanology and Geotechniques (INVOGE) program has been a demanding, yet exceptionally rewarding experience and was an irreplaceable first plunge into a career in volcanology. I could not have made it through the rough spots without the support and encouragement of many friends and colleagues.

I have received generous financial support for this research and for my entire journey as a graduate student at both Michigan Technological University (MTU) and Université Blaise Pascal (UBP). The INVOGE program has provided me with two years of full support and the unique opportunity to serve as one of the first American students to study at the Master's level at UBP's Laboratoire Magmas et Volcans. Upon my arrival at MTU after spending a year in France, the Department of Geological and Mining Engineering and Sciences funded my travel to the Geological Society of America and American Geophysical Union annual conferences where I presented my research-inprogress and received valuable feedback. The fieldwork for this research was fully funded by PIRE Grant \#0530109. Laboratory analyses of rock samples, as well as associated travel costs, were funded by a grant from the LMV. Thanks to all of my funding sources for making it possible for me to focus on research and academics during a very hectic period of my life.

Many, many thanks to my committee members; Dr. Simon Carn, Dr. William Rose, and Dr. Andrew Harris (UBP) for their guidance and support as I navigated the perils of a brand new international Master's program. I would also like to thank Dr. Benjamin Van Wyk De Vries (UBP) for facilitating the integration of my fellow American classmates and myself into the daunting French academic system. It takes an extraordinary amount of enthusiasm and persistence to successfully organize, fund, and manage INVOGE, and I greatly appreciate their tireless efforts that have made it so successful.

I would also like to thank the many individuals who have supported this research. Thanks especially to my fellow pioneering INVOGE student, Lauren Schaefer, who organized our trip to Guatemala and helped me survive there for two weeks with poor 
Spanish. I could never have collected so many lava samples without the help of my caballos, Chet Hopp and Jordan Van Sickle. Thanks also to Brianna Hetland and Edrick Ramos for their assistance in the field. Thanks very much to Lucia Gurioli, who spent six long weeks helping me with grueling lab work, Mhammed Benbakkar, who coached me through my first ICP-AES chemical analysis, and the myriad researchers at the LMV who supported this research. Thanks also to Andrea Steffke who taught me how to obtain satellite imagery and provided the GOES imagery for Pacaya, and to Rüdiger EscobarWolf, who was always happy to answer my questions and offer advice. Amie Ledgerwood and Kelly McLean are single-handedly responsible for keeping me on-track both abroad and at MTU.

Most of all, thanks to my wonderful fiancé, who grudgingly endures the sporadic travel schedule and financial difficulties that accompany a life of international volcanochasing, yet has never once wavered in his support of my dreams. Thank you, James. Where would I be without you? 


\section{Abstract}

Time-averaged discharge rates (TADR) were calculated for five lava flows at Pacaya Volcano (Guatemala), using an adapted version of a previously developed satellite-based model. Imagery acquired during periods of effusive activity between the years 2000 and 2010 were obtained from two sensors of differing temporal and spatial resolutions; the Moderate Resolution Imaging Spectroradiometer (MODIS), and the Geostationary Operational Environmental Satellites (GOES) Imager. A total of 2873 MODIS and 2642 GOES images were searched manually for volcanic "hot spots". It was found that MODIS imagery, with superior spatial resolution, produced better results than GOES imagery, so only MODIS data were used for quantitative analyses. Spectral radiances were transformed into TADR via two methods; first, by best-fitting some of the parameters (i.e. density, vesicularity, crystal content, temperature change) of the TADR estimation model to match flow volumes previously estimated from ground surveys and aerial photographs, and second by measuring those parameters from lava samples to make independent estimates. A relatively stable relationship was defined using the second method, which suggests the possibility of estimating lava discharge rates in nearreal-time during future volcanic crises at Pacaya. 


\section{Introduction}

\subsection{Geologic Background}

The Pacaya complex (Guatemala; $14.381^{\circ} \mathrm{N}, 90.601^{\circ} \mathrm{W}$ ) is one of many currently active volcanic centers along the Central American Volcanic Front, which stretches over $1100 \mathrm{~km}$ from Mexico to Panama (Figure 1.1). Volcanism in this region results from the northeast-trending subduction of the Cocos plate beneath the Caribbean plate [Mann et al., 2007], producing a densely occupied volcanic arc with average spacing between volcanoes of $27 \mathrm{~km}$ [Carr et al., 2003]. Pacaya is located in southeastern Guatemala just outside the southern rim of the actively resurging Amatitlán caldera [Wunderman and Rose, 1984], and is only about $30 \mathrm{~km}$ from the capital city.

Eggers [1971] provides the first thorough description of Pacaya's eruptive history and divides it into three distinct phases. Phase I was characterized by the growth of a large, ancestral andesitic cone of undetermined age, very few outcrops of which exist today. Phase II commenced with an increase in explosive activity, voluminous pumice eruptions, and lava dome construction. Ash deposits have dated the span of Phase II activity to between 40 k.y. and 1.27 m.y. \pm 0.57 m.y. ago [Eggers, 1971]. Finally, Phase III (which is further divided into the initial, historical, and modern subphases) has produced primarily basaltic lava flows and associated tephras that have continued to erupt to the present day.

The start of Phase III activity was dated via tephrachronology to less than $23 \mathrm{k} . \mathrm{y}$. B.P. by Kitamura and Matías [1995]. Activity throughout Phase III has been highly episodic; eruptive periods featuring emission of basaltic lava and tephra last 100 to 300 years and are separated by longer repose periods of 300 to 500 years [Conway et al., 1992]. Phase III lavas are mostly porphyritic olivine basalts exhibiting no significant temporal chemical or petrographic variation [Eggers, 1971; Bardinzteff and Deniel, 1992; Matías, 2009]. The collapse of a cone built during the initial period of Phase III produced a prominent scarp that has been dated to between 2000 and 400 years B.P. [Vallance et al., 1995]. The scarp protrudes along the western side of the currently active cone, presenting a topographical barrier to lava flows [Matías, 2009]. The historical subphase 


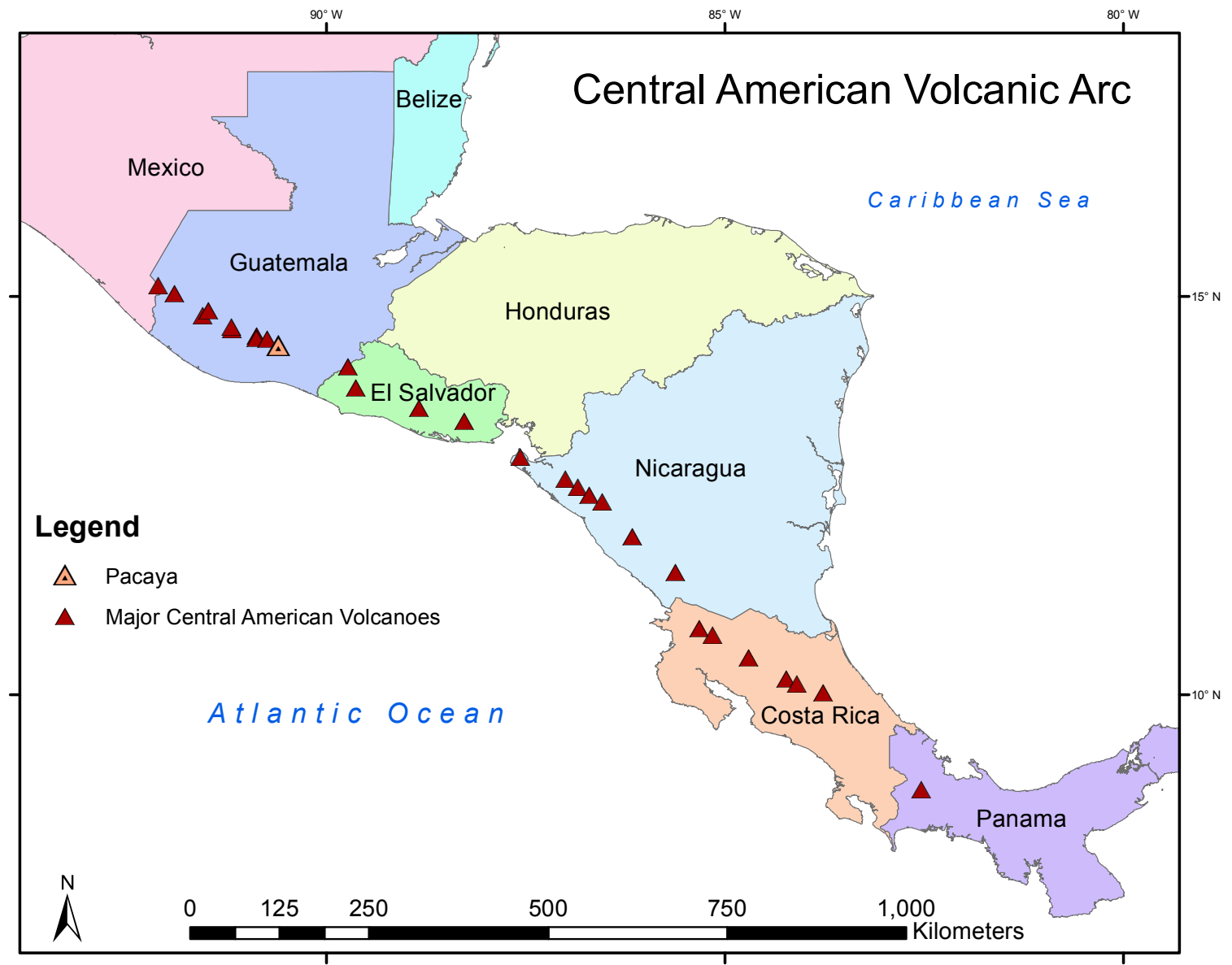

Figure 1.1: Map of the Central American Volcanic Arc. Recently active (Quaternary) volcanoes are shown in red. Pacaya is located is southeastern Guatemala.

began in 1565 when the first reliable account of an eruption was recorded; other major eruptions are thought to have occurred in 1756 and 1880 [Eggers, 1971]. After nearly a century of repose, Pacaya awoke on March 10, 1961 and the regular activity that has persisted to the present day is referred to as the modern subphase. The center of modern activity is the MacKenney Cone, which has been steadily constructed of lava flows and tephra erupted during episodes of Strombolian and Vulcanian activity [Eggers, 1983].

The main volcanic hazards posed by Pacaya include tephra fall, lava flow, and debris avalanche [Vallance et al., 1995]. During the May 2010 eruption, tephra affected an area of over $100 \mathrm{~km}^{2}$ and ballistics damaged structures up to $3.5 \mathrm{~km}$ north of the vent [Escobar-Wolf, unpublished data, 2012]. Lava flows have tended not to extend beyond the immediate vicinity of the flanks of the MacKenney cone and are blocked to the east 


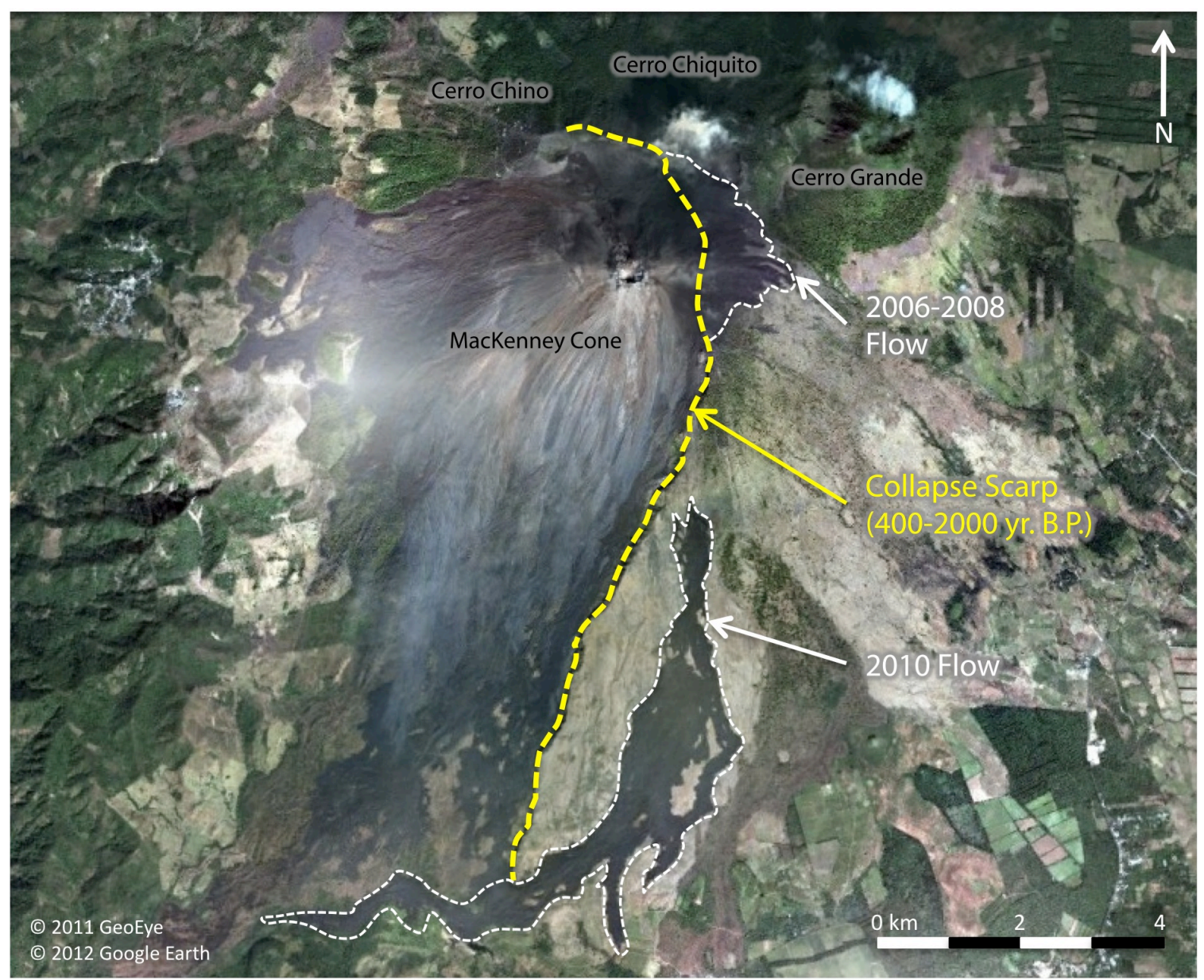

Figure 1.2: Aerial image of the Pacaya volcanic complex from December 13, 2010. The modern center of activity is the MacKenney cone, which is contained by the collapse scarp (yellow dashed line). The 2006-2008 flow (which overran the scarp) and the 2010 flows (which occurred outside of the main center of activity) are outlined in white. (C) Google Earth, (C) GeoEye.

by the collapse scarp [Matías, 2009]. However, during a 27-month-long effusive event from 2006 to 2008, lava finally filled the valley between the cone and the scarp and breached the barrier for the first time (Figure 1.2). During the May 2010 eruption, a new vent opened to the east of the collapse scarp where no modern lava flows have originated. The ensuing flow advanced rapidly down a stream channel, eventually reaching a length of $\sim 5 \mathrm{~km}$ and destroying three structures [Escobar-Wolf, unpublished data, 2012].

The formation of a new vent outside of the modern area of activity and the breaching of a significant topographic barrier present unique circumstances for lava flow risk assessment. Future work will need to account for the possibility of lava reaching previously untouched areas and affecting new communities. It is therefore important to 
expand the current understanding of effusive activity at Pacaya, especially the rates at which lava flows are fed, this being a primary control on final flow dimensions [Harris et al., 2007].

\subsection{Lava Discharge Rate}

This text adopts the lava flow discharge rate terminology as defined by Harris et al. [2007]. An instantaneous effusion rate is the volume flux of erupted lava feeding a flow at any point in time. An eruption rate is defined as the total volume of lava accumulated at a given time during an eruption divided by the time elapsed since the start of the eruption. Mean output rate is the final volume of a lava flow divided by the total duration of the eruption. The term time-averaged discharge rate (TADR) refers to volume flux averaged over a given time period. Volume fluxes calculated via the approach of this study are most accurately termed TADR [Wright et al., 2001].

Discharge rate, defined in any of the ways above, is an important physical parameter that is empirically related to a lava flow's final area and length [e.g., Walker, 1973; Wadge, 1978; Malin, 1980; Pieri and Baloga, 1986; Pinkerton and Wilson, 1994; Kilburn and Lopez, 1988; Harris et al., 2007]. Discharge rate estimates are valuable in emergency planning and hazard mitigation efforts. Through modeling and near-real-time estimation of discharge rate, lava flow paths and extents can be estimated and used to create hazard maps, which then guide the development and enactment of emergency procedures as well as issuing of appropriate warnings [e.g., Harris and Rowland, 2001; Rowland et al., 2005; Del Negro et al., 2008, Wright et al., 2008; Ganci et al., 2012].

Though discharge rates are tremendously useful for both short and long-term risk assessment, it is notoriously difficult to obtain very precise measurements. Direct measurements of channel dimensions and active flow velocity can yield good estimates, but require ground access to an active flow and the exposure of geologists to arguably unnecessary risk [e.g., Guest et al., 1987; Barberi et al., 1993; Calvari et al., 2003]. Additionally, isolated, instantaneous measurements do not provide a good representation of fluctuations in discharge rate throughout the life of a flow. Post-eruption measurements of total erupted volume can be used to calculate a mean output rate if the 
duration of the eruption is also known; however these types of estimates are also unable to resolve temporal variation in discharge rate [e.g., Wadge, 1981; Rowland, 1996]. More recently, both ground-based [e.g., Calvari et al., 2005; Harris et al., 2005] and satellitebased thermal infrared (TIR) imagery [e.g., Harris et al., 1997a; Wright et al., 2001] have been used to estimate TADR. Satellite-based remote sensing methods are particularly attractive because they provide a quicker, safer, and less expensive alternative to ground-based measurements and also allow the study of activity that otherwise could not be accessed due to geographic, financial, or political restrictions.

\subsection{Satellite-Based Thermal Infrared Remote Sensing of Lava Flows}

Any object at a temperature above absolute zero emits radiation continuously throughout the electromagnetic spectrum, and the amount of emission varies as a function of wavelength. The relationship between temperature $(T)$, wavelength $(\lambda)$, and spectral radiance $(L(\lambda, T))$ is described by the Planck Function:

$$
L(\lambda, T)=2 \pi h c^{2} \lambda^{-5}\left[\exp ^{\frac{h c}{\lambda k T}}-1\right]^{-1}
$$

where $h, c, \lambda, k$, and $T$ are Planck's constant $\left(6.625 \times 10^{-34} \mathrm{~J} \cdot \mathrm{s}\right)$, the speed of light in a vacuum $\left(2.9979 \times 10^{8} \mathrm{~m} \cdot \mathrm{s}^{-1}\right)$, wavelength $(\mathrm{m})$, Boltzmann constant $\left(1.38 \times 10^{-23} \mathrm{~J} \cdot \mathrm{K}^{-1}\right)$, and temperature $(\mathrm{K})$, respectively. Figure 1.3 illustrates the Planck function graphically. There are three important points to note about this graph. First, as an object increases in temperature, the peak of emitted radiation shifts towards shorter (higher energy) wavelengths (Wien's Displacement Law). So, the amount of radiation emitted by freshly erupted lava at $1000^{\circ} \mathrm{C}$ at a wavelength of $4 \mu \mathrm{m}$ (mid-wavelength infrared region, or MIR) is an order of magnitude higher than the amount radiated at $11 \mu \mathrm{m}$ (longwavelength infrared region, or LIR). Second, the emission curves for objects of all temperatures converge towards longer wavelengths, so that the difference in emission between objects of distinct temperatures becomes less apparent with increasing wavelength. Third, emission drops off abruptly towards shorter wavelengths.

The wavelength at which an object's emission peaks is proportional to the temperature of that object. For example, the maximum emission from an object at $\sim 5800^{\circ}$ 


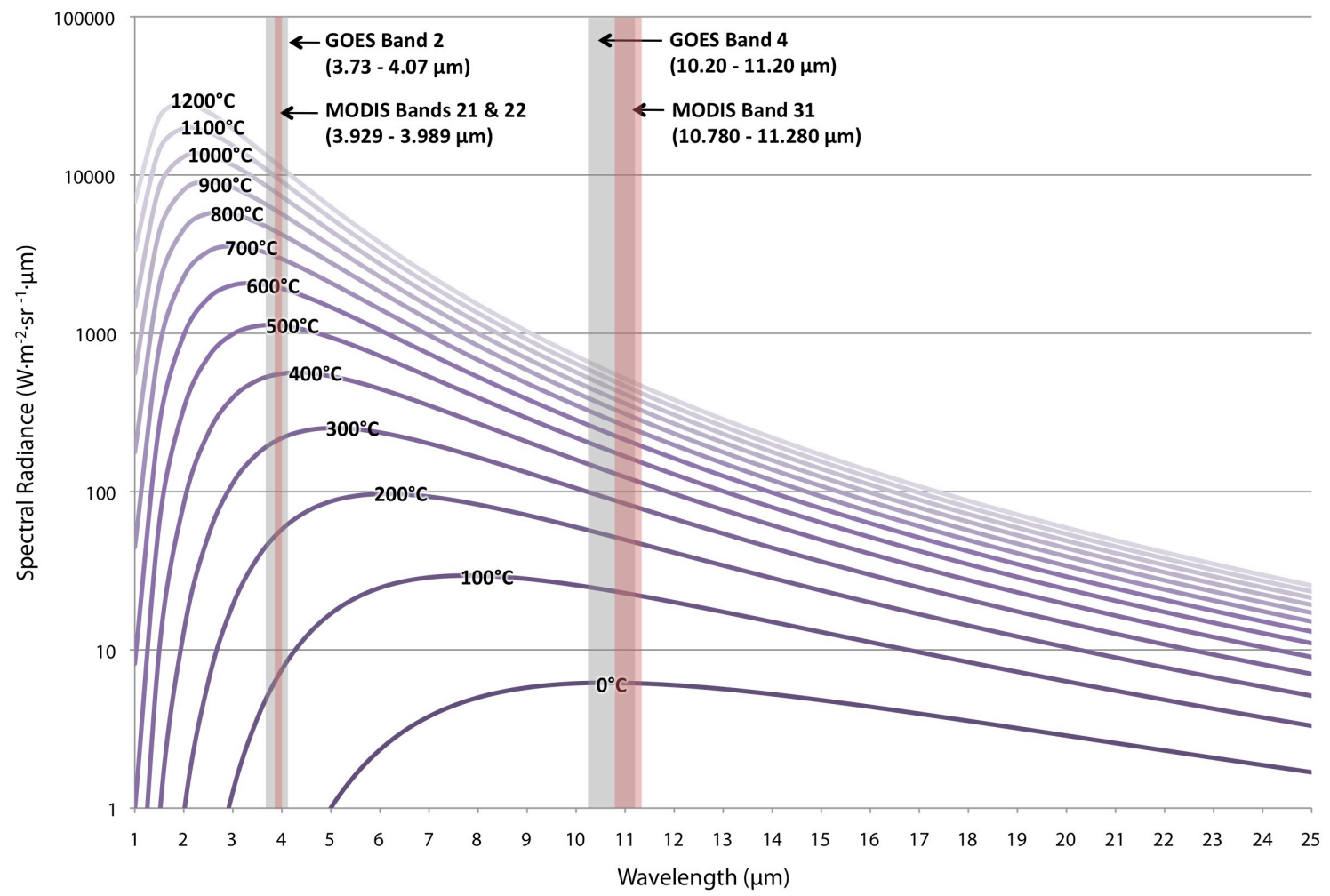

Figure 1.3: Radiance as a function of wavelength and temperature as predicted by the Planck function. Bandwidths of the MODIS and GOES bands used in this research are represented as red and gray bars, respectively. The thermal infrared region is from $\sim 3$ to $\sim 15 \mu \mathrm{m}$. Temperature curves are labeled at the peak of emitted radiance. GOES band 2 and MODIS bands $21 \& 22$ detect radiation around $4 \mu \mathrm{m}$ in the mid-infrared region (MIR) where emission from lava peaks, while GOES band 4 and MODIS band 31 detect radiation around $11 \mu \mathrm{m}$ in the long-wavelength infrared region (LIR), where emission from objects at ambient temperatures peak. See text for further discussion.

$\mathrm{K}$ (e.g. the sun) occurs at the wavelength corresponding to visible yellow light ( $\sim 500$ $\mu \mathrm{m})$. If the amount of radiation emitted by an object at a given wavelength is known, then its temperature can be derived, and vice versa (if the object is assumed to be a blackbody). Most of the emission by terrestrial materials $\left(\sim 0-1000^{\circ} \mathrm{C}\right)$ occurs in the infrared region (Figure 1.3), and this is the basis of TIR remote sensing of lava flows.

There are many spaceborne imaging systems that detect terrestrial radiation in the infrared region and at spatial resolutions appropriate for the detection of volcanic heat sources. The two sensors chosen for this project are the Moderate Resolution Imaging Spectroradiometer (MODIS) and the imager carried by the Geostationary Operational Environmental Satellites (GOES). MODIS records pixel values in units of spectral radiance $\left(\mathrm{W} \cdot \mathrm{m}^{-2} \cdot \mathrm{sr}^{-1} \cdot \mu \mathrm{m}^{-1}\right.$; watts per meter-squared per steradian per micron), and the 
GOES Imager records pixel values in temperature Kelvin (K). Since the former units are not particularly useful to the volcanological community, it is desirable to convert spectral radiance measurements into heat or volume flux, which then have a variety of applications. TIR satellite imagery is used to identify, monitor, and analyze a variety of volcanic phenomena such as lava flows [e.g., Harris and Baloga 2009; Harris et al., 2011], lava lakes [e.g., Oppenheimer, 1998; Wright and Pilger, 2008], ash plumes [e.g., Gangale et al., 2010; Newman et al., 2012], and even pyroclastic flows [Thouret et al., 2010].

A method for calculating TADR from the heat flux measured over a lava flow was initially described by Pieri and Baloga [1986] and Crisp and Baloga [1990], and was applied to TIR satellite data by Harris et al. [1997a]. This technique employs a twocomponent mixed-pixel model to estimate the area of active lava present in a pixel that would be required to produce the observed radiance. This model applies only to coolinglimited flow, and not to volume-limited flows. In this model, it is assumed that a pixel contains two thermal components; the lava and the ambient ground. By measuring or estimating the amount of radiation emitted by the two components, the area of the lava flow can be found. This is discussed in detail in section 2.3. The derived area is then used to calculate the heat loss from the flow and subsequently, volume flux. The resulting value is a TADR rather than an instantaneous effusion rate [Wright et al., 2001]. An adapted version of this approach was used here to calculate TADR time series for several lava flows at Pacaya.

\subsection{Premise of Research}

Pacaya's activity during the modern eruptive subphase (1961 - present) has been relatively well documented. Matías [2009] compiled a detailed volcanological map of Pacaya and a corresponding database containing information on 248 lava flows erupted between 1961 and 2009. The database includes statistics such as flow length, surface area, thickness, and duration for each flow, as well as calculations including mean output rates and volumes for each flow. This thorough dataset provides the independent estimates that make it possible to calibrate and validate the satellite-based TADR 
calculation method of Harris et al. [1997a] specifically at Pacaya. The objectives of this research are to:

1. Estimate lava discharge rates for a subset of Pacaya's modern flows using the satellite-based method described by Harris et al. [1997a] in two ways; first by best-fitting initial data to the independent estimates of Matias [2009], and second by measuring the parameters of the TADR model from rock samples.

2. Compare results from MODIS and GOES sensors and explore the possibility of combining datasets to provide more complete coverage of eruptive periods, and to make inferences on the feasibility of using low-spatial, high-temporal resolution imagery for calculating lava discharge rates at Pacaya.

3. Measure the physical characteristics of individual lava flows to uncover any significant differences between flows that may influence the TADR model.

4. Potentially define a relationship between discharge rate and supply rate at Pacaya, and to make inferences about the dynamics of, and hazards posed by, this persistently active system.

5. Lay the groundwork for future lava flow emplacement modeling and the creation of a hazard map based on historic and possible future vent locations and discharge rates. 


\section{Methodology}

\subsection{Satellite Data Sources}

\subsubsection{Moderate Resolution Imaging Spectroradiometer (MODIS)}

The MODIS sensor was chosen for this project because it provides moderate spatial resolution data (1-km in infrared wavelengths) that are downloadable directly from NASA for no cost at http://modis.gsfc.nasa.gov/data. The MODIS instrument is carried on both the Aqua and Terra satellites. Both are polar-orbiting, sun-synchronous satellites that pass over a given point on the equator twice per day, and travel six hours apart from each other [Guenther et al., 2002]. Terra passes over Pacaya at about 1030 and 2230 LST, and Aqua passes over Pacaya at about 0130 and 1330 LST. Their complimentary configuration provides between four and six images containing Pacaya per day. MODIS/Terra science-quality data are available from February 2000 and MODIS/Aqua data from July 2002. MODIS collects data in 36 spectral bands at spatial resolutions ranging from $250 \mathrm{~m}$ to $1000 \mathrm{~m}$. The primary bands used here are band 21 ( $\sim 4$ $\mu \mathrm{m}$, band 22 (also $\sim 4 \mu \mathrm{m}$ ), and band $31(\sim 11 \mu \mathrm{m})$, each of which has 1-km spatial resolution at nadir (Table 2.1). Band 22 is more sensitive than band 21, but saturates at a lower temperature. Though MODIS provides reasonable spatial resolution for the purposes of detecting lava flows, its relatively poor temporal resolution warrants supplementation with a second dataset.

\subsubsection{Geostationary Operational Environmental Satellites (GOES)}

GOES data were chosen as a supplement to MODIS data because of their very high temporal resolution. The GOES series of satellites are geostationary, remaining in a fixed position relative to a given point on the Earth's surface. The GOES Imager scans the entire Earth disc approximately every 26 minutes, and can image smaller sections of the disc very rapidly $\left(<1\right.$ minute) $[N A S A, 2006]$. The GOES East satellite position $\left(75^{\circ}\right.$ $\mathrm{W}, 0^{\circ} \mathrm{N}$ ) provides the best view of Guatemala. GOES 12 was active at this position from July 2001 to April 2010 (the entire duration of this investigation). The GOES Imager collects data in five spectral bands at various spatial resolutions [NASA, 2006]. The bands 
used here are band $2(\sim 4 \mu \mathrm{m})$ and band $4(\sim 11 \mu \mathrm{m})$, each of which has 4-km resolution at nadir (Table 2.1).

\subsection{Data Acquisition and Image Processing}

The temporal breadth of this investigation was limited primarily by the availability of satellite data during lava flow activity at Pacaya. Of the 248 lava flows listed by Matias [2009], a subset of ten flows occurred since the first availability of science-quality data from MODIS/Terra (February 2000). Table 2.2 lists those flows and some of their attributes. MODIS Level 1B Calibrated Radiance products were obtained from NASA's LAADS Web distribution center. GOES images were acquired from an archive held by the Hawaii Institute of Geophysics and Planetology (HIGP).

Seven of the flows were "short-duration" ( $<35$ days) and all available MODIS data were acquired for those. For the three "long-duration" flows $(210,239$, and 810 days, respectively), data volume was essentially halved by only obtaining nighttime images (the benefit of nighttime imagery is discussed in section 2.3). All available GOES images were acquired, however due to gaps in the archive, data were not available for every flow and sometimes only for a portion of the total duration of a given flow. A total of 2873 MODIS and over 25,000 GOES images were acquired for the 10 available flows.

Table 2.1

Specifications for MODIS and GOES sensors.

\begin{tabular}{|c|c|c|c|c|c|}
\hline & \multicolumn{3}{|c|}{ MODIS } & \multicolumn{2}{|c|}{ GOES } \\
\hline $\begin{array}{l}\text { Temporal } \\
\text { resolution }\end{array}$ & \multicolumn{3}{|c|}{6 hours } & \multicolumn{2}{|c|}{$\sim 15$ minutes } \\
\hline resolution & \multicolumn{3}{|c|}{$1000 \mathrm{~m}$} & \multicolumn{2}{|c|}{$4000 \mathrm{~m}$} \\
\hline & Band 21 & Band 22 & Band 31 & Band 2 & Band 4 \\
\hline Region & MIR & MIR & LIR & MIR & LIR \\
\hline $\begin{array}{c}\text { Central } \\
\text { wavelength } \\
(\mu \mathrm{m})\end{array}$ & 3.96 & 3.96 & 11.03 & 3.9 & 10.7 \\
\hline $\begin{array}{c}\text { Saturation } \\
(\mathrm{K})\end{array}$ & 335 & 300 & 300 & 335 & 320 \\
\hline
\end{tabular}


All images were viewed and enhanced using ENVI 4.1 software (Environment for Visualizing Images). MODIS images were first georeferenced using the built-in “Georeference MODIS 1B" function, so that Pacaya could be quickly and precisely located (after georeferencing, calculated latitude/longitude coordinates for each pixel could be viewed in the Cursor Location/Value window). Geographic information also helped to determine whether or not a suspected thermal anomaly was coincident with the location of Pacaya (fires in the fields surrounding Pacaya and volcanic activity from nearby Fuego also produce thermal anomalies). To further reduce processing time, only bands 21, 22, and 31 were georeferenced (as opposed to all 32 available bands, which were sometimes used to determine the amount of cloud cover). Additional image processing was unnecessary for GOES data because they arrived as clipped, 1000 by 1000 pixel sub-images in which Pacaya was always located in the same pixel.

Table 2.2

All lavas flows that occurred after the availability of MODIS data and selected attributes. Flows for which there was sufficient data to produce time series are highlighted in gray.

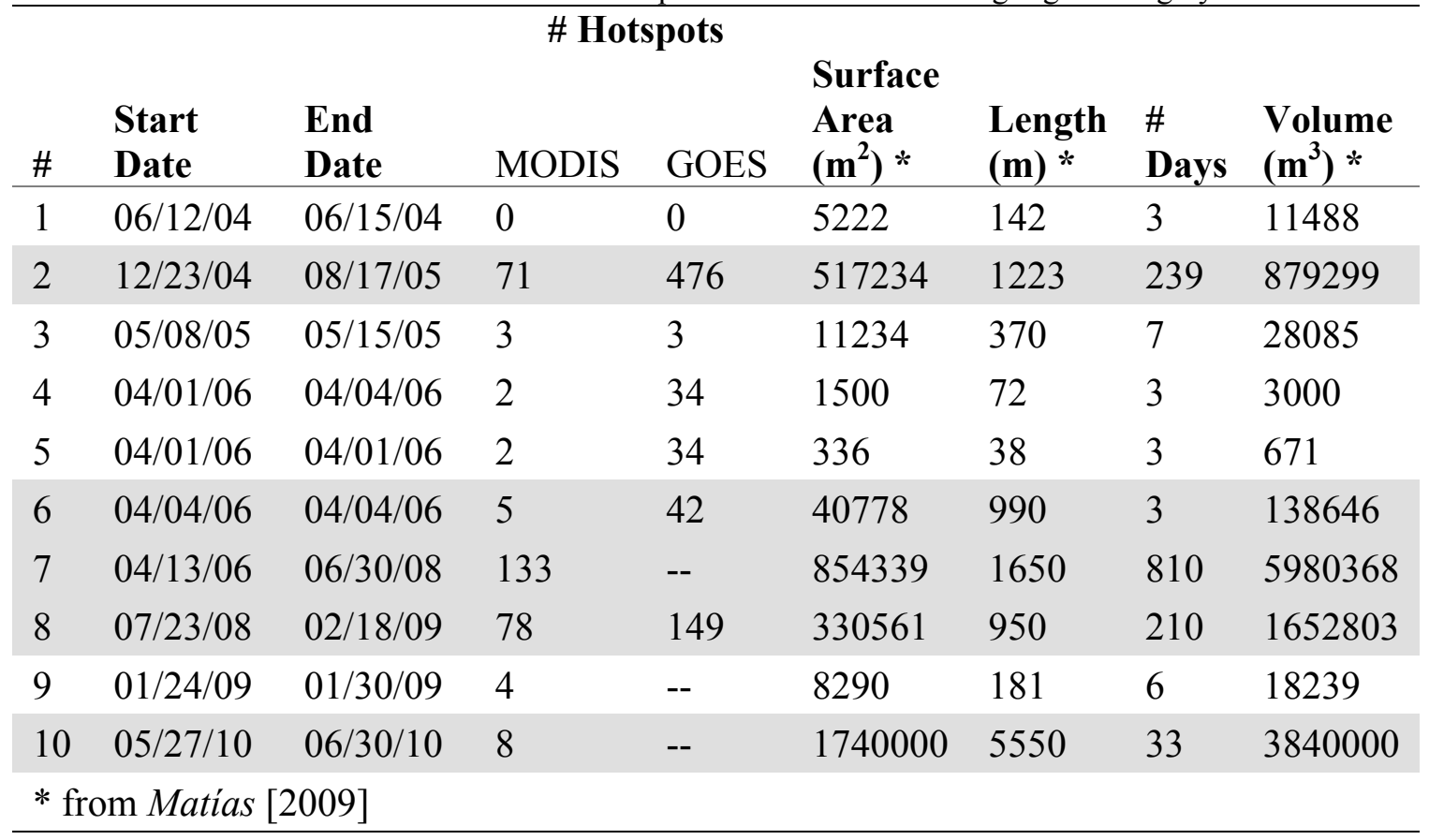




\subsection{Hot Spot Identification}

A "hot spot" is a pixel that is thermally anomalous (i.e. has higher radiance in a TIR band) compared to the surrounding pixels. The increased radiance is caused by the presence of a "hot" component within the pixel (Figure 2.1). In the MIR-band image (i.e. $4 \mu \mathrm{m}$ ), volcanic hot spots usually appear visibly brighter than adjacent "ambient" pixels, and if the pixel-integrated radiance is high enough the pixel will also appear brighter in a corresponding LIR-band image (i.e. $11 \mu \mathrm{m}$ ).

However, since a relatively large portion $(>0.1 \%)$ of the LIR pixel must be occupied by the hot component in order to raise the pixel-integrated radiance above background levels [Harris et al., 1997b], very small flows (such as most of those encountered in this project) may not cause observable increases in radiance at LIR wavelengths. For example, a 1-km thermally homogenous MODIS pixel at $300 \mathrm{~K}$ emits $0.4 \mathrm{~W} \cdot \mathrm{m}^{-2} \cdot \mathrm{sr}^{-1} \cdot \mu \mathrm{m}^{-1}$ at $4 \mu \mathrm{m}$ and $9.5 \mathrm{~W} \cdot \mathrm{m}^{-2} \cdot \mathrm{sr}^{-1} \cdot \mu \mathrm{m}^{-1}$ at $11 \mu \mathrm{m}$ [Wright et al., 2001]. If a sub-pixel lava flow at $850 \mathrm{~K}$ occupies $0.05 \%$ (i.e. $500 \mathrm{~m}^{2}$ ) of the pixel, the radiance increases to $1.3 \mathrm{~W} \cdot \mathrm{m}^{-2} \cdot \mathrm{sr}^{-1} \cdot \mu \mathrm{m}^{-1}$ at $4 \mu \mathrm{m}$ and $9.6 \mathrm{~W} \cdot \mathrm{m}^{-2} \cdot \mathrm{sr}^{-1} \cdot \mu \mathrm{m}^{-1}$ at $11 \mu \mathrm{m}[$ Wright et al., 2001]. That is, when a small amount of lava is present, emission at $4 \mu \mathrm{m}$ increases by

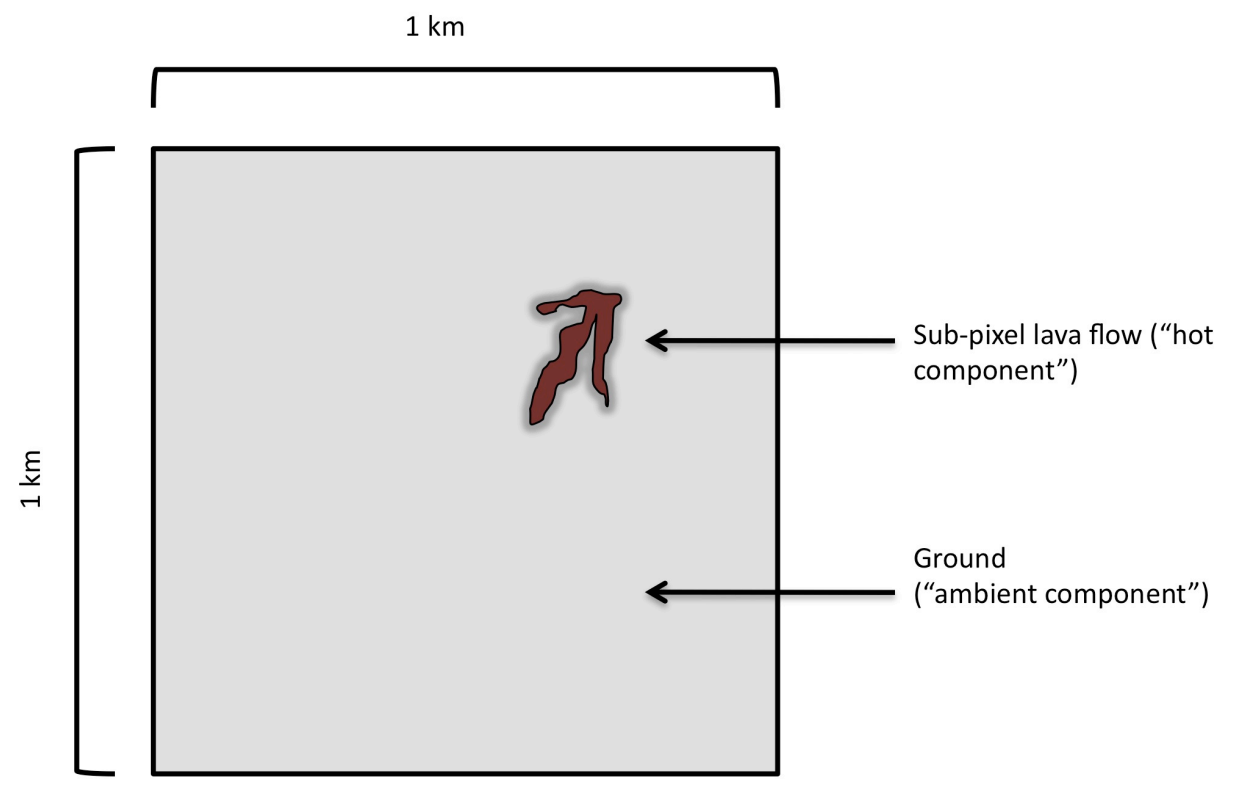

Figure 2.1: Representation of a single-pixel MODIS hot spot containing two thermal components; 1) a sub-pixel lava flow, and 2) the ambient surface. The extra radiance contributed by the hot component (i.e. lava) raises the total pixel-integrated radiance. Note that the lava flow shown here is not to scale (typical lava percentages were $<0.1 \%$ ). 
more than $200 \%$, while emission at $11 \mu \mathrm{m}$ only increases by $1 \%$. When emission at 11 $\mu \mathrm{m}$ is weak or negligible, a second atmospheric window that occurs around $4 \mu \mathrm{m}$ can be used to measure the radiance of the lava. For such a case, the anomalous temperature of the pixel can be calculated from the MIR band and the background temperature can be calculated from the LIR band of the same pixel.

In cases where the LIR-band radiance was above ambient, the background radiance was instead estimated by averaging the radiances of the surrounding ambient pixels. In previous applications of this method, only a LIR-band is used, but this would have resulted in large errors in many cases. For example, the pixel at the center of the Pacaya sub-scene is usually the coldest (due to high elevation) and if a flow isn't strong enough to increase the Band 31 radiance above that of the adjacent pixels, then the resulting volcanic radiance would actually be negative (volcanic radiance is the amount of radiation contributed by the lava and is equal to the anomalous radiance minus the background radiance).

Several hot spot detection algorithms have been developed for fire-detection and volcanological applications [e.g., Higgins and Harris, 1997; Tramutoli, 1998; Wright et al., 2002; Di Bello et al., 2004]. Each algorithm has strengths and weaknesses for a given application, but none are able to detect $100 \%$ of the hot spots that can be identified by the human eye [Steffke and Harris, 2011]. The most significant limitations of algorithms are the tendencies to falsely identify hot spots and/or to overlook true hot spots. Because most of the flows analyzed here were relatively small in area, their presence in a pixel contributed very small increases in radiance. Additionally, the images used in this investigation were acquired over six years throughout a variety of seasons and weather conditions and some flows were very short-lived. Variation due to these factors is apparent to a trained human observer, but can pose difficulty for an algorithm. To ensure as complete a dataset as possible, hot spots were identified manually (Figure 2.2). This maximized the inclusion of true hot spots and minimized the inclusion of false hot spots. 


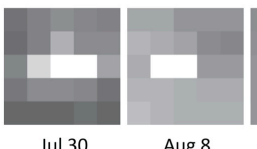

Jul 30

Aug 8

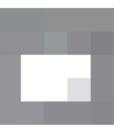

Aug 25

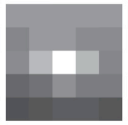

Sep 16

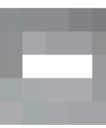

Oct 3

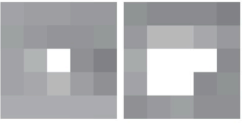

Oct 28

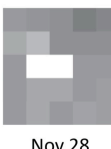

Nov 28

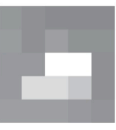

Dec 15

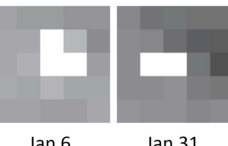

$\operatorname{Jan} 31$

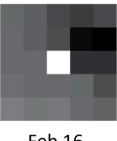

Feb 16

Figure 2.2: Example of variation in MODIS hot spot size and relative intensity throughout the life of the 2004-2005 lava flow. Images are taken as close to bi-weekly as possible. Each pixel is approximately $1 \mathrm{~km}^{2}$.

\subsubsection{MODIS}

All MODIS images were individually opened, georeferenced, evaluated for quality, and searched manually for hot spots. The location of Pacaya was different in each image, so georeferencing was necessary to ensure that the coordinates of a suspected hot spot actually coincided with Pacaya. This reduced or eliminated the inclusion of false hot spots such as those due to fire or nearby volcanoes (see Appendix A). In a given image, the active flow area was usually represented by between one and four hot pixels. In the case of the May 2010 eruption, more than ten hot pixels were present in most images.

The central wavelength of both MODIS ands 21 and 22 is $3.96 \mu \mathrm{m}$, but the more sensitive band 22 becomes saturated at a lower temperature than band 21, so a pixel that is saturated in Band 22 will usually still appear in band 21 (no saturated band 21 pixels were found in images analyzed here). Both bands 21 and 22 were always opened simultaneously in adjacent ENVI windows so that saturated pixels would not mistakenly be overlooked. This configuration was especially important in nighttime images when saturated pixels (which are assigned a fill value and appear black) often appeared indistinguishable from the cool background.

If a hot spot was identified in bands 21 and/or 22, the corresponding pixel(s) were then viewed in band $31\left(11.03 \mu \mathrm{m}\right.$ ), and the spectral radiance (units of $\mathrm{W} \cdot \mathrm{m}^{-2} \cdot \mathrm{sr}^{-1} \cdot \mu \mathrm{m}^{-1}$ ) for each hot pixel in each of the three bands was recorded. Measurements from bands 21 and 22 represented anomalous radiances and the measurements from band 31 represented the background radiances. Band 21 was substituted for the band 22 measurement when the latter was saturated. On occasions when there was a non-negligible increase in band 31 radiance, the background radiances were instead averaged from adjacent band 31 
pixels (Figure 2.3). "Volcanic" radiances (defined as anomalous radiance minus background radiance) were calculated and plotted as a time series for each eruption.

\subsubsection{GOES}

Over 25,000 GOES images were acquired, so it would have been impractical to view all of them. Instead, images were opened at approximately 3-hour intervals. When a hot spot was identified, the image in which it first appeared was found and each successive file was opened until the hot spot disappeared (usually because of cloud cover). During periods of sustained cloud cover (sometimes lasting several weeks), only

\section{Case \# 1} Unsaturated Pixel

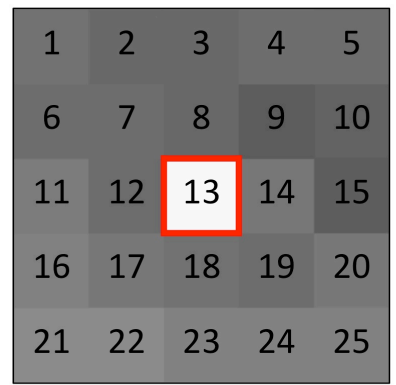

a. MODIS Band 21

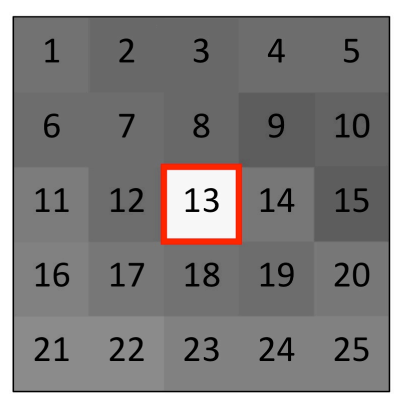

b. MODIS Band 22

\begin{tabular}{|ccccc|}
\hline 1 & 2 & 3 & 4 & 5 \\
6 & 7 & 8 & 9 & 10 \\
11 & 12 & 13 & 14 & 15 \\
16 & 17 & 18 & 19 & 20 \\
21 & 22 & 23 & 24 & 25 \\
\hline
\end{tabular}

c. MODIS Band 31

\section{Case \#2}

\section{Saturated Pixel}

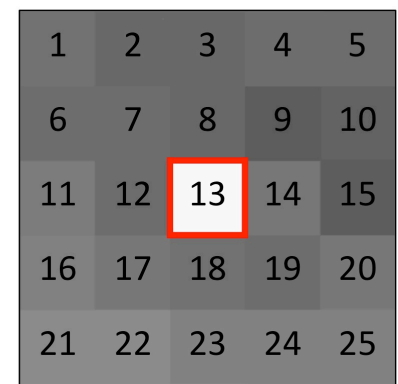

d. MODIS Band 21

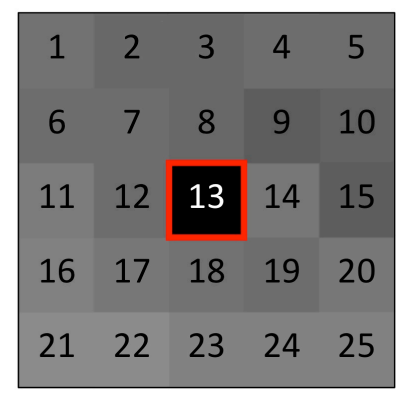

e. MODIS Band 22

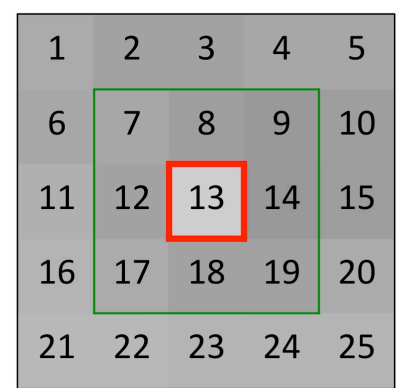

f. MODIS Band 31
Figure 2.3: Representations of unsaturated and saturated hot spots (1-km pixels). Case \#1 shows a typical hot spot occupying pixel 13 that is visible to approximately the same degree in (a) MODIS band 21 and $(b)$ MODIS band 22. In this case, the band 22 radiance is used as the anomalous radiance. Because a very small lava flow causes this hot spot, the $(c)$ band 31 radiance is not raised above ambient. So pixel 13 in band 31 is used as the background radiance. In case \#2, the hot spot is caused by a slightly larger flow, so while it is visible in $(d)$ band 21 , it is saturated (appearing black) in (e) band 2 . In this case, the band 21 radiance is used as the anomalous radiance. Since this flow was large enough to raise the radiance in $(f)$ band 31 above ambient, the background radiance is instead averaged from the surrounding band 31 pixels (green box). 
about four images per day were opened in order to monitor cloud conditions. Locating Pacaya in GOES images was simpler than in MODIS images because Pacaya always appeared in the same location. The location was confirmed by overlaying several GOES images with suspected true hot spots over high-resolution imagery in Google Earth. After those were confirmed to match the geographic location of Pacaya, only images that contained hot spots in the designated area were considered. GOES images usually contained one to three hot pixels, which generally appeared duller than MODIS hot pixels because of GOES's lower spatial resolution (i.e. the radiance emitted by the same lava was diluted by the larger ambient surface area contained in a 4-km GOES pixel). In a given image, the active flow area was usually represented by between one and two hot pixels.

Band $2(3.9 \mu \mathrm{m})$ is the only MIR band available on the GOES imager, and saturated pixels were never found in any images viewed. When a hot spot was identified in Band 2, it was then viewed in Band $4(10.7 \mu \mathrm{m})$, and temperatures for each hot pixel in both bands were recorded. In a few cases, the hot pixels in Band 4 were slightly anomalous, so surrounding ambient pixel temperatures were also recorded (GOES pixel values were retrieved as brightness temperature in Kelvin). Band 2 temperatures represented the anomalous temperature and Band 4 temperatures represented background. When an anomalous pixel was detectable in Band 4 (very rarely), the background temperature was instead averaged from the adjacent ambient pixels. "Volcanic radiances" were calculated for each image and were plotted in a time series for each eruption.

\subsection{Data Quality}

Three main factors contributed to reduction of data quality: cloud cover, solar heating, and geometric effects. Thick clouds frequently cover Pacaya and the surrounding area, especially during the summer wet season from about May through October (see Appendix A for examples). Water vapor readily absorbs TIR radiation, so even a very thin cloud layer or volcanic gas plume can significantly attenuate or even totally block TIR emission from reaching a spaceborne sensor. Therefore all images in which clouds were present over Pacaya were discarded. Heavy cloud cover was easily identified as 
relatively cold objects in the TIR images. Lighter cloud cover was identified in the corresponding higher-resolution (250 $\mathrm{m}$ at nadir) visible-wavelength images.

High-emissivity materials (e.g. soil, basalt, scoria) readily absorb incoming shortwave solar radiation by transforming the energy to heat. The subsequent increase in temperature is compensated by increased emission of longwave (i.e. IR) radiation by the material. The material continues to heat up until a balance between absorbed shortwave and emitted longwave radiation is reached. Solar heating hinders the identification and quantification of volcanic thermal anomalies during the day because the basaltic substrate surrounding Pacaya can emit non-negligible amounts of radiation in the wavelength region of interest. To reduce processing time, daytime images were ignored for the three longest flows. All available images, including daytime images were obtained for the shorter flows, only a few of which were found suitable for use.

Cloud cover and solar heating affected both MODIS and GOES images, but geometric distortion was effectively only an issue for the MODIS images. MODIS has 1$\mathrm{km}$ spatial resolution at nadir, but that resolution decreases toward the edge of the image. Because Pacaya appeared in a unique location in each image (with a repeat geometry every 16 days), the pixels containing it are distorted to different degrees. The area of the pixel's footprint on the ground can be calculated from the pixel's position and the sensor's field of view (Appendix B). However, the amount of radiance reaching the sensor also decreases with increasing scan angle, so when the scan angle of the pixel containing Pacaya was greater than 50 degrees, the image was discarded [Harris et al., 1997a]. A related problem is that many of the MODIS images acquired were unusable because Pacaya was located just beyond the edge of the image. Though the MODIS data archive was searched geographically using latitude and longitude parameters centered on Pacaya, the search frequently returned images that did not actually contain Pacaya. All images had to be viewed in order to determine if Pacaya was actually contained in the image.

Thus, in order to be considered of usable quality an image had to 1) contain Pacaya, 2) contain a volcanic heat signature or "hot spot", 3) have a scan angle of less than 50 degrees, 4) not exhibit significant solar heating (e.g. nighttime or early morning 
images), and 5) be cloud free over Pacaya. Out of 2873 MODIS images, 312 (9\%) met these criteria. Of the 2642 GOES images that were actually viewed, 704 (27\%) met these criteria.

Additionally, each hot spot was given a qualitative ranking of "Good", "Fair", or "Poor". "Good" hot spots were clearly identifiable (bright), had no observable cloud cover near Pacaya, were located within the scan angle limit (MODIS only), and were acquired at night (no solar heating). "Fair" hot spots may have had a slight chance of cloud contamination (e.g. cloud was present in nearby pixels), or may have been acquired during the day. "Poor" data either had a high probability of cloud contamination (cloud in adjacent pixel), or contained other interesting anomalies, and were saved for reference purposes. "Poor" hot spots were never used in the final datasets.

\subsection{Time-averaged Discharge Rate Calculation}

All calculations were performed in Microsoft ${ }^{\circledR}$ Excel. The discharge rate calculation method described by Harris et al. [1997a] is based on the work of Pieri and Baloga [1986] and Crisp and Baloga [1990] and consists of two main steps: estimation of lava flow area from radiance measurements, and subsequent calculation of heat flux (which is related to discharge rate). This conversion is based on the assumption that, in cooling from eruption temperature to the temperature at which motion ceases, the heat lost by the flow is balanced by the heat supplied [Harris et al. 1997a]. In this model, heat is supplied from advected heat plus the latent heat of crystallization $\left(Q_{i n}\right)$ :

$$
\begin{aligned}
& Q_{i n}=Q_{a d v}+Q_{\text {cryst }} \\
& Q_{a d v}=D_{r} \rho C_{p}\left(T_{\text {erupt }}-T_{\text {stop }}\right) \\
& Q_{c r y s t}=D_{r} \rho \phi C_{L}
\end{aligned}
$$

where $D_{r}, \rho, C_{p}, T_{\text {erupt }}, T_{\text {stop }}, C_{L}$ are the time-averaged discharge rate, lava density, specific heat capacity, eruption temperature, temperature at which motion ceases, and average mass fraction of crystals grown in cooling through $\left(T_{\text {erupt }}-T_{\text {stop }}\right)$, and latent heat of crystallization. 
Assuming that heat lost by a lava flow through conduction is negligible, the total heat lost by the flow $\left(Q_{\text {out }}\right)$ is from radiation and convection:

$$
\begin{aligned}
& Q_{\text {out }}=Q_{\text {rad }}+Q_{\text {conv }} \\
& Q_{\text {rad }}=A_{\text {tot }} \sigma \varepsilon T^{4} \\
& Q_{\text {conv }}=A_{\text {tot }} h_{c}\left(T-T_{\text {amb }}\right)
\end{aligned}
$$

where $A_{t o t}, \sigma, \varepsilon, T, h_{c}$, and $T_{a m b}$ are the total area of the lava flow, Stefan-Boltzmann constant, lava emissivity, lava surface temperature, convective heat transfer coefficient, and ambient air temperature, respectively.

Setting $Q_{\text {in }}$ equal to $Q_{\text {out }}$, the above equations can be combined and rearranged to solve for time-averaged discharge rate:

$$
\begin{aligned}
& Q_{\text {in }}=Q_{\text {out }} \\
& D_{r} \rho C_{p}\left(T_{\text {erupt }}-T_{\text {stop }}\right)+D_{r} \rho \phi C_{L}=A_{\text {tot }} \sigma \varepsilon T^{4}+A_{\text {tot }} h_{c}\left(T-T_{\text {amb }}\right) \\
& D_{r}=\frac{Q_{\text {tot }}}{\rho\left[C_{p} \Delta T+\phi C_{L}\right]}
\end{aligned}
$$

\begin{tabular}{|c|c|c|c|c|}
\hline Parameter & Symbol & Initial Value & Unit & Source \\
\hline DRE lava density & $\rho_{\text {DRE }}$ & 2678 & $\mathrm{~kg} \cdot \mathrm{m}^{-3}$ & $1,2,3$ \\
\hline $\mathrm{T}_{\text {erupt }}-\mathrm{T}_{\text {stop }}$ & $\Delta \mathrm{T}$ & 200 (variable) & ${ }^{\circ} \mathrm{C}$ & 5 \\
\hline $\begin{array}{l}\text { Mass fraction of crystals } \\
\text { grown through } \Delta \mathrm{T}\end{array}$ & $\phi$ & 0.5 & fraction & 4 \\
\hline Vesicularity & $\mathrm{V}$ & 0.10 & fraction & 4 \\
\hline Lava surface temperature & $\mathrm{T}$ & 250,350, or 600 & ${ }^{\circ} \mathrm{C}$ & 4 \\
\hline Ambient air temperature & $\mathrm{T}_{\mathrm{amb}}$ & 25 & ${ }^{\circ} \mathrm{C}$ & 4 \\
\hline Emissivity & $\varepsilon$ & 0.9887 & fraction & 4 \\
\hline Specific heat capacity & $\mathrm{C}_{\mathrm{p}}$ & 1130 & $\mathrm{~J} \cdot \mathrm{kg}^{-1} \cdot \mathrm{K}^{-1}$ & 4,5 \\
\hline Latent heat of crystallization & $\mathrm{C}_{\mathrm{L}}$ & 350000 & $\mathrm{~J} \cdot \mathrm{kg}^{-1}$ & 5 \\
\hline $\begin{array}{l}\text { Convective heat transfer } \\
\text { coefficient }\end{array}$ & $\mathrm{h}_{\mathrm{c}}$ & 10 & $\mathrm{~W} \cdot \mathrm{m}^{-2} \cdot \mathrm{K}^{-1}$ & 5 \\
\hline Lava area & $\mathrm{A}_{\text {tot }}$ & calculated & $\mathrm{m}^{2}$ & calculated \\
\hline Stefan-Boltzmann constant & $\sigma$ & $5.67 \times 10^{-8}$ & $\mathrm{~W} \cdot \mathrm{m}^{-2} \cdot \mathrm{K}^{-1}$ & constant \\
\hline
\end{tabular}

Table 2.3

Input parameters for the TADR estimation model. Default values for average basalt are listed. Three separate models were run for three different lava surface temperatures $(\mathrm{T})$. 
where $Q_{\text {tot }}$ is the total heat flux from radiation and convection (equal to $Q_{\text {out }}$ the right side of Equation 2.5b) and ( $T_{\text {erupt }}-T_{\text {stop }}$ ) has been simplified to $\Delta T$. All terms besides $A_{\text {tot }}$ and $\Delta T$ can be set to literature values (Table 2.3) for a given lava type to yield a rough estimate of discharge rate. However, one also needs to assume a value for either $A_{t o t}$ or $\Delta T$. Either is acceptable, but it is clearly easier to assume the temperature of a given flow rather than the area. Therefore, the area of lava contained in each hot spot was calculated using a thermally-mixed-pixel model. First, the at-sensor spectral radiances were corrected for emissivity and atmospheric transmissivity for the appropriate wavelength. This is achieved by multiplying the measured radiance by the assumed emissivity of basalt (0.95 for MIR and LIR wavelengths), and the atmospheric transmissivity (0.98 and 0.96 for MIR and LIR wavelengths, respectively).

In the case of GOES data, the pixel values (brightness temperatures in Kelvin) had to be transformed into radiance values. This was achieved via the Planck function:

$$
L(\lambda, T)=c_{1} \lambda^{-5}\left(\exp ^{\frac{c_{2}}{\lambda T}}-1\right)^{-1}
$$

where the constants from Equation 1.1 have been simplified to $c_{1}\left(2 \mathrm{hc}^{2}\right)$ and $c_{2}(\mathrm{hc} / \mathrm{k})$. This equation was rearranged in order to calculate temperatures from MODIS pixel values (units of spectral radiance; $\mathrm{W} \cdot \mathrm{m}^{-2} \cdot \mu \mathrm{m}^{-1} \cdot \mathrm{sr}^{-1}$ ):

$$
T=\frac{c_{2}}{\lambda \ln \left(\frac{c_{1} \lambda^{-5}}{L(\lambda, T)}+1\right)}
$$

Because anomalous and background radiances were measured at different wavelengths $(\sim 4$ and $\sim 11 \mu \mathrm{m}$ ), one measurement had to be transformed into the radiance that would be produced at the second wavelength. Here, the LIR measurements were converted into MIR-equivalent radiances. Radiance varies as a function of wavelength and temperature according to the Planck function, so if the temperature of an object is known, the blackbody radiance it emits at any given wavelength can be calculated. GOES measurements are already provided in temperature units of Kelvin, and MODIS measurements were converted to temperature via Equation 2.6b. The temperatures were 
then used in Equation 2.6a to find the radiance that would be emitted in the MIR band (MODIS Band 22/21 and GOES Band 2). The MIR-equivalent radiances were used in the final calculations.

After obtaining the background and anomalous pixel-integrated temperatures, the area of lava contained in a hot spot could be calculated. A single-band mixed-pixel model was applied [Harris et al. 1997a] that assumes a pixel contains two thermal components; hot (lava) and ambient (background) (Figure 2.1):

$$
R_{\lambda}=p L\left(\lambda, T_{h}\right)+(1-p) L\left(\lambda, T_{a}\right)
$$

where $R_{\lambda}, p, L\left(\lambda, T_{h}\right), L\left(\lambda, T_{a}\right)$ are the pixel-integrated radiance of the hot pixel (i.e. measured pixel value), portion of the pixel containing the hot component (lava), radiance of the cold portion, and radiance of the hot portion, respectively. This equation can be rearranged to solve for $p$, the portion of the pixel that must be occupied by lava at given temperature in order to produce the observed radiance:

$$
p=\frac{R_{\lambda}-L\left(\lambda, T_{a}\right)}{L\left(\lambda, T_{h}\right)-L\left(\lambda, T_{a}\right)}
$$

Here, the wavelength $\lambda$ is known, $R_{\lambda}$ is also known (value of the hot pixel), and $L\left(\lambda, T_{a}\right)$ is an approximation represented by the background radiance (value of the ambient pixel). This leaves two unknowns; $p$ and $L\left(\lambda, T_{h}\right)$, one of which must be assumed. Because lava surface temperature can be more precisely confined [Harris et al. 1997a], $T_{h}$ was assumed for a wavelength of $\sim 4 \mu \mathrm{m}$. In order to span a range of realistic situations, three separate mixture models were applied for lava surface temperatures of $250^{\circ} \mathrm{C}, 350^{\circ} \mathrm{C}$, and $600^{\circ} \mathrm{C}$.

Having calculated the pixel portion $p$, the area occupied by lava within a pixel is given by:

$$
A=p A_{\text {pixel }}
$$

where $A_{\text {pixel }}$ is the area of the pixel. At nadir, the area is $1 \mathrm{~km}^{2}$ for MODIS, and $4 \mathrm{~km}^{2}$ for GOES. However, this value increases with distance from nadir. Thus, unique pixel areas had to be calculated for each hot spot (only for MODIS pixels). For MODIS the area is a function of the pixel's line and sample number (i.e. $x, y$ coordinate of the pixel in the image) and the sensor scan angle (see Appendix B). To find the total area of lava $\left(A_{t o t}\right)$ 
associated with a heat signature covering multiple pixels, the areas occupied by lava in each pixel were summed:

$$
A_{\text {tot }}=\sum A_{n}
$$

This total area was then used to calculate the heat flux terms given by Equations 2.3 and 2.4, yielding all of the terms necessary to calculate discharge rates via Equation $2.5 \mathrm{c}$. Calculations were carried out for each image at each of the three lava surface temperature models $\left(250^{\circ} \mathrm{C}, 350^{\circ} \mathrm{C}, 600^{\circ} \mathrm{C}\right)$, yielding TADR in cubic meters per second $\left(\mathrm{m}^{3} \mathrm{~s}^{-1}\right)$ for a range of lava surface temperatures.

Note that Equation 2.5c can be reduced to a linear relationship between area and effusion rate [Wright et al., 2001; Harris and Baloga, 2009]:

$$
\begin{aligned}
& T A D R=\frac{Q_{t o t}}{\rho\left[C_{p} \Delta T+\phi C_{L}\right]} \\
& T A D R=A_{t o t} \frac{\sigma \varepsilon T^{4}+h_{c}\left(T-T_{a m b}\right)}{\rho\left[C_{p} \Delta T+\phi C_{L}\right]} \\
& T A D R=A_{t o t} M
\end{aligned}
$$

where $D_{r}$ has been renamed $T A D R$, and $M$ is a coefficient that relates the flow area to the time-averaged discharge rate. TADR estimates were calculated for every image and were plotted in time series for each flow.

\subsection{Volume Calculation}

The volume of lava accumulated between each TADR estimate was calculated by integrating the area between each measurement using the trapezium rule:

$$
V_{i}=\int_{a}^{b} f(x) d x \approx(b-a) \frac{f(a)+f(b)}{2}=\left(t_{1}-t_{2}\right) \frac{T A D R_{1}-T A D R_{2}}{2}
$$

where $t_{1}$ and $T A D R_{1}$ are the time and TADR at point one, and $t_{2}$ and $T A D R_{2}$ are the time and TADR at point two (time $=0$ was set to the first measurement of a given dataset). Successively summed volumes were used to derive a running cumulative volume for each flow: 


$$
V_{\text {cum }}=\sum V_{i}
$$

where $V_{\text {cum }}$ is the cumulative volume at a given measurement in the time series $i$. The final point for a given dataset represented the total volume accumulated. Cumulative volumes were plotted in time series for each flow.

\subsection{Two Methods of Determining Conversion Factor "M"}

As previously stated, flow area and discharge rate are linearly related via the coefficient $M$ (Equation 2.10c). Therefore, the key to calculating accurate discharge rates for a given flow via the above method is to define the correct value of $M$. This was achieved in the two ways described below. The first was used before fieldwork and laboratory analyses were completed and the second was used after. Collection procedures and resulting conversion factors for each flow are discussed in sections 2.8 and 3.2, respectively.

\subsubsection{Method 1: Best-Fitting}

First, if an independent estimate or series of estimates of discharge rate are available, then Equation $2.10 \mathrm{c}$ can be solved for $M\left(A_{t o t}\right.$ having been calculated independently from the satellite imagery). This method does not allow for the constituents of $M$ to be individually defined. However, it is useful to determine whether the resulting conversion factor can be produced using realistic values of its constituents. Therefore, best-fitting was achieved by first assigning all variables with values reasonable for a typical basalt (Table 2.3). Then the resulting volumes and TADR were adjusted to match the total volume and mean output rates calculated by Matias [2009] by allowing just one variable to be adjusted. Specific heat capacity $\left(C_{p}\right)$, and latent heat of crystallization $\left(C_{L}\right)$ cannot realistic vary enough to significantly affect the model output, so they were held constant. Three other terms remained: vesicularity ( $v$, which with DRE density is used to calculated bulk density $(\rho)$ ), mass fraction of crystals grown in cooling through $\Delta T(\phi)$, and cooling from eruption to the point at which motion ceases $(\Delta T)$.

Since $v$ and $\phi$ are fractions and can only vary between 0 and 1, they were held constant at values of 0.1 and 0.5 , respectively, and only $\Delta T$ was allowed to vary. 
The final lava flow volumes calculated by Matias [2009] were used as target values for the cumulative volume calculations, however it is important to note that missing data at the beginning and/or end of a flow had to be accounted for. That is, if the first satellite measurement occurred three days after the start of a flow, then the volume accumulated during that time must be subtracted from the total volume. To reduce the target volume to the proper value, the number of unaccounted-for days was multiplied by the intermediate mean output rate from Matias [2009]. This volume was then subtracted from the total actual volume, and the result was used as the target volume for each flow. The target volume is given by:

$$
V_{t a r}=V_{a c t}-\left(\frac{V_{a c t}}{n} m\right)
$$

where $V_{\text {tar }}, V_{\text {act }}, n$, and $m$ are the target volume, actual volume (from Matias, 2009), total duration of the flow (days), and the number of days unaccounted for at the beginning and end of the flow, respectively. The intermediate temperature model $\left(350^{\circ}\right.$ C) was manipulated to best-fit the target volume. This was achieved using Microsoft ${ }^{\circledR}$ Excel's "Goal Seek" function, which adjusts the value of a selected cell (total cumulative volume) to the target value by manipulating a second cell $(\Delta \mathrm{T})$, yielding the set of effusion rates necessary to attain the target volume.

\subsubsection{Method 2: Measured Values}

Second, the constituents of $M$ can be defined. Some of these variables, including density $(\rho)$, mass fraction of crystals grown in cooling through $\Delta T(\phi)$, and vesicularity $(v)$, can be directly measured from rock samples. The other parameters are either constants, or can be constrained to a range of reasonable values. For example, a value for $\Delta T$ of between 150 and $250^{\circ} \mathrm{C}$ has been shown empirically to produce good results [Harris et al., 2005]. Hence, a good estimate of the value of $M$ can be made if lava samples are available from the flow in question. An even more robust estimate of $M$ can be made if the temperature variables ( $T$ and $\Delta T$ ) can be directly measured; however this is only possible if the active flow can be accessed in the field. 


\subsection{Field Collection Methods}

Fieldwork was carried out in January 2012 with the objective of collecting samples from five lava flows to determine the density, vesicularity, crystal content, and whole-rock chemistry of each flow. Defining these parameters serves to confine the limits of the TADR model, and allows the identification of physical differences between flows that may indicate fundamental differences in eruption and cooling dynamics.

Samples were successfully collected from four flows (April 2006, 2006-2007, 2008-2009, and May 2010), which spanned a time period of four years. Sampling of a fifth flow (2004-2005) was originally planned, but it was not accessible due to hazards posed by frequent rock falls and a steep, unstable slope. Whenever possible, two samples (one of crust and one of core material) were collected at each sampling location. Crust samples were collected from the uppermost layer of lava found at each site (Figure 2.4). Core samples were always taken as deep into the flow as possible, either from exposed outcrops, or by digging through channel walls to remove crust (Figure 2.4).

Twelve (12) samples were obtained from the May 2010 flow; five crust and seven core, and were collected at semi-regular intervals down-flow (see Figure 2.5), allowing analysis of down-flow variation in lava properties. Four (4) samples were obtained from the 2008-2009 flow; two crust and two core. This flow was nearly completely covered by tephra and only two suitable sampling locations were found. Ten (10) samples were obtained from the 2006-2008 flow; five crust and five core. The northern/western section of this flow was covered in tephra and lava from the large May 2010 eruption and was not able to be sampled. However, plentiful sampling locations were available on the eastern/southern section. Six (6) samples were collected from the very small April 2006 flow; three crust and three core. Only a small portion of this flow was exposed, and samples were taken at three locations, at down-flow intervals of approximately 20 meters. Sample locations for all flows are summarized in Figure 2.5 and Table 2.4. 


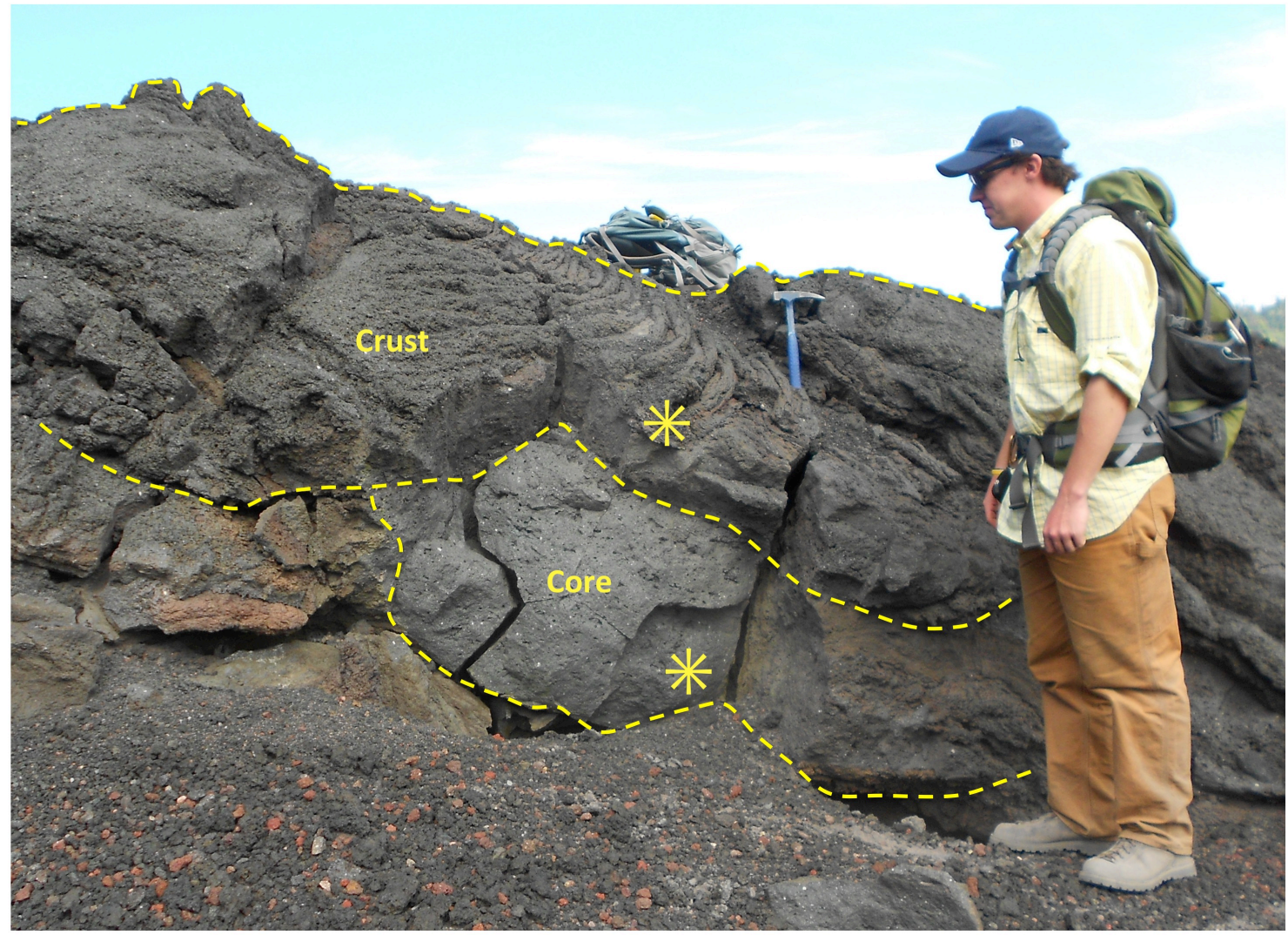

Figure 2.4: Example of crust and core sampling locations in a lava flow. Crust samples were taken from the uppermost portion of the flow. Core samples were taken from the deepest exposed part of a flow. The core of this pahoehoe flow is exposed to about one meter. Yellow stars represent actual sampling sites. 


\section{Pacaya Sample Locations (January 2012)}

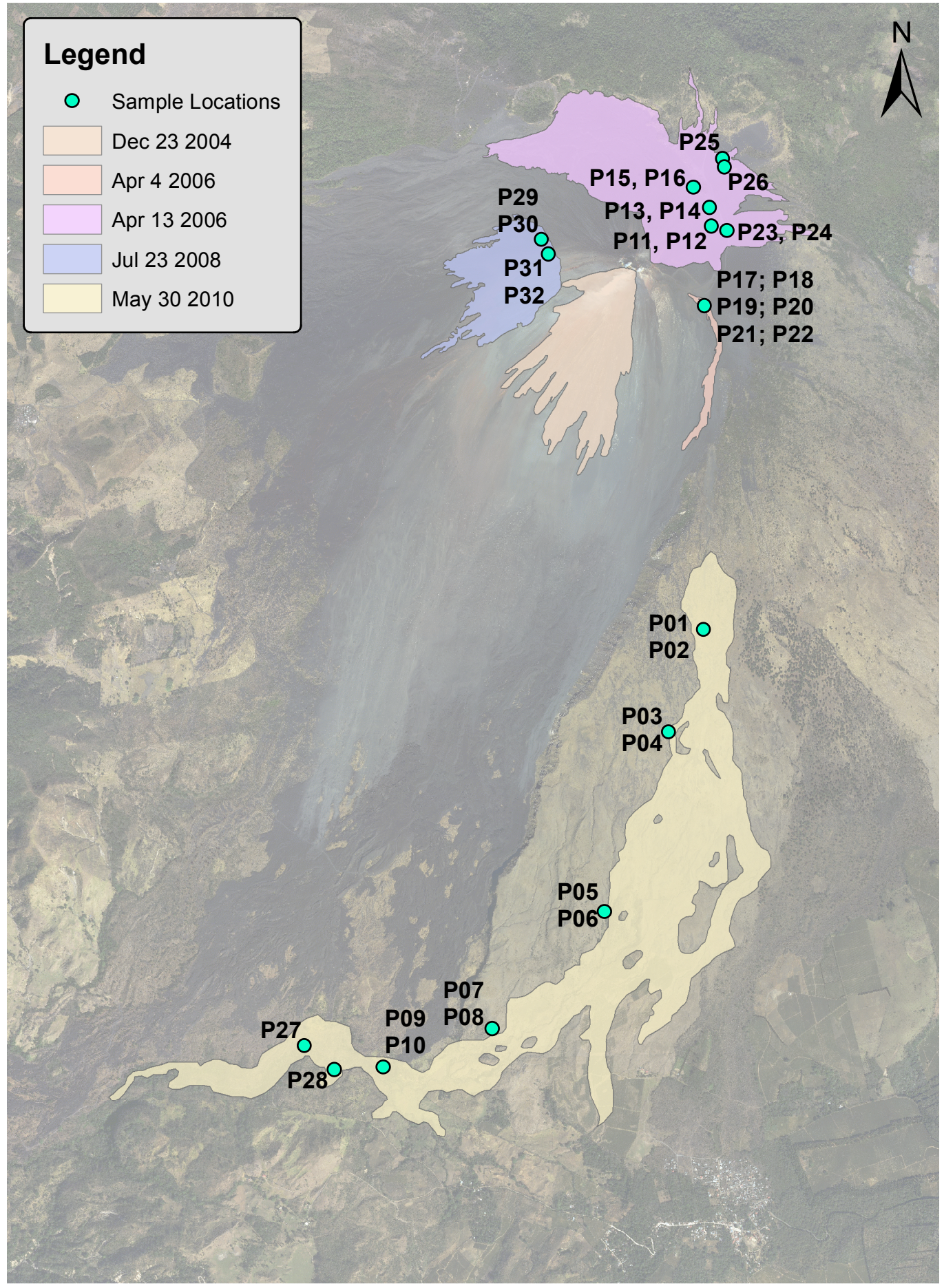

0

500

1,000

2,000

3,000

Meters

Figure 2.5: Map of sampling locations for January 2012 fieldwork. Base image source: Instituto Geografico Nacional, Guatemala. 
Table 2.4

Sample locations and analyses performed on each sample. ICP refers to major element chemical composition, TS refers to thin section, and SEM refers to scanning electron microscope imaging.

\begin{tabular}{ccccccccc}
\hline \# & Flow & Type & Lat. & Long. & ICP & TS & SEM & Density \\
\hline P01 & May 2010 & Core & 14.3639 & -90.5983 & $\checkmark$ & $\checkmark$ & & $\checkmark$ \\
P02 & May 2010 & Crust & 14.3639 & -90.5983 & & $\checkmark$ & & $\checkmark$ \\
P03 & May 2010 & Core & 14.3587 & -90.6001 & & $\checkmark$ & & $\checkmark$ \\
P04 & May 2010 & Crust & 14.3587 & -90.6001 & & $\checkmark$ & & $\checkmark$ \\
P05 & May 2010 & Core & 14.3497 & -90.6033 & & $\checkmark$ & $\checkmark$ & $\checkmark$ \\
P06 & May 2010 & Crust & 14.3497 & -90.6033 & & $\checkmark$ & & $\checkmark$ \\
P07 & May 2010 & Core & 14.3438 & -90.6090 & & $\checkmark$ & & $\checkmark$ \\
P08 & May 2010 & Crust & 14.3438 & -90.6090 & & $\checkmark$ & & $\checkmark$ \\
P09 & May 2010 & Core & 14.3418 & -90.6145 & & $\checkmark$ & & $\checkmark$ \\
P10 & May 2010 & Crust & 14.3418 & -90.6145 & & $\checkmark$ & & $\checkmark$ \\
P11 & $2006-2008$ & Crust & 14.3843 & -90.5979 & & $\checkmark$ & & $\checkmark$ \\
P12 & $2006-2008$ & Crust & 14.3843 & -90.5979 & $\checkmark$ & $\checkmark$ & & $\checkmark$ \\
P13 & $2006-2008$ & Crust & 14.3852 & -90.5980 & & $\checkmark$ & & $\checkmark$ \\
P14 & $2006-2008$ & Core & 14.3852 & -90.5980 & $\checkmark$ & $\checkmark$ & $\checkmark$ & $\checkmark$ \\
P15 & $2006-2008$ & Crust & 14.3862 & -90.5988 & & $\checkmark$ & & $\checkmark$ \\
P16 & $2006-2008$ & Core & 14.3862 & -90.5988 & $\checkmark$ & $\checkmark$ & & $\checkmark$ \\
P17 & Apr 2006 & Crust & 14.3803 & -90.5982 & & $\checkmark$ & $\checkmark$ & $\checkmark$ \\
P18 & Apr 2006 & Core & 14.3803 & -90.5982 & $\checkmark$ & $\checkmark$ & & $\checkmark$ \\
P19 & Apr 2006 & Crust & 14.3803 & -90.5982 & & & & \\
P20 & Apr 2006 & Core & 14.3803 & -90.5982 & & & & \\
P21 & Apr 2006 & Crust & 14.3803 & -90.5982 & & & & \\
P22 & Apr 2006 & Core & 14.3803 & -90.5982 & & & & \\
P23 & $2006-2008$ & Crust & 14.3841 & -90.5971 & & $\checkmark$ & & $\checkmark$ \\
P24 & $2006-2008$ & Core & 14.3841 & -90.5971 & $\checkmark$ & $\checkmark$ & & $\checkmark$ \\
P25 & $2006-2008$ & Crust & 14.3877 & -90.5973 & & $\checkmark$ & $\checkmark$ & $\checkmark$ \\
P26 & $2006-2008$ & Core & 14.3873 & -90.5973 & $\checkmark$ & $\checkmark$ & & $\checkmark$ \\
P27 & May 2010 & Core & 14.3429 & -90.6184 & & $\checkmark$ & & $\checkmark$ \\
P28 & May 2010 & Core & 14.3417 & -90.6184 & & $\checkmark$ & & $\checkmark$ \\
P29 & $2008-2009$ & Crust & 14.3836 & -90.6065 & & & & \\
P30 & $2008-2009$ & Core & 14.3836 & -90.6065 & $\checkmark$ & $\checkmark$ & $\checkmark$ & $\checkmark$ \\
P31 & $2008-2009$ & Crust & 14.3829 & -90.6061 & & $\checkmark$ & $\checkmark$ & $\checkmark$ \\
P32 & $2008-2009$ & Core & 14.3829 & -90.6061 & & & & \\
\hline & & & & & & & & \\
\end{tabular}




\subsection{Measurement of Physical Properties}

\subsubsection{Chemical Composition and DRE Density}

Whole-rock chemical composition was determined for eight samples (seven core samples and one crust sample) by inductively coupled plasma atomic emission spectroscopy (ICP-AES). One sample was analyzed from each of the four flows, plus four more samples from the 2006-2008 flow. Dense-rock-equivalent (DRE) densities for each sample were then calculated via the method of Bottinga and Weill [1970] (see Appendix C).

\subsubsection{Bulk Density}

Lava densities for 26 samples were measured via the method described by Shea et al. [2010], which follows from Houghton and Wilson [1989]. Small blocks were weighed in air, then wrapped with waterproof film and weighed in water. Bulk density is then given by:

$$
\rho_{\text {bulk }}=\frac{w_{\text {air }}}{w_{\text {air }}-\left(w_{\text {water }}-w_{\text {film }}\right)}
$$

where $w_{\text {air }}, w_{\text {water }}$, and $w_{\text {film }}$ are the sample weight in air, sample weight in water, and film weight in water, respectively.

\subsubsection{Vesicle and Crystal Content}

Combining the bulk density with the DRE density calculated from the whole-rock chemistries, vesicularity $(v)$ can be obtained:

$$
v=\frac{\rho_{D R E}-\rho_{\text {bulk }}}{\rho_{D R E}} \cdot 100
$$

where $\rho_{D R E}$ is the DRE density calculated from the whole-rock chemistry.

Vesicle and crystal size, shape, and distribution were also analyzed using the MATLAB-based code called FOAMSC, developed by Shea et al. [2010]. This program analyzes the texture of vesicular rock samples at various magnifications and determines the distribution and characteristics of vesicles or other object classes. To provide the images for FOAMS $\odot$ to process, each rock sample was cut in half parallel to the flow 
direction. The first half of the sample was scanned, and the second half was cut into smaller blocks for density measurements, thin sections, and chemical analysis. Thin sections were made for 26 samples and were scanned for use in FOAMS. Scanning electron microscope images (at 25x magnification) were taken for six samples (Table 2.4) for use in FOAMS. All images were preprocessed and formatted to 16-bit grayscale images with three color-levels associated with vesicles, crystals, and matrix/glass (Figure 2.6). The two-dimensional integrated volume percentages of crystals calculated by FOAMS were used in the final TADR model.

\subsection{Long-term Magma Supply Rate}

The total volume of lava accumulated over a period of 20 years (from 1990-2010) was plotted using the volumes calculated via method 2 (measured values) and supplementary data from Matias [2009]. A long-term magma supply rate was estimated by averaging the TADR for the three long-duration flows. 

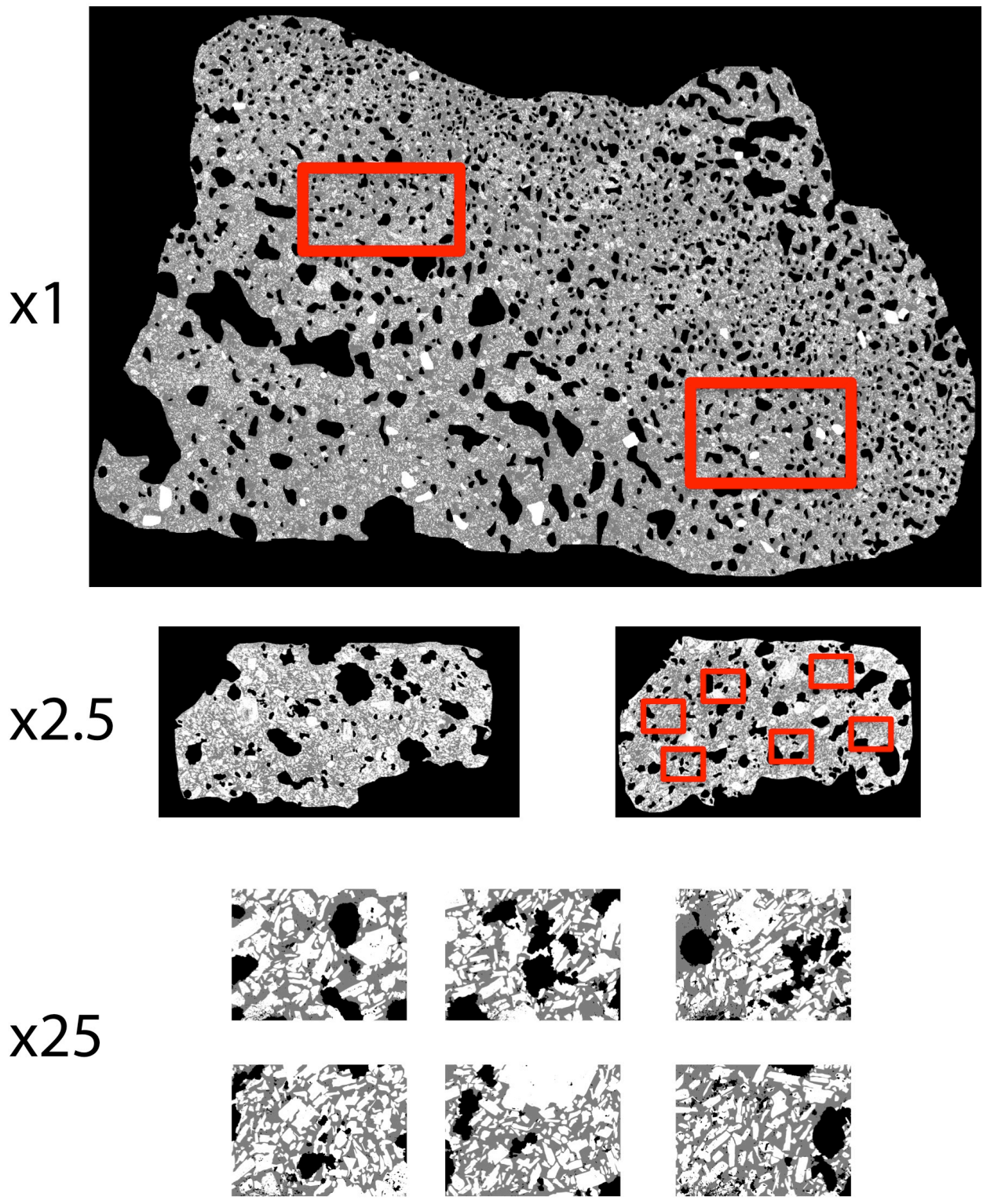

Figure 2.6: Example of FOAMS input images. The first image at $x 1$ magnification is a scan of the samples after it has been sawn in half. The x 2.5 images are scans of thin sections. The x 25 images are captured with a scanning electron microscope. These images have been processed so that there are three discrete color levels, where white represents crystals, gray represents background or matrix, and black represents vesicles. These are the actual images from sample P31 (2008-2009 flow). 


\section{Results}

\subsection{Satellite Data Quality and Temporal Coverage}

Several issues affected the quality and coverage of satellite data. First, imagery was only available for the ten flows that occurred after the launch of MODIS/Terra in 1999 (Table 2.2). Of these ten flows, only five had coverage sufficient to create a time series. Flow \#1 was discarded because no cloud-free data was available from either MODIS or GOES. Flows \#4 and \#5 were short-lived and occurred simultaneously. Since the areas of two flows obviously could not be separated, they were also discarded. Additionally, flows \#3 and \#9 occurred during longer, overlapping flows, so these flows were not analyzed, and their dates were ignored in the time series of the larger flows with which they overlapped. MODIS data was available for the remaining five flows, but GOES was only available for three. GOES data was not available for any dates during flows \#7, \#9, and \#10, and very little was available for flow \#3, and gaps in availability affected coverage for flow \#6. In summary, good-quality datasets were compiled for five flows: \#2 (2004-2005), \#6 (April 2006), \#7 (2006-2008) \#8 (2008-2009), and \#9 (May 2010). However, only two of these (2004-2005, and 2008-2009) had relatively complete sets of both MODIS and GOES data. Appendix D contains calendars representing image coverage of MODIS and GOES data for each flow.

\subsection{Lava Properties}

The physical properties that were calculated for each flow were used in the TADR model to independently define the $M$ value for each flow. Differences in physical properties between flows and within the Flow C (2006-2008) flows were also examined.

\subsubsection{Chemical Composition and DRE Density}

Major element chemical compositions for the eight samples were effectively identical both between flows and within the 2006-2008 flow (Table 3.1). They were also very similar to previously published whole-rock analyses [Eggers, 1971; Bardinzteff and 
Deniel, 1992; Matias, 2009] (Appendix C). The three most abundant chemical components and their average weight percentages were $\mathrm{SiO}_{2}(50.8 \%), \mathrm{Al}_{2} \mathrm{O}_{2}(17.8 \%)$, and $\mathrm{Fe}_{2} \mathrm{O}_{3}$ (11.3\%). Appendix $\mathrm{C}$ contains a list of published major element chemical compositions for Pacaya's lavas. The DRE densities calculated from of eight samples were also effectively identical. The average DRE value, which was used in the TADR model, was $2.72 \mathrm{~g} / \mathrm{cm}^{3}$ (Figure 3.1).

Table 3.1

Major element chemical compositions (weight \%) for new Pacaya samples.

\begin{tabular}{|c|c|c|c|c|c|c|c|c|}
\hline $\begin{array}{l}\text { Sample } \\
\text { Flow }\end{array}$ & $\begin{array}{l}\text { P01 } \\
\text { May } \\
2010\end{array}$ & $\begin{array}{l}\text { P12 } \\
2006- \\
2008\end{array}$ & $\begin{array}{l}\mathbf{P 1 4} \\
2006- \\
2008\end{array}$ & $\begin{array}{l}\mathbf{P 1 6} \\
2006- \\
2008\end{array}$ & $\begin{array}{l}\text { P18 } \\
\text { Apr } \\
2006\end{array}$ & $\begin{array}{l}\mathbf{P 2 4} \\
2006- \\
2008\end{array}$ & $\begin{array}{l}\mathbf{P 2 6} \\
2006- \\
2008\end{array}$ & $\begin{array}{l}\text { P30 } \\
2008- \\
2009\end{array}$ \\
\hline $\mathrm{SiO}_{2}$ & 49.27 & 50.52 & 50.93 & 50.56 & 51.77 & 51.16 & 51.11 & 50.81 \\
\hline $\mathrm{TiO}_{2}$ & 1.17 & 1.34 & 1.27 & 1.32 & 1.34 & 1.33 & 1.28 & 1.29 \\
\hline $\mathrm{Al}_{2} \mathrm{O}_{3}$ & 18.96 & 17.88 & 17.87 & 17.32 & 17.22 & 17.28 & 17.92 & 18.01 \\
\hline $\mathrm{Fe}_{2} \mathrm{O}_{3}$ & 10.87 & 11.33 & 11.11 & 11.63 & 11.3 & 11.59 & 11.21 & 11.3 \\
\hline $\mathrm{MnO}$ & 0.18 & 0.19 & 0.19 & 0.2 & 0.2 & 0.2 & 0.19 & 0.19 \\
\hline $\mathrm{MgO}$ & 4.9 & 4.56 & 4.6 & 4.8 & 4.33 & 4.68 & 4.64 & 4.58 \\
\hline $\mathrm{CaO}$ & 9.96 & 9.13 & 9.01 & 8.98 & 8.36 & 8.84 & 9.08 & 9.24 \\
\hline $\mathrm{Na}_{2} \mathrm{O}$ & 3.52 & 3.69 & 3.71 & 3.64 & 3.77 & 3.69 & 3.66 & 3.61 \\
\hline $\mathrm{K}_{2} \mathrm{O}$ & 0.76 & 0.96 & 0.92 & 0.94 & 1.18 & 0.99 & 0.94 & 0.9 \\
\hline $\mathrm{P}_{2} \mathrm{O}_{5}$ & 0.26 & 0.33 & 0.32 & 0.33 & 0.36 & 0.33 & 0.33 & 0.3 \\
\hline $\mathrm{H}_{2} \mathrm{O}+$ & 0.04 & 0.03 & 0.03 & 0.03 & 0 & 0.04 & 0.02 & 0.01 \\
\hline $\mathrm{H}_{2} \mathrm{O}-$ & -0.35 & -0.037 & -0.44 & -0.4 & -0.41 & -0.51 & -0.52 & -0.45 \\
\hline Totals & 99.64 & 99.7 & 99.64 & 99.45 & 99.52 & 99.71 & 99.95 & 99.89 \\
\hline $\begin{array}{l}\text { Density } \\
\left(\mathrm{g} / \mathrm{cm}^{3}\right)\end{array}$ & 2.732 & 2.724 & 2.717 & 2.732 & 2.708 & 2.726 & 2.719 & 2.724 \\
\hline
\end{tabular}




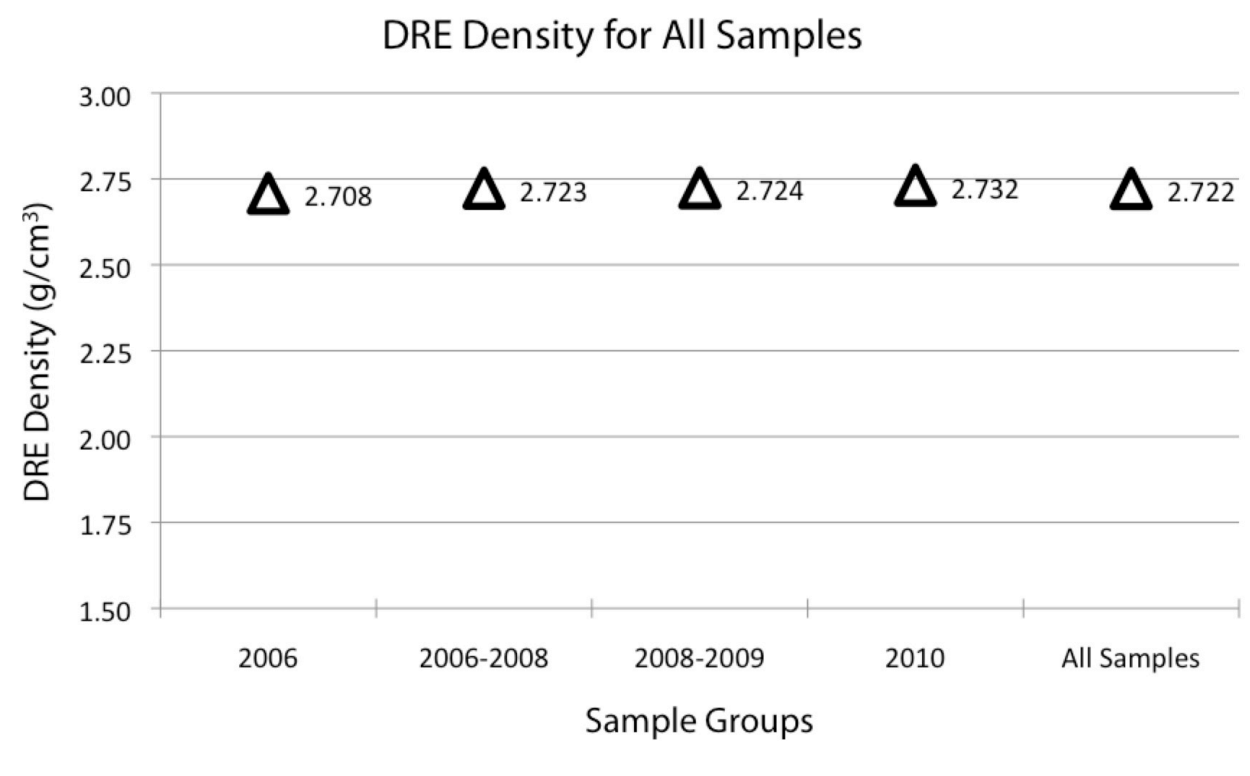

$\Delta$ All Samples

Figure 3.1: Average DRE densities calculated from major element chemical compositions for each of the four sampled flows. DRE densities of all flows were essentially identical. The average value of 2.72 $\mathrm{g} / \mathrm{cm}^{3}$ was value in the TADR model (method \#2).

\subsubsection{Bulk Density and Measured Vesicularity}

Bulk densities varied both between flows and within flows. As a function of bulk density, the calculated vesicularities also varied in the same way. The average bulk density for all samples was $2.14 \mathrm{~g} / \mathrm{cm}^{3}$, and the average vesicularity was $21.28 \%$. For all flows except the April 2006 flow, core samples were denser (less vesicular) than crust samples. See Figures 3.2 and 3.3. 


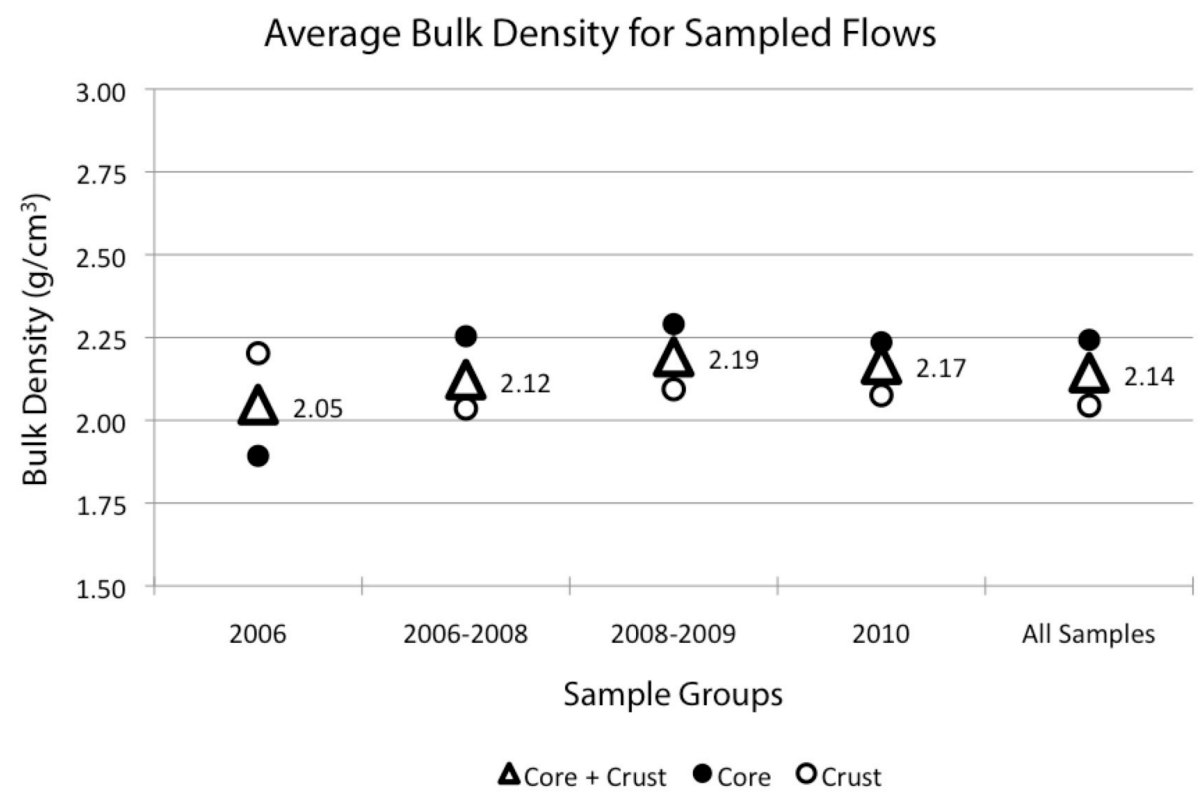

Figure 3.2: Average bulk densities for each of the four sampled flows. In general, core samples were denser (less vesicular) than crust samples.

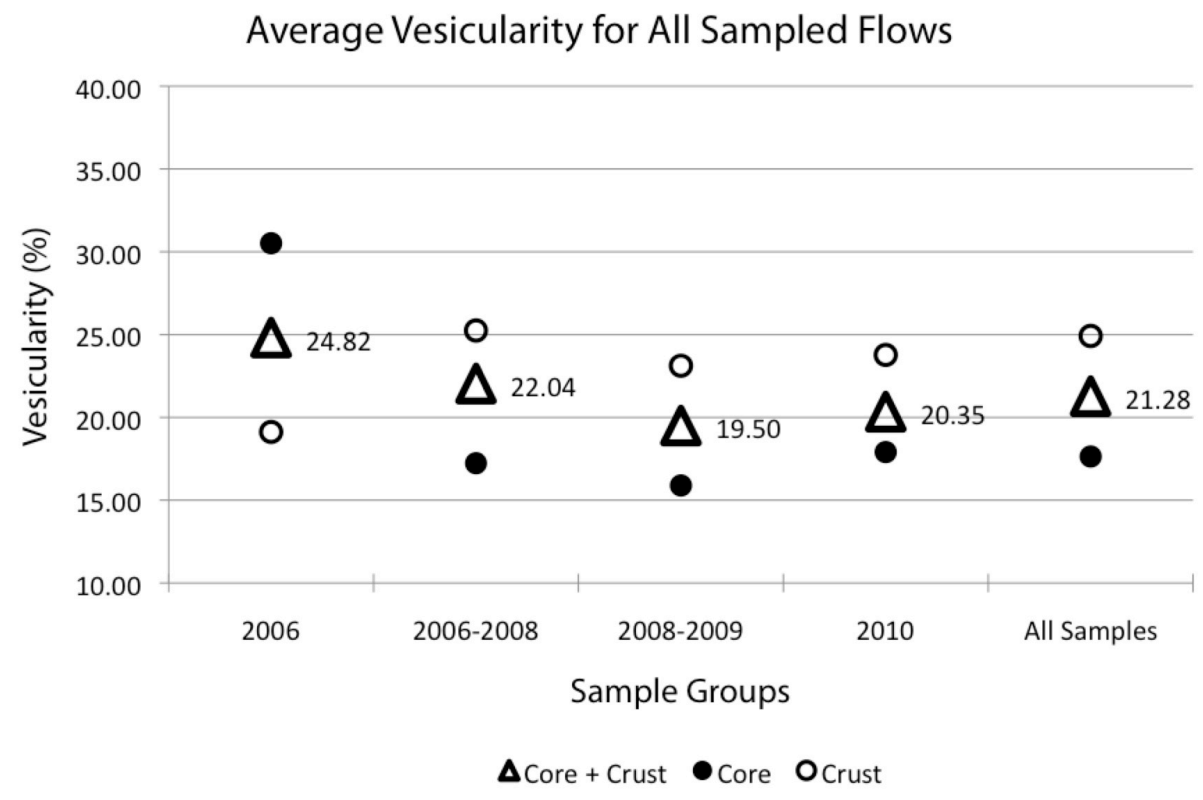

Figure 3.3: Vesicularities for each of the four sampled flows. In general, core samples were less vesicular (denser) than crust samples. The average vesicularity of core and crust samples for each flow was used in the TADR model (method \#2). 


\subsubsection{FOAMS Output (Vesicle and Crystal Content)}

FOAMS 2D-integrated vesicularities were similar to measured vesicularities, however only the measured vesicularities were used to calculate TADR. The 2Dintegrated, vesicle-corrected crystal percentages calculated by FOAMS were assumed to be a maximum value for $\phi$, the average mass fraction of crystals grown in cooling through $\triangle T$, and were used in the TADR model (method \#2). The vesicularities calculated by FOAMS agreed well with the independently measured vesicularities. Results are summarized in Table 3.2 .

\subsubsection{Conversion Factors $(M)$}

Table 3.3 shows the values of the conversion factor $M$ found by each of the two method, as well as the values of each parameter of the TADR model for both methods (i.e. best-fitting and calculated values). Both methods achieved final volumes of the same order-of-magnitude for three of the four flows (2006-2008, 2008-2009, and May 2010). The 2008-2009 datasets showed the most agreement, with resulting TADR's of 0.099 $\mathrm{m}^{3} / \mathrm{s}$ and $0.116 \mathrm{~m}^{3} / \mathrm{s}$ for methods $\# 1$ and $\# 2$, respectively. Conversely, the average TADR

Table 3.2

Two-dimensional integrated vesicle and crystal volume percentages calculated using FOAMS, vesiclecorrected crystal percentages, and independently measured vesicularities.

\begin{tabular}{lllllll}
\hline \# & Flow & Type & $\begin{array}{l}\text { 2D Int. } \\
\text { Vesicle } \%\end{array}$ & $\begin{array}{l}\text { Measured } \\
\text { Vesicularity }\end{array}$ & $\begin{array}{l}\text { 2D Int. } \\
\text { Crystal \% }\end{array}$ & $\begin{array}{l}\text { Corrected } \\
\text { Crystal \% }\end{array}$ \\
\hline P05 & $\begin{array}{l}\text { May } \\
2010\end{array}$ & Core & 25.6 & 23.6 & 33.6 & 44.0 \\
P14 & $\begin{array}{l}2006- \\
2008\end{array}$ & Core & 19.9 & 18.3 & 36.0 & 44.0 \\
P17 & $\begin{array}{l}\text { Apr } \\
2006\end{array}$ & Crust & 31.7 & 30.5 & 30.4 & 43.7 \\
P25 & $\begin{array}{l}2006- \\
2008\end{array}$ & Crust & 16.7 & 15.9 & 37.7 & 44.8 \\
P30 & $\begin{array}{l}2008- \\
\text { 200 }\end{array}$ & Core & 18.4 & 15.9 & 35.9 & 42.7 \\
P31 & 2009 & & & & & \\
& 2009 & Crust & 31.1 & 23.1 & 35.0 & 45.6
\end{tabular}


calculated using method \#2 for the April 2006 flow was nearly three times lower that found via method \#1. The calculated value of $M$ was similar for each flow and the average value was $1.38 \mathrm{E}-5 \mathrm{~m} / \mathrm{s}$. Some of the values for $\Delta T$ are clearly impossible (Table 3.3, best-fitting model of the April 2006 and May 2010 flows). A negative value of $\Delta T$ indicated that the lava actually increased in temperature, which is impossible. Such values are most likely the results of the variation of only one parameter $(\Delta T)$ in the bestfitting model, but could also indicate that the model cannot be applied to these cases (e.g. these flows were volume-limited, not cooling-limited).

Table 3.3

Parameters used in the TADR models for both methods 1 and 2 for MODIS datasets.

\begin{tabular}{|c|c|c|c|c|c|c|c|c|c|}
\hline & & $\begin{array}{l}\boldsymbol{\rho}_{\text {DRE }} \\
\mathrm{kg} / \mathrm{m}^{3}\end{array}$ & $\begin{array}{l}\mathbf{v} \\
\text { Frac. }\end{array}$ & $\begin{array}{l}\phi \\
\text { Frac. }\end{array}$ & $\begin{array}{l}\text { MODIS } \\
\Delta \mathrm{T} \\
{ }^{\circ} \mathrm{C}\end{array}$ & $\begin{array}{l}\mathbf{V} \\
\mathrm{m}^{3}\end{array}$ & $\begin{array}{l}\mathbf{V}_{\text {tar }} \\
\mathrm{m}^{3}\end{array}$ & $\begin{array}{l}\text { TADR } \\
\mathrm{m}^{3} / \mathrm{s}\end{array}$ & $\begin{array}{l}\mathbf{M} \\
\mathrm{m} / \mathrm{s}\end{array}$ \\
\hline \multirow{2}{*}{ 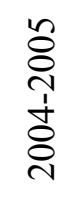 } & $\begin{array}{l}\text { Best- } \\
\text { Fit }\end{array}$ & 2678 & 0.1 & 0.5 & 485.6 & $8.43 \mathrm{E} 5$ & $8.43 \mathrm{E} 5$ & 0.435 & $6.35 \mathrm{E}-6$ \\
\hline & Calc. & -- & -- & -- & -- & -- & -- & -- & -- \\
\hline \multirow{2}{*}{ 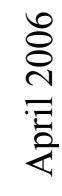 } & $\begin{array}{l}\text { Best- } \\
\text { Fit }\end{array}$ & 2678 & 0.1 & 0.5 & -70.38 & $1.21 \mathrm{E} 5$ & $1.21 \mathrm{E} 5$ & 0.612 & $4.81 \mathrm{E}-5$ \\
\hline & Calc. & 2723 & 0.248 & 0.437 & 200 & $3.60 \mathrm{E} 4$ & -- & 0.184 & $1.43 \mathrm{E}-5$ \\
\hline \multirow{2}{*}{$\begin{array}{l}\infty \\
\text { ஸे } \\
\text { ஸे } \\
\stackrel{0}{0}\end{array}$} & $\begin{array}{l}\text { Best- } \\
\text { Fit }\end{array}$ & 2678 & 0.1 & 0.5 & 273.2 & $5.82 \mathrm{E} 6$ & $5.82 \mathrm{E} 6$ & 0.077 & $9.50 \mathrm{E}-6$ \\
\hline & Calc. & 2723 & 0.220 & 0.444 & 200 & $8.38 \mathrm{E} 6$ & -- & 0.111 & $1.37 \mathrm{E}-5$ \\
\hline \multirow{2}{*}{ 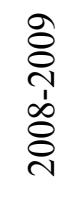 } & $\begin{array}{l}\text { Best- } \\
\text { Fit }\end{array}$ & 2678 & 0.1 & 0.5 & 197.2 & $1.60 \mathrm{E} 6$ & $1.60 \mathrm{E} 6$ & 0.099 & $1.15 \mathrm{E}-5$ \\
\hline & Calc. & 2723 & 0.195 & 0.442 & 200 & $1.84 \mathrm{E} 6$ & -- & 0.116 & $1.33 \mathrm{E}-5$ \\
\hline \multirow{2}{*}{ 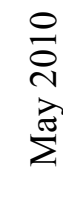 } & $\begin{array}{l}\text { Best- } \\
\text { Fit }\end{array}$ & 2678 & 0.1 & 0.5 & -16.93 & $2.74 \mathrm{E} 6$ & $2.74 \mathrm{E} 6$ & 1.823 & $2.95 \mathrm{E}-5$ \\
\hline & Calc. & 2723 & 0.204 & 0.440 & 200 & $1.25 \mathrm{E} 6$ & -- & 0.831 & $1.34 \mathrm{E}-5$ \\
\hline
\end{tabular}


Table 3.4

Parameters used in the TADR models for both methods 1 and 2 for GOES datasets.

\begin{tabular}{|c|c|c|c|c|c|c|c|c|c|}
\hline & & $\begin{array}{l}\boldsymbol{\rho}_{\text {DRE }} \\
\mathrm{kg} / \mathrm{m}^{3}\end{array}$ & $\begin{array}{l}\mathbf{V} \\
\text { Frac. }\end{array}$ & $\begin{array}{l}\phi \\
\text { Frac. }\end{array}$ & $\begin{array}{c}\text { GOH } \\
\Delta \mathbf{T} \\
{ }^{\circ} \mathrm{C}\end{array}$ & $\begin{array}{l}\mathbf{V} \\
\mathrm{m}^{3}\end{array}$ & $\begin{array}{l}\mathbf{V}_{\text {tar }} \\
\mathrm{m}^{3}\end{array}$ & $\begin{array}{l}\text { TADR } \\
\mathrm{m}^{3} / \mathrm{s}\end{array}$ & $\begin{array}{l}\mathbf{M} \\
\mathrm{m} / \mathrm{s}\end{array}$ \\
\hline \multirow{2}{*}{ 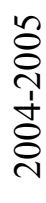 } & $\begin{array}{l}\text { Best- } \\
\text { Fit }\end{array}$ & 2678 & 0.1 & 0.5 & 1376 & $6.63 \mathrm{E} 5$ & $6.63 \mathrm{E} 5$ & 0.356 & $2.66 \mathrm{E}-6$ \\
\hline & Calc. & -- & -- & -- & -- & -- & -- & -- & -- \\
\hline \multirow{2}{*}{ 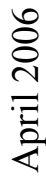 } & $\begin{array}{l}\text { Best- } \\
\text { Fit }\end{array}$ & 2678 & 0.1 & 0.5 & 8.287 & $1.21 \mathrm{E} 5$ & $1.21 \mathrm{E} 5$ & 0.908 & $2.49 \mathrm{E}-5$ \\
\hline & Calc. & 2723 & 0.248 & 0.437 & 200 & $6.90 \mathrm{E} 4$ & -- & 0.516 & $1.43 \mathrm{E}-5$ \\
\hline \multirow{2}{*}{ 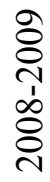 } & $\begin{array}{l}\text { Best- } \\
\text { Fit }\end{array}$ & 2678 & 0.1 & 0.5 & 606.6 & 1.37E6 & $1.37 \mathrm{E} 6$ & 0.972 & $5.34 \mathrm{E}-6$ \\
\hline & Calc. & 2723 & 0.195 & 0.442 & 200 & $3.41 \mathrm{E} 6$ & -- & 0.242 & $1.33 \mathrm{E}-5$ \\
\hline
\end{tabular}

\subsection{Volcanic Radiances}

"Volcanic radiances" (anomalous minus background) for confirmed hot spots were plotted in time series for each eruption (Figure 3.4). In general, GOES radiances were smaller than MODIS radiances because the extra radiance contributed by lava was diluted in the much larger ambient background portion of the pixel. In these graphs, gaps caused either by poor weather conditions or gaps in the imagery database are obvious. In Figure 3.5b (April 2006 flow), the potential utility of GOES data is obvious; weather conditions were ideal and good-quality image were available every 15 minutes. Unfortunately, data were only available until the evening of April 5, though the flow continued until April 7. 


\subsection{Time-averaged Discharge Rates}

Two sets of TADR time series were created for each flow using the two different conversion factors derived by the described methods. In the first case, the dataset was best-fit to produce total volumes for each flow identical to those calculated by Matias [2009]. Figure 3.5 shows the resulting TADR time series for five MODIS and three GOES datasets calculated by the first method. In the second case, the dataset was calculated using measured values (note that $\Delta T$, which could not be measured, was set to $200^{\circ} \mathrm{C}$ [Harris et. al, 2005]). Because they appear very similar to the graphs in Figure 3.5 , the TADR and cumulative volume time series produced using the second method are included in Appendix E.

\subsection{Cumulative Volumes}

Again, two sets of cumulative volume time series were created using the two conversion factors calculated by separate methods. Those calculated via the first method are shown in Figure 3.5, and those calculated via the second method are shown in Appendix E.

\subsection{Down-flow Variation in the May 2010 and 2006-2008 Flows}

The May 2010 flow was sampled in six locations at approximately $\sim 1 \mathrm{~km}$ intervals down-flow (Figure 2.5). Bulk density decreased slightly in the down-flow direction in the 2010 core samples $\left(R^{2}=0.31\right)$, but bulk density of crust samples was more stable and the slight observed decrease was not necessarily systematic $\left(R^{2}=0.19\right)$ (Figure 3.6).

The 2006-2008 was not sampled with the intent to analyze down-flow variation, however enough samples were collected to attempt this (Figure 3.7). The overall downflow decrease in bulk density does not appear to be systematic in the 2006-2008 flow ( $\mathrm{R}^{2}$ $=0.17$ for core samples, $R^{2}=0.01$ for crust samples). 


\subsection{Long-term Magma Supply Rate}

Two types of activity were identified in Figure 3.8 ; 1) long, steady periods of volumetric increase (low TADR) broken by 2) short, more rapid periods of volumetric increase (high TADR) (green and blue respectively in Figure 3.8). The supply rate estimated by averaging the TADR of the three longer flows (i.e. 2004-2005, 2006-2008, and 2008-2009) was $7800 \mathrm{~m}^{3} /$ day or $0.0903 \mathrm{~m}^{3} / \mathrm{s}$. 
a

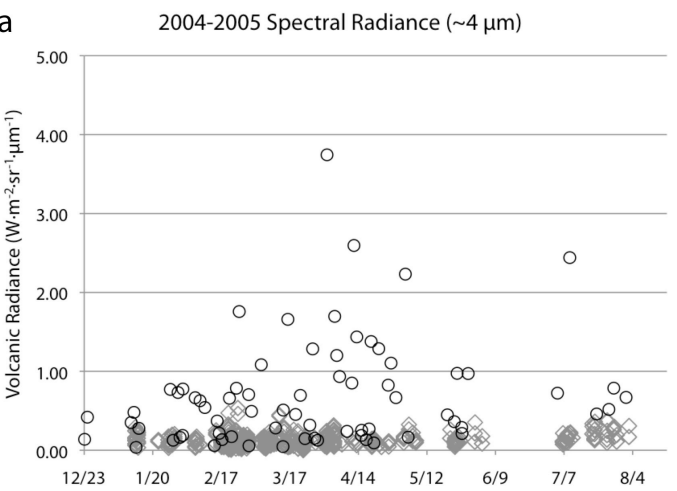

C

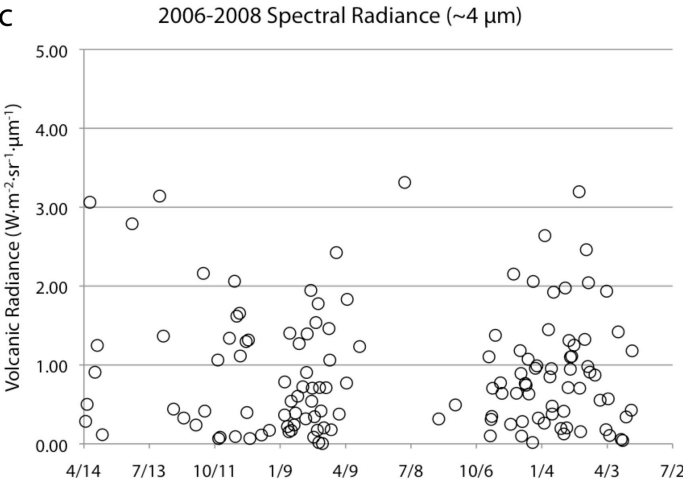

e

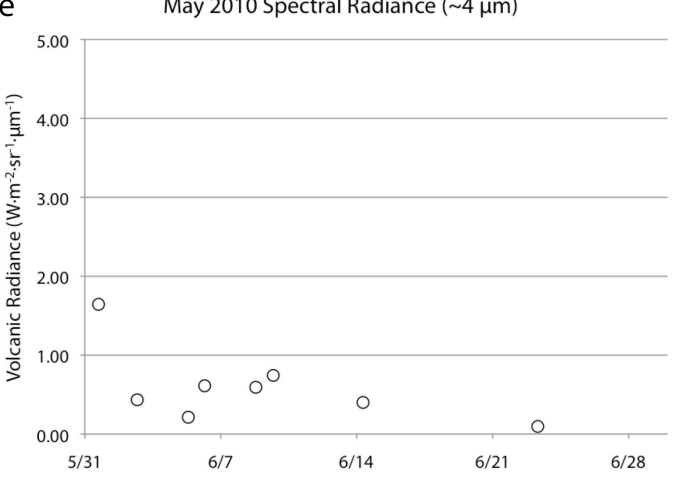

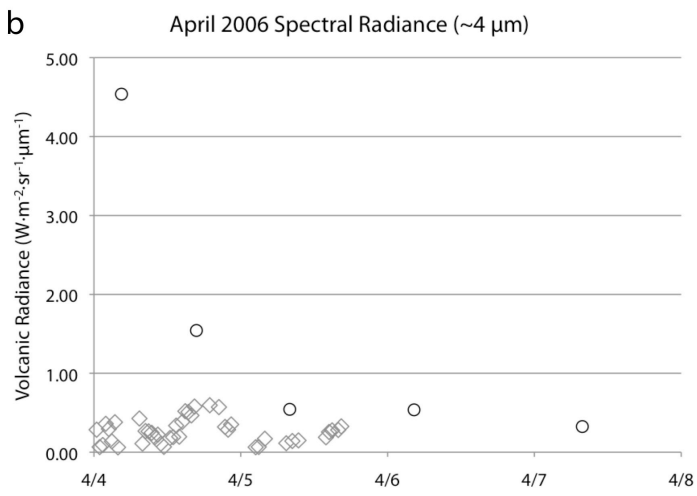

d 2008-2009 Spectral Radiance $(\sim 4 \mu \mathrm{m})$

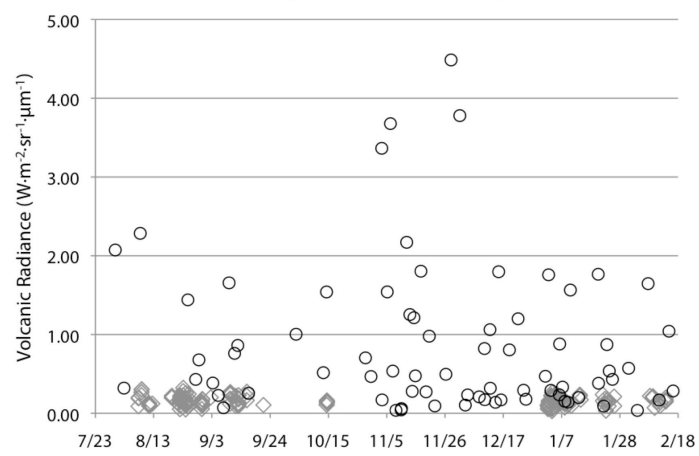

$\begin{array}{lllllllllll}7 / 23 & 8 / 13 & 9 / 3 & 9 / 24 & 10 / 15 & 11 / 5 & 11 / 26 & 12 / 17 & 1 / 7 & 1 / 28 & 2 / 18\end{array}$

Figure 3.4: Volcanic radiance (anomalous minus ambient) time series for each of the five flows. GOES data were only available during three of these (2004-2005; April 2006; and 2008-2009). 
a

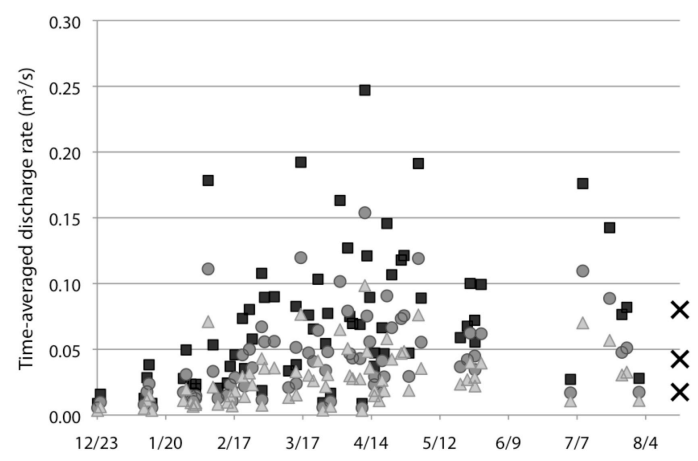

2004-2005 Cumulative Volume (MODIS)

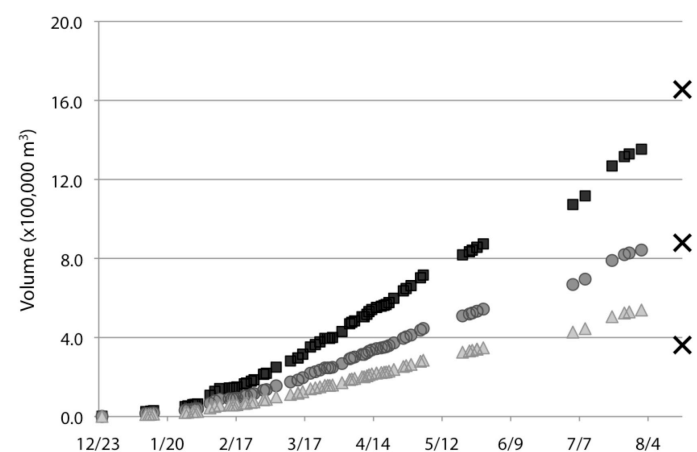

C

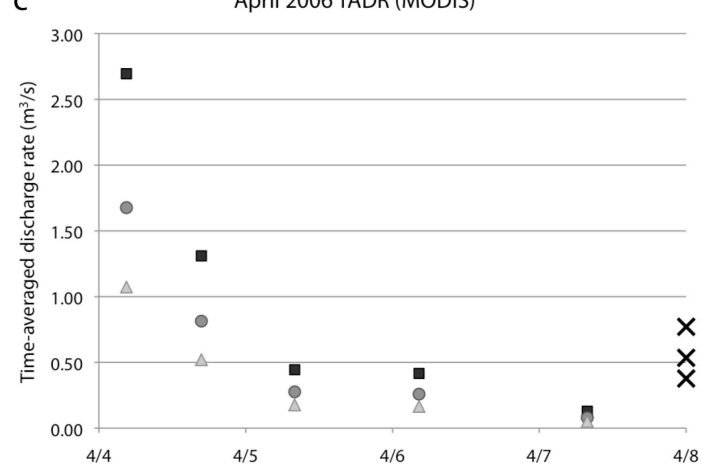

April 2006 Cumulative Volume (MODIS)

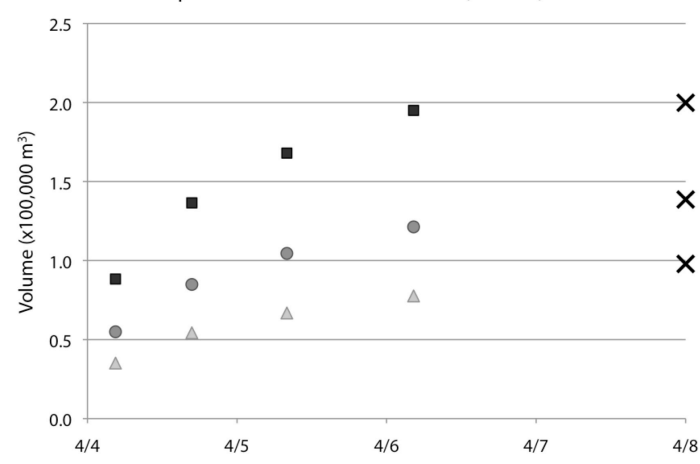

b 2004-2005 TADR (GOES)

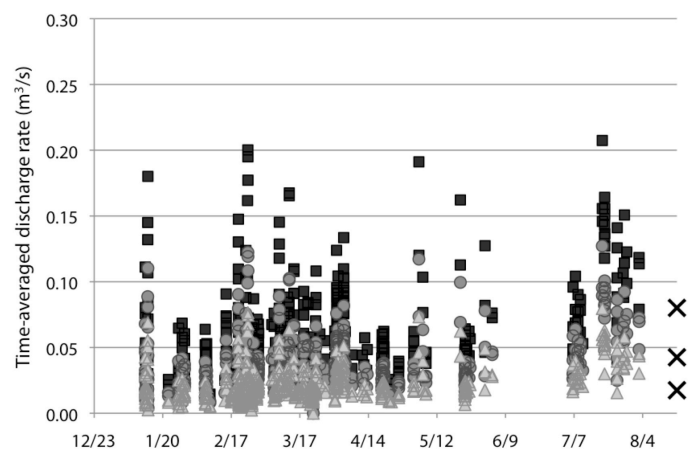

2004-2005 Cumulative Volume (GOES)

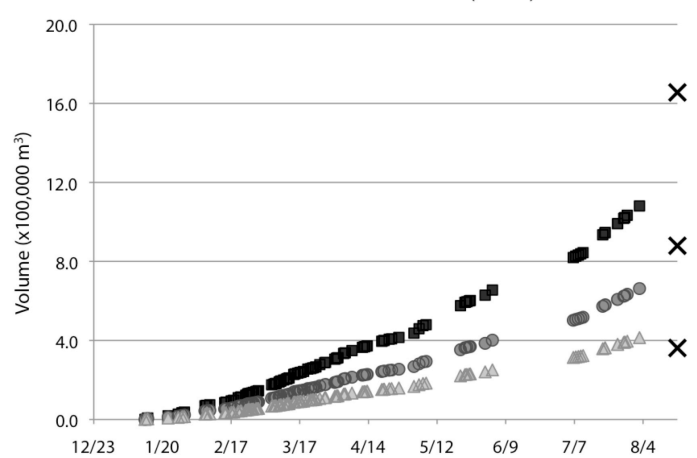

d

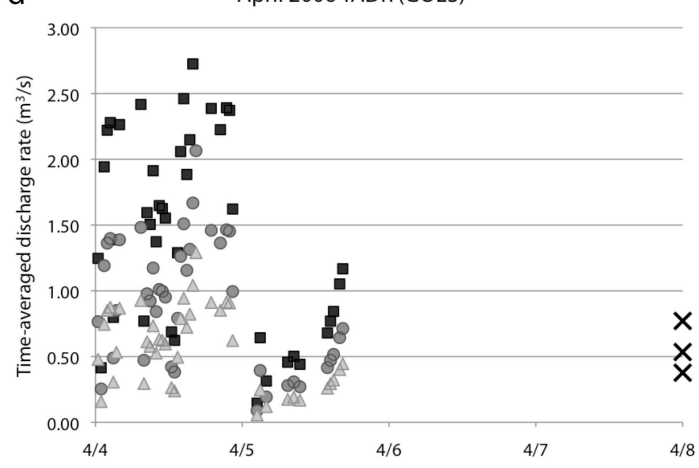

April 2006 Cumulative Volume (GOES)

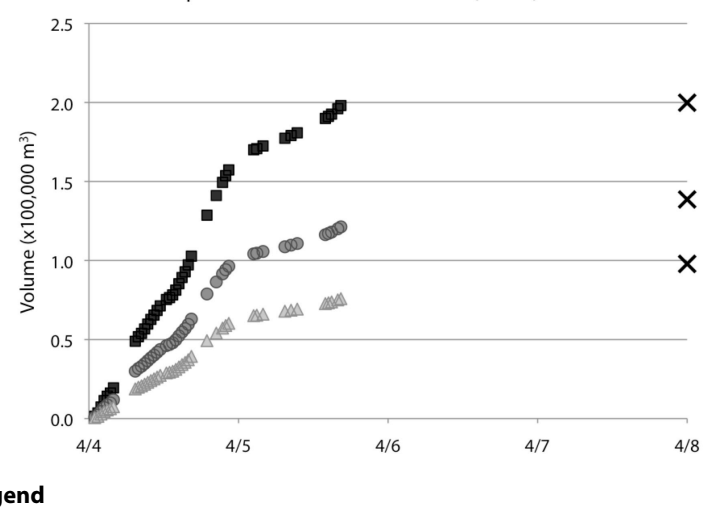

$\square 250^{\circ} \mathrm{C}$ Model $\bigcirc 350^{\circ} \mathrm{C}$ Model $\triangle 600^{\circ} \mathrm{C}$ Model

$\times$ Max., Int., and Min. values from Matías [2009] 
e

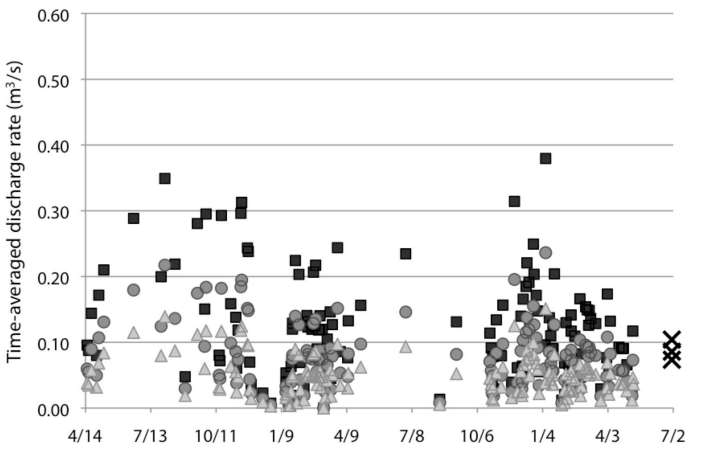

2006-2008 Cumulative Volume (MODIS)

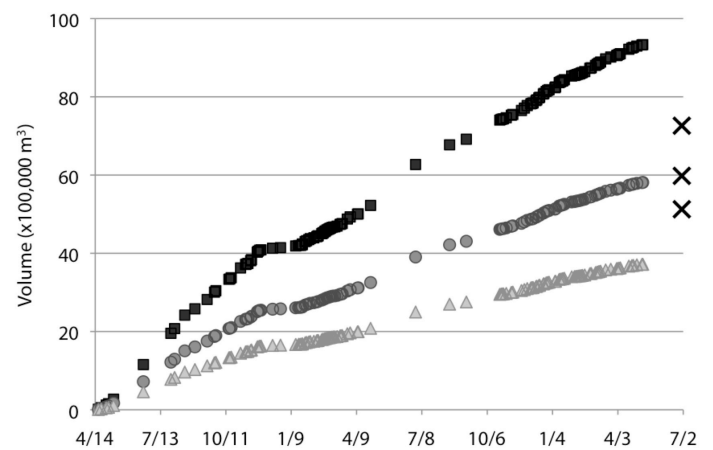

$f$
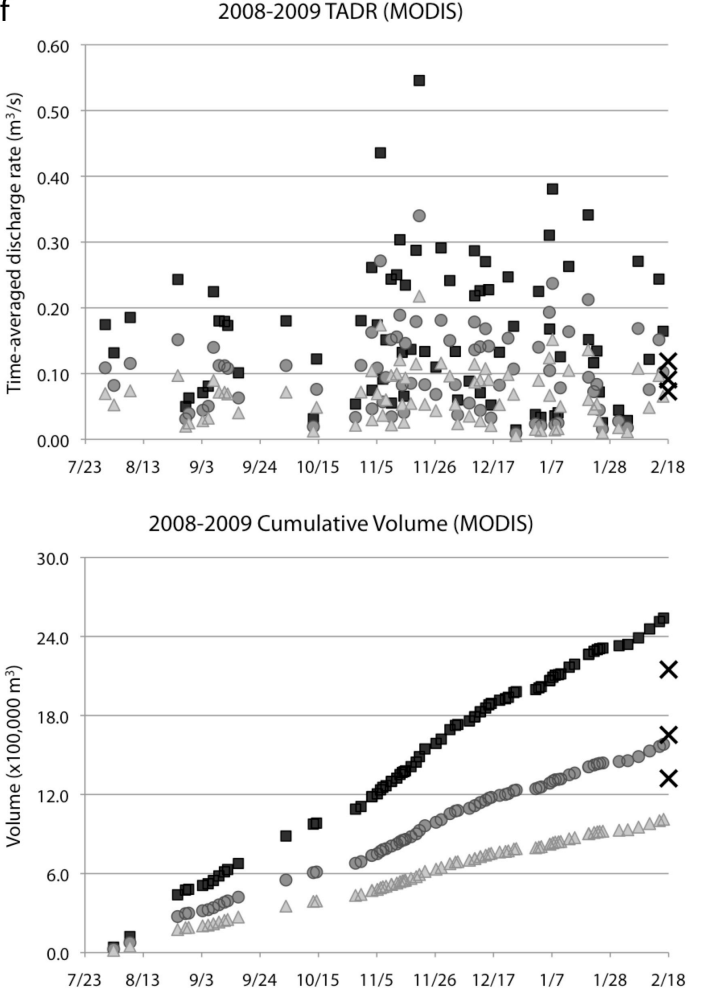

Figure 3.5: Time-averaged discharge rate and cumulative volume time series for each of the five flows using Method 1 (best-fitting). GOES data was only available during three of these (20042005; April 2006; and 2008-2009).

Legend

- $250^{\circ} \mathrm{C}$ Model $\bigcirc 350^{\circ} \mathrm{C}$ Model $\triangle 600^{\circ} \mathrm{C}$ Model

$\times$ Max., Int., and Min. values from Matías [2009]

9
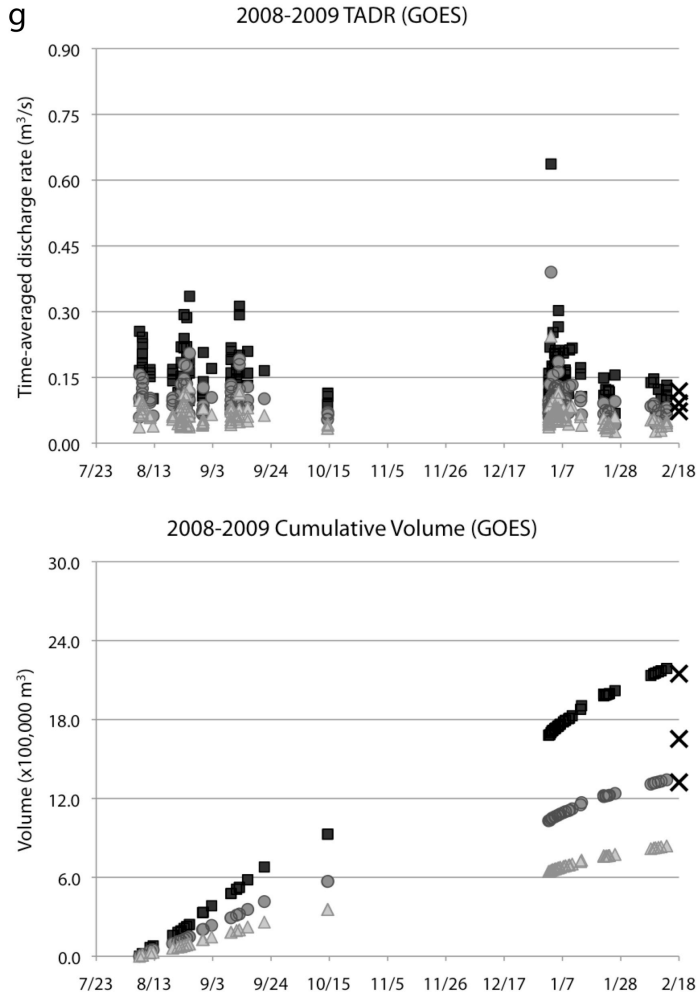
h
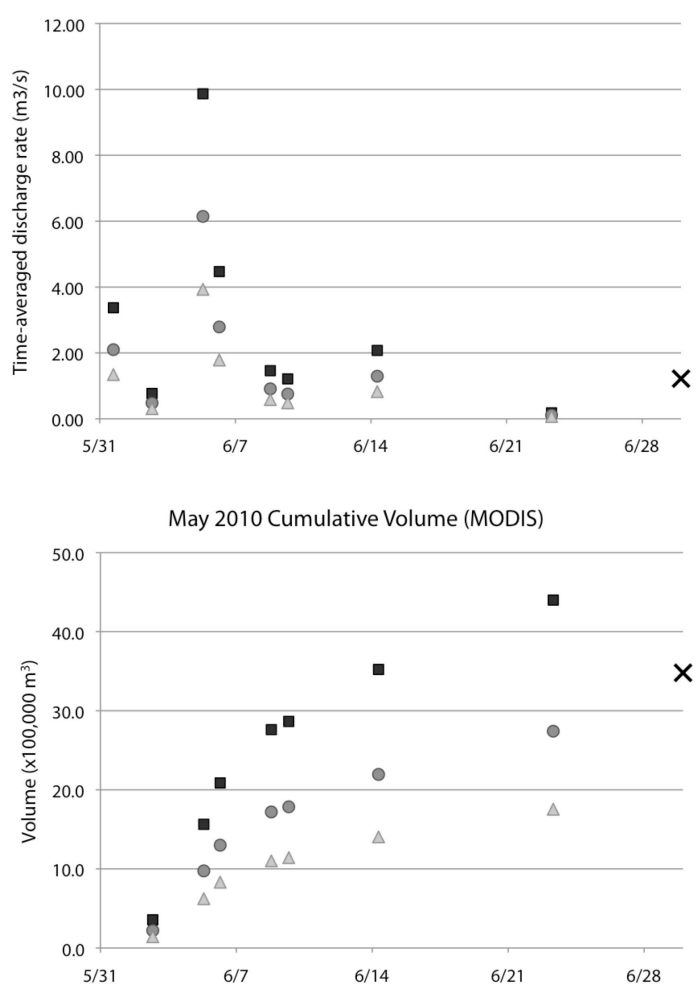

Legend

- $250^{\circ} \mathrm{C}$ Model $\bigcirc 350^{\circ} \mathrm{C}$ Model $\triangle 600^{\circ} \mathrm{C}$ Model $X$ Max., Int., and Min. values from Matías [2009]
Figure 3.5 continued. 


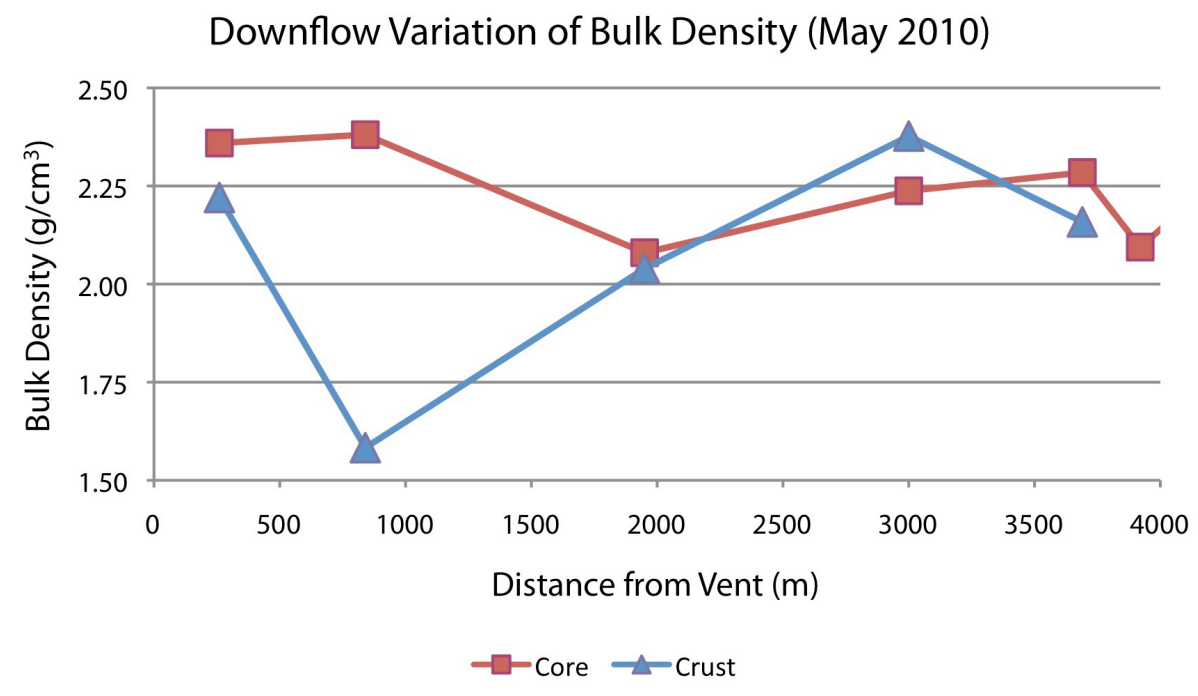

Figure 3.6: Downflow variation of bulk density in the May 2010 flow.

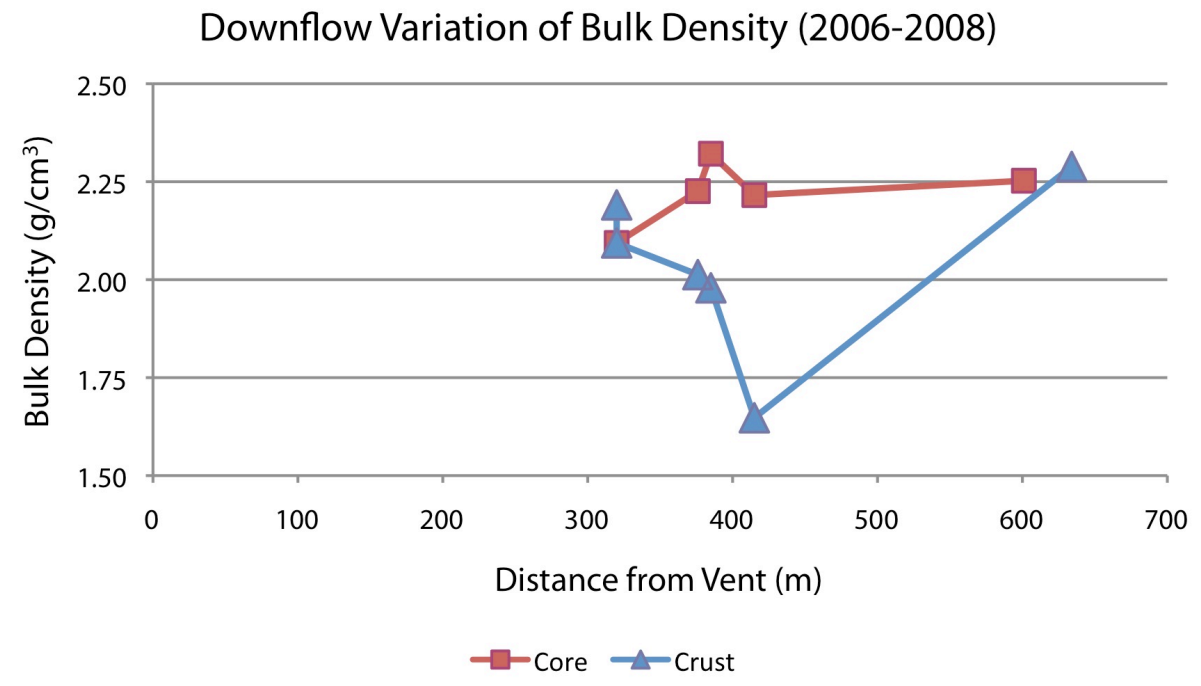

Figure 3.7: Downflow variation of bulk density in the 20062-2008 flow. 


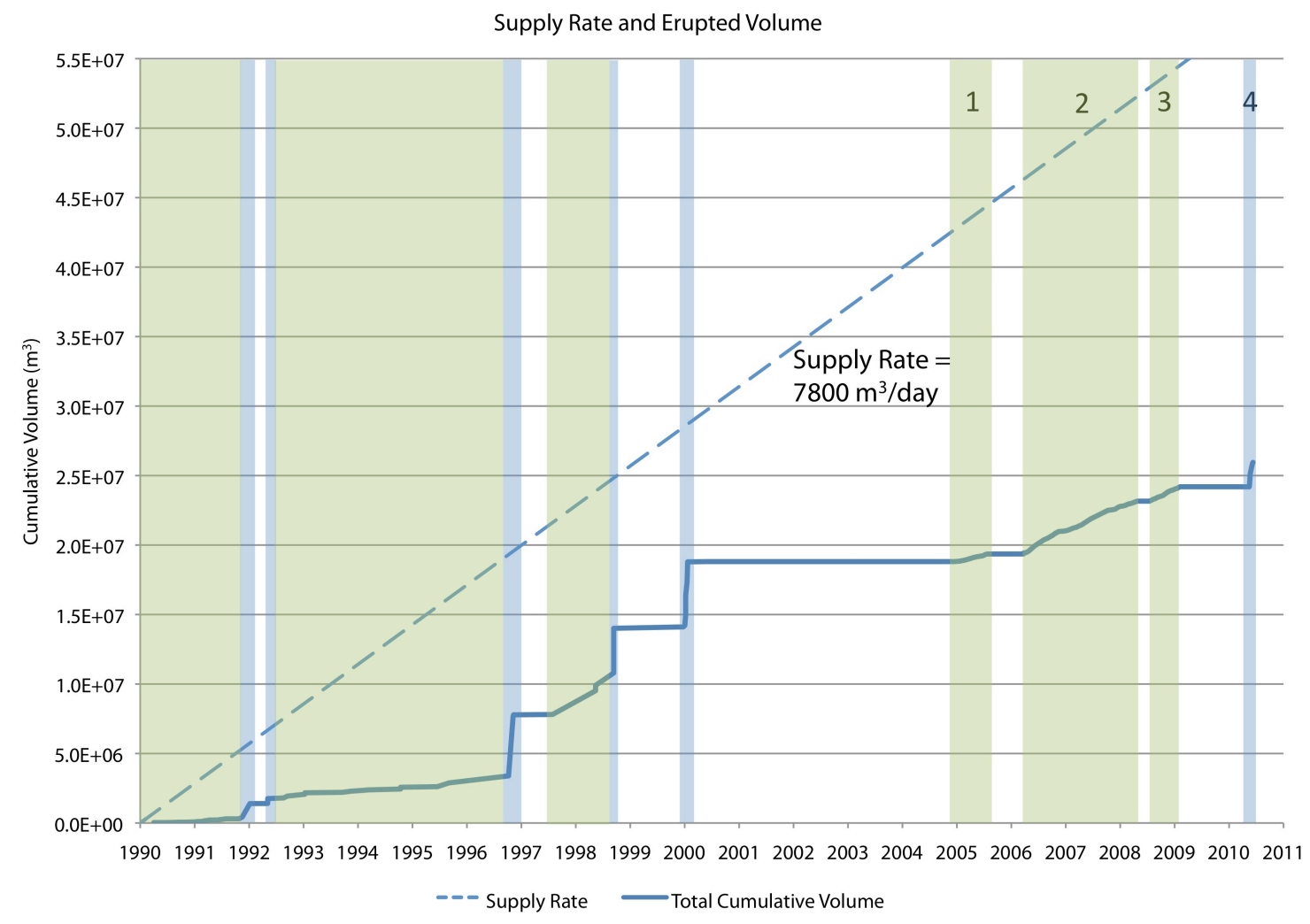

Figure 3.8: Long-term magma supply rate and cumulative eruptive volume over 20 years. The supply rate is averaged from TADR of the three long flows $(1,2$, and 3$)$. The cumulative eruptive volume curve is created with supplementary data from Matías [2009]. The long, low-TADR periods (green) represent Type 1 activity (e.g. blocks 1, 2,3). The short, high-TADR periods (blue) represent Type 2 activity (e.g. block 4). 


\section{Discussion}

\subsection{Applicability of the Model at Pacaya}

\subsubsection{Comparison of MODIS and GOES Datasets}

The datasets derived separately for MODIS and GOES imagery for the same flows showed similar qualitative trends (i.e. volcanic radiance patterns), but did not necessarily agree quantitatively (i.e. TADR and volumes estimates). For example, the average area of active lava determined via the mixed-pixel model (section 2.5) was higher in GOES datasets. These and other discrepancies could be due to a number of factors such as fundamental errors in the model or the difference in bandwidth between the two sensors, but are probably due mostly to the inability of the low-spatial-resolution GOES imager to resolve the relatively small lava flows at Pacaya. The conversion factors derived via method 1 (best-fitting), and the total volumes derived via method 2 (measured values) were different in MODIS and GOES datasets (Tables 3.3 and 3.4). In both methods, the MODIS datasets produced more realistic parameters and/or agreed better with the estimates made by Matías [2009].

Ideally, the MODIS and GOES datasets would agree well enough to be combined into a single dataset that has the advantage of very good spatial resolution and very good temporal resolution. However, the discrepancies between MODIS and GOES datasets eliminated this possibility in this particular circumstance. Because of their superior spatial resolution and better agreement with an independent dataset, only MODIS data were considered usable for quantitative purposes (i.e. calculating TADR and cumulative volume). Even though the GOES datasets proved to be less accurate for the flows investigated here, they still provided qualitative information about changes in thermal signatures at Pacaya. For instance, the GOES data confirmed the same trend of low, scattered measurements that are exhibited by the MODIS data. Additionally, GOES imagery is useful for monitoring large flow fields like those that occur at Kilauea Volcano, Hawaii [e.g. Harris et al., 2001]. 


\subsubsection{Conversion Factors for MODIS datasets}

It would be convenient to produce accurate TADR and volumes estimates for all flows from the same volcano using a single conversion factor $(M)$. For example, a distinctive relationship between active flow area and time-average discharge rate exists for separate time periods at Etna Volcano, Sicily, and can be used to make accurate estimate of discharge rates when ground-based measurements are not available [Harris et $a l ., 2011]$. The conversion factor consists of six variables, which are shown in Table 2.3 with all of the other parameters of the TADR model, and are also summarized below in Table 4.1. In method 1 (best-fitting), the MODIS datasets produced different $M$ values for each flow, ranging from 9.50E-06 to $1.15 \mathrm{E}-05 \mathrm{~m} / \mathrm{s}$ (Table 2.3 ), although they only varied within an order of magnitude $\left(10^{-5}\right.$ to $\left.10^{-6}\right)$. These differences could have arisen from a number of sources including errors in previous estimates of total volume, fundamental errors in the TADR calculation, factors unaccounted-for such as slope or heat loss due to rainfall, or differences in the physical properties of the lavas.

The conversion factors produced via the second method (measuring of the constituents in Table 4.1) were all very similar (Table 3.3). That is, the measured physical characteristics did not vary significantly between the flows. With these calculated conversion factors (average 1.38E-5 m/s), the total volumes achieved for each flow fell into the ranges, or at least the order-of-magnitude estimated by Matías [2009]. Considering that the errors in the Matias [2009] volumes are potentially large and that the different $M$ values produced by method 1 are due to factors others than the physical properties of the lavas (i.e. incomplete dataset), these results indicates that a single conversion factor may in fact be applicable at Pacaya.

A single conversion factor only holds for eruptions of the same style, environmental setting, and magma composition, so these observations imply that the discrepancies found in Method 1 must be due to either 1) errors in the dataset (e.g. available imagery is not representative, inaccurate assumptions for the mixed-pixel model, inaccurate ground-based volume estimates), or 2) variation in eruption, emplacement, and cooling conditions (e.g slope angle, rainfall, ambient air temperature, wind, topographic confinement, eruption style). 
The 2008-2009 flow produced the most similar factors; 1.15E-5 for Method 1, and 1.33E-5 for Method 2. This flow also had the best temporal coverage (one image every 2.7 days on average). Based on these observations, the calculated conversion factor (with an average value of $1.38 \mathrm{E}-5 \mathrm{~m} / \mathrm{s}$ ), could probably be used to find a rough estimate TADR for future eruptions at Pacaya. That is:

$$
T A D R_{\text {PACAYA }}=1.38 \times 10^{-5} \cdot A_{\text {tot }}
$$

Table 4.1

Constituents of the conversion factor, $M$, which relates area to time-averaged discharge rate.

\begin{tabular}{lll}
\hline Parameter & Symbol & Unit \\
\hline DRE lava density & $\rho_{\mathrm{DRE}}$ & $\mathrm{kg} \cdot \mathrm{m}^{-3}$ \\
$\mathrm{~T}_{\text {erupt }}-\mathrm{T}_{\text {stop }}$ & $\Delta \mathrm{T}$ & ${ }^{\circ} \mathrm{C}$ \\
Mass fraction of crystals grown through $\Delta \mathrm{T}$ & $\phi$ & fraction \\
Vesicularity & $\mathrm{V}$ & fraction \\
Specific heat capacity & $\mathrm{C}_{\mathrm{p}}$ & $\mathrm{J} \cdot \mathrm{kg}^{-1} \cdot \mathrm{K}^{-1}$ \\
Latent heat of crystallization & $\mathrm{C}_{\mathrm{L}}$ & $\mathrm{J} \cdot \mathrm{kg}^{-1}$ \\
\hline${ }^{*}$ Note that $\rho_{D R E}$ and $v$ are used to calculated $\rho$ (bulk density) in Equation $2.5 \mathrm{c}$ & \\
\hline
\end{tabular}

\subsection{Supply Rate and Conduit Convection}

Degassing and heat loss measurements can be used to estimate the amount of magma supplied to a volcanic system [e.g., Francis, 1993; Allard et al., 1994; Kazahaya et al., 1994; Allard, 1997; Allard et al., 2006; White et al., 2006]. Eggers [1971] originally suggested that the petrographic and chemical uniformity of Pacaya's lavas throughout its history implies a continuous supply to an open magma chamber. Such uniformity is confirmed by this study and others [i.e., Eggers, 1971; Bardinzteff and Deniel, 1992; Matías, 2009]. Assuming that Pacaya receives an approximately constant supply of magma from the magma chamber to the conduit, a supply rate can be estimated based on observations of the eruptive cycles defined in this investigation (Type 1: long, low-TADR periods, and Type 2: short, high-TADR periods).

It is possible that the low, steady discharge rates exhibited during Type 1 activity represented lava bleeding or leaking from the conduit at approximately the rate at which it is being supplied [Ripepe et al., 2005, Harris et al., 2005]. That is, when a dike taps the conduit or when the vent overflows, the associated low TADR is representative of the 
long-term supply rate into the conduit (Figure 4.1b). The TADR's of the three-longduration flows (2004-2005, 2006-2007, and 2008-2009) were averaged to yield an estimate of the supply rate of $7800 \mathrm{~m}^{3} /$ day or $.0903 \mathrm{~m}^{3} / \mathrm{s}$.

Figure 3.8 shows that the difference between the theoretically supplied volume and the actual erupted volume becomes larger through time. Francis [1993] stated that whenever the inferred supply of magma exceeds the rate of eruption, formation of suband/or intra-volcanic intrusive complexes is indicated. (i.e. endogenous or cryptic growth). Mechanisms of endogenous growth at other volcanoes have been suggested, including cumulate formation, convection and recycling in a large magma chamber, or storage as dike intrusions [Francis, 1993; Kazahaya et al., 1994; Allard, 1997]. For example, Allard [1997] concluded that the supplied magma flux at Etna (which greatly exceeds the actual erupted volume) was due to convection and recycling of magma and that recycled magma may be stored in the crust as cumulates. At Pacaya, supplied magma may continue to convect in the conduit and collect in the shallow magmatic system between eruptions.

The short, but voluminous bursts of activity (Type 2) such as in 2000 and 2010 (Figure 3.8) might be explained by the eruption of the "collected" magma that has been stored in the conduit or shallow reservoir between eruptions. That is, these eruptions may release larger volumes of magma at higher discharge rates, allowing the actual erupted volume to "catch-up" with the theoretically supplied volume. However, these pulses

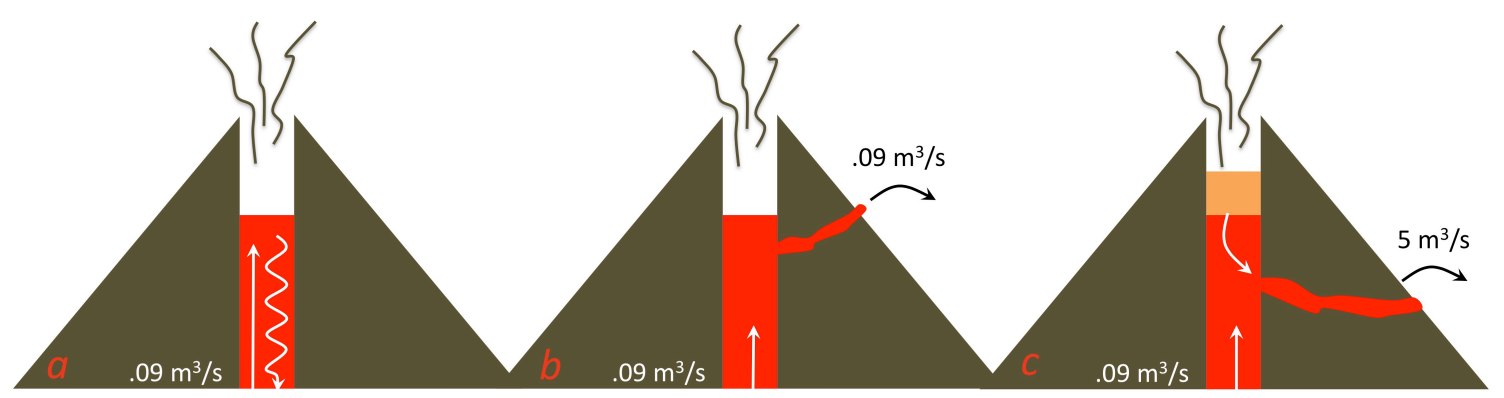

Figure 4.1: Conduit convection diagram. The average discharge rate observed during Type 1 activity (long, low-TADR periods) may be representative of the long-term supply rate. (a) Conduit convection with no eruption. Magma is supplied to the conduit at a steady rate of $0.9 \mathrm{~m}^{3} / \mathrm{s}$. (b) When a dike is formed or the vent overflows, instead of degassing and sinking back down the conduit, lava is extruded at the supply rate. (c) Type 2 activity may also result from hydrostatic influence as the upper portion of the conduit is drained. 
could also be due to temporary increases in supply rate, as is likely the case with the May 2010 flow, which erupted from a low flank (Figure 4.1c). It is also important to note that the cumulative erupted volume graphed in Figure 3.8 is only the volume of lava, and does not include volumes erupted as tephra. Constraints on the volume of magma erupted as tephra is extremely difficult to measure, but if they were included in the graph, the observed erupted volume would be even closer to the estimated supply rate. Additionally, the discrepancy between the erupted volume and supply rate could be due to the endogenous growth (i.e. storage of magma as dikes).

Pacaya is a continuously degassing volcano [Dalton et al., 2010], and in such a system, the supplied volume may travel to the top of the conduit where it degasses and sinks back down due to an increase in density (i.e. density-driven convection) [Kazahaya et al., 1994]. One option for future work is to obtain regular, long-term measurements of passively degassed sulfur dioxide and measured the amount of sulfur in the undegassed magma, then derive a second, independent supply rate to compare with the rate estimated here.

\subsection{Implications for Hazard Mitigation}

Two types of effusive activity are readily distinguishable from the subset of flows analyzed in this investigation: 1) long, low-TADR periods, and 2) short, high-TADR periods. The latter pose more immediate risk since their flows move quickly and cover larger areas and distances. So, the ability to distinguish between these two types of activity in near-real-time could be useful to hazard mitigation at Pacaya. This investigation has produced a record of the relative radiances emitted by these two types of activity in both MODIS and GOES imagery (Figure 3.4). Continuous long-term monitoring of radiances may provide a means of determining the relative rate of eruption and hence the relative level of risk. However, in emergency situations, data would need to be analyzed in near-real-time and at fairly high temporal resolutions in order to serve a practical purpose (e.g. issuing warnings or evacuations). Because of their very high temporal resolution, GOES data may prove useful for documenting the advancement of larger flow (those similar in size to the May 2010 flow). However, MODIS imagery is 
better suited for quantitative estimates (e.g. heat and volume flux), and monitoring the geographic extent of smaller flows such as those seen at Pacaya.

It may be possible to use the calculated conversion factor to make precise nearreal-time discharge rate estimates for future flows. However, it is unlikely that satellite imagery can do more than simply notify the appropriate authorities of increased thermal activity. MODIS imagery is available every six hours at best, so near-real-time monitoring of a quick-moving flow may be impractical. However, long-term monitoring of discharge rates can offer insight into the evolving eruption processes at Pacaya. Moderate-resolution satellite imagery should probably not be used as a primary means of risk assessment at Pacaya.

However, as a next step, the discharge rates calculated here can be used as inputs in lava flow modeling software. If simulations using these rates can generate final flow geometries comparable to actual mapped dimensions, then a reasonably accurate lava flow risk map based on vent location and discharge rate can be produced. Then preliminary estimates of the extent of future flows can be approximated and appropriate action can be taken to reduce losses at this active volcano. 


\section{Conclusion}

This project aimed to test the accuracy of an adapted version of the timeaveraged-discharge rate estimation model developed by Harris et al. [1997a]. The database compiled by Matías [2009] offered a rare opportunity to calibrate the satellite method specifically at Pacaya.

Imagery was acquired from both the MODIS and GOES sensors for ten flows, and time series could be produced for five of those. Hot spots were identified manually in order to maximize the inclusion of true hot spots and minimize the inclusion of false hot spots. It was determined that MODIS datasets produced significantly more accurate TADR and volume estimates (due to their higher spatial resolution and ability to resolve the relatively small flow at Pacaya), so MODIS and GOES datasets were not combined, and GOES data was not used in quantitative analyses.

The conversion factor, $M$, which relates active flow area to TADR was calculated in two ways. First, by best-fitting the cumulative volume (i.e. adjusting the parameters of the model) for each flow to match the volumes of the preexisting database, and second, by measuring the physical characteristics of the lavas in order to calculate $M$ independently. The conversion factors produce by method 1 varied between flows, indicating either differences in lava properties and eruption dynamics, unaccounted-for environmental factors such as rainfall or slope angle, deficient satellite datasets, or modeling errors. However, the $M$ values calculated from measurements (similar for all flows, with an average value of $1.38 \mathrm{E}-5 \mathrm{~m} / \mathrm{s}$ ), was able to produce total volumes that were close to those in the preexisting database, especially considering that the error on those volumes is admittedly large. This suggests a relationship that can be used to estimate discharge rates of future eruptions in near-real-time.

Two types of eruptive activity were identified 1) long, low-TADR periods, and 2) short, high-TADR periods. It was suggested that the average discharge rate observed

during the former represents bleeding of the conduit, so that the discharge rate during these periods can be used as an approximation for the supply rate to the shallow system. Within this model, sometimes lava is able to leak form the system at rates equal to the 
supply rate; other times, larger eruptions represent the release of lava that has accumulated during the non-eruptive, convective phase, or to an increase in supply rate.

Radiance records for both types of activity that MODIS imagery may be useful for determining the relative intensity of effusive activity in near-real-time at Pacaya. However, near-real-time quantitative monitoring (i.e. discharge rate estimation) is probably not a possibility with current sensors.

Future work will include more detailed analyses of vesicle and crystal distribution through FOAMS as it applies to emplacement and cooling dynamics, the modeling of lava flows using the discharge rates calculated here, and potentially the creation of a lava flow hazard map based on historic discharges rate and vent locations. 


\section{References}

Allard, P. (1997), Endogenous magma degassing and storage at Mount Etna, Geophysical Research Letters, 24, 2219-2222, doi:10.1029/97GL02101.

Allard, P., B. Behncke, S. D'Amico, M. Neri, and S. Gambino (2006), Mount Etna 19932005: Anatomy of an evolving eruptive cycle, Earth Science Reviews, 78, 85-114, doi:10.1016/j.earscirev.2006.04.002.

Allard, P., J. Carbonnelle, N. Métrich, H. Loyer, and P. Zettwoog (1994), Sulfur output and magma degassing budget of Stromboli Volcano, Nature, 368, 326-330, doi:10.1038/368326a0.

Bailey, J.E., A.J.L. Harris, J. Dehn, S. Calvari, and S.K. Rowland (2006), The changing morphology of an open lava channel on Mt. Etna, Bulletin of Volcanology, 68, 497-515, doi:10.1007/s00445-005-0025-6.

Barberi, F., M.L. Carapezza, M. Valenza, and L. Villari (1993), The control of lava flow during the 1991-1992 eruption of Mount Etna, Journal of Volcanology and Geophysical Research, 56, 1-34, doi:10.1016/0377-0273(93)90048-V.

Bardintzeff, J.M., and C. Deniel (1992), Magmatic evolution of Pacaya and Cerro Chino volcanic complex, Guatemala. Bulletin of Volcanology, 54, 267-283, doi:10.1007/BF00301482.

Bottinga, Y., and D.F. Weill (1970), Densities of liquid silicate systems calculated from partial molar volumes of oxide components, American Journal of Science, 269, 169-182, doi:10.2475/ajs.269.2.169.

Calvari, S., N. Marco, and H. Pinkerton (2003), Effusion rate estimations during the 1999 summit eruption on Mount Etna, and growth of two distinct lava flow fields, Journal of Volcanology and Geophysical Research, 119, 107-123, doi:10.1016/S0377-0273(02)00308-6.

Calvari S., L. Spampinato, L. Lodato, A.J.L. Harris, M.R. Patrick, J. Dehn, M.R. Burton, and D. Andronico (2005), Chronology and complex volcanic processes during the 2002-2003 flank eruption at Stromboli Volcano (Italy) reconstructed from direct observations and surveys with a hand-held thermal camera, Journal of Geophysical Research, doi:10.1029/2004JB003129.

Carr, M.J., M.D. Feigenson, L.C. Patino, and J.A. Walker (2003), Volcanism and geochemistry in Central America: progress and problems, in Inside the Subduction Factory, AGU Geophysical Monographs, vol. 138, edited by J. Eiler, pp. 153-174. 
Conway, F.M., J.F. Diehl, and O. Matías (1992), Paleomagnetic constraints on eruption patterns at the Pacaya composite volcano, Guatemala, Bulletin of Volcanology, 55, 25-32, doi:10.1007/BF00301117.

Crisp, J., and S. Baloga (1990), A method for estimating eruption rates of planetary lava flows, Icarus, 85, 512-515, doi:10.1016/0019-1035(90)90129-W.

Del Negro, C., L. Fortuna, A. Herault, and A. Vicari (2008), Simulations of the 2004 lava flow at Etna volcano using the MAGFLOW automata model, Bulletin of Volcanology, 70, 805-812, doi:10.1007/s00445-007-0168-8.

Di Bello, G., C. Filizzola, T. Lacava, F. Marchese, N. Pergola, C. Pietrapertosa, S. Piscitelli, I. Scaffidi, and V. Tramutoli (2004), Robust satellite techniques for volcanic and seismic hazards monitoring, Annals of Geophysics, 47, 1593-5213.

Eggers, A.A. (1971), The geology and petrology of the Amatitlán quadrangle, Guatemala, Ph.D. thesis, 221 pp., Dartmouth College, Hanover, NH.

Eggers, A.A. (1983), Temporal gravity and elevation changes at Pacaya volcano, Guatemala, Journal of Volcanology and Geothermal Research, 19, 223-237, doi:10.1016/0377-0273(83)90111-7.

Francis, P., C. Oppenheimer, and D. Stevenson (1993), Endogenous growth of persistently active volcanoes, Nature, 366, 554-557, doi:10.1038/366554a0.

Ganci, G., A. Vicari, A. Cappello, and C. Del Negro (2012), An emergent strategy for volcano hazard assessment: From thermal satellite monitoring to lava flow modeling, Remote Sensing of Environment, 119, 197-207, doi:10.1016/j.rse.2011.12.021.

Gangale, G., A.J. Prata, and L. Clarisse (2010), The infrared spectral signature of volcanic ash determined from high-spectral resolution satellite measurements, Remote Sensing of Environment, 114, 414-425, doi:10.1016/j.res.2009.09.007.

Guenther, B., X. Xiong, V.V. Salomonson, W.L. Barnes, and J. Young (2002), On-orbit performance of the Earth Observing System Moderate Resolution Imaging Spectroradiometer; first year data, Remote Sensing of Environment, 83, 16-30, doi:10.1016/S0034-4257(02)00097-4.

Guest, J.E., C.R.J. Kilburn, H. Pinkerton, and A.M. Duncan (1987), The evolution of lava flow-fields: observations of the 1981 and 1983 eruptions of Mount Etna, Sicily, Bulletin of Volcanology, 49, 527-540, doi:10.1007/BF01080447. 
Harris, A.J.L., and S.M. Baloga (2009), Lava discharge rates from satellite-measured heat flux, Geophysical Research Letters, 36, L19302, doi:10.1029/2009GL039717.

Harris, A.J.L., and S.K. Rowland (2001), FLOWGO: a kinematic thermo-rheological model for lava flowing in a channel, Bulletin of Volcanology, 63, 20-44, doi:10:1007/s004450000120.

Harris, A.J.L., S. Blake, D.A. Rothery, and N.F. Stevens (1997), A chronology of the 1991 to 1993 Mount Etna eruption using advanced very high resolution radiometer data: Implications for real-time thermal volcano monitoring, Journal of Geophysical Research, 102, 7985-8003, doi:10.1029/96JB03388.

Harris, A.J.L., A.L. Butterworth, R.W. Carlton, I. Downey, P. Miller, P. Navarro, and D.A. Rothery (1997b) Low-cost volcano surveillance from space: case studies from Etna, Krafla, Cerro Negro, Fogo, Lascar, and Erebus, Bulletin of Volcanology, 59, 49-64, doi:10.1007/s004450050174.

Harris, A.J.L., E. Pilger, L.P. Flynn, H. Garbeil, P.J. Mougins-Mark, and J. Kauahikaua, C. Thornber (2001), Automated, high temporal resolution, thermal analysis of Kilauea volcano, Hawaii, using GOES satellite data, International Journal of Remote Sensing, 22, 945-967, doi:10.1080/0143111601300074487.

Harris, A.J.L., J. Dehn, M. Patrick, S. Calvari, M. Ripepe, and L. Lodato (2005), Lava effusion rates from hand-held thermal infrared imagery: an example from the June 2003 effusive activity Stromboli, Bulletin of Volcanology, 68, 107-117, doi:10.1007/s00445-005-0425-7.

Harris, A.J.L., J. Dehn, and S. Calvari (2007), Lava effusion rate definition and measurement: a review, Bulletin of Volcanology, 70, 1-22, doi:10.1007/s00445007-0120-y.

Harris, A.J.L., A. Steffke, S. Calvari, and L. Spampinato (2011), Thirty years of satellitederived lava discharge rates at Etna: Implications for steady volumetric output, Journal of Geophysical Research, 116, doi:10.1029/2011JB008237.

Higgins, J., and A.J.L. Harris (1997), VAST: a program to locate and analyse volcanic thermal anomalies automatically from remotely sensed data, Computers \& Geoscience, 23, 627-645, doi:10.1016/S00098-3004(97)00039-3.

Houghton, B.F., and C.J.N. Wilson (1989), A vesicularity index for pyroclastic deposits, Bulletin of Volcanology, 51, 451-462, doi:10.1007/BF01078811.

Kazahaya K., H. Shinohara, and G. Saito (1994), Excessive degassing of Izu-Oshima volcano: magma convection in a conduit, Bulletin of Volcanology, 56, 207-216, doi:10.1007/BF00279605. 
Kilburn, C.R.J., and R.M.C. Lopes (1988), The growth of aa lava flow fields on Mount Etna, Sicily, Journal of Geophysical Research, 93, 14759-14772, doi:10.1029/JB093iB12 p14759.

Kitamura, S., and R.O.M. Matías (1995), Tephra stratigraphic approach to the eruptive history of Pacaya volcano, Guatemala. Science Reports - Tohoku University, Seventh Series: Geography, 45(1):1-41.

Malin, M.C. (1980), Lengths of Hawaiian lava flows, Geology, 8, 306-308, doi:10.1130/0091-7613(1980)8<306:LOHLF>2.0.CO;2.

Mann P., R.D. Rogers, and L. Gahagan (2007), Overview of plate tectonic history and its unresolved tectonic problems, in Central America: Geology, Resources, and Hazards (Volume 1), edited by J. Bundschuh, and G. Alvarado, pp. 201-237, Taylor \& Francis, London.

Matías, R.O.M. (2009), Volcanological map of the 1961-2009 eruption of Volcan de Pacaya, Guatemala, M.S. thesis, 56 pp., Michigan Technological University, Houghton, MI.

National Aeronautics and Space Administration (2006), GOES-N Databook, Boeing, http://goes.gsfc.nasa.gov/text/GOES-N_Databook.

Newman, S.M., L. Clarisse, D. Hurtsmans, F. Marenco, B. Johnson, K. Turnbull, S. Havemann, A. Baran, D. O'Sullivan, and J. Haywood (2012), A case study of observations of volcanic ash from the Eyjafjallajokull eruption: 2. Airborne and satellite radiative measurements, Journal of Geophysical Research, 117, D00U13, doi:10.1029/2011JD016780.

Oppenheimer, C. (1998), Satellite observations of lava lake activity at Nyiragongo volcano, ex-Zaire, during the Rwandan Refugee Crisis, Disasters, 22, 268-281, doi:10.1111/1567-7717.00091.

Pieri, D.C., and S.M. Baloga (1986), Eruption rate, area, and length relationships for some Hawaiian lava flows, Journal of Volcanology and Geothermal Research, 30, 29-45, doi:10.1016/0377-0273(86)90066-1.

Pinkerton, H., and L. Wilson (1994), Factors affecting the lengths of channel-fed lava flows, Bulletin of Volcanology, 56, 167-182, doi:10.1007/s004450050020.

Ripepe, M., M. Marchetti, G. Ulivieri, A.J.L. Harris, J. Dehn, M. Burton, T. Calabiano, and G. Salerno (2005), Effusive to explosive transition during the 2003 eruption of Stromboli volcano, Geology, 33, 341-344, doi:10.1130/G21173.1. 
Rowland, S.K. (1996), Slopes, lava flow volumes, and vent distributions of Volcan Fernandina, Galapagos Islands, Journal of Geophysical Research, 101, 2765727672, doi:10.1029/96JB02649.

Rowland, S.K., H. Garbeil, and A.J.L. Harris (2005), Lengths and hazards from channelfed lava flows on Mauna Loa, Hawaii, determined from thermal and downslope modeling with FLOWGO, Bulletin of Volcanology, 67, 634-647: doi:10.1007/s00445-004-0399-x.

Shea, T., B.F. Houghton, L. Gurioli, K.V. Cashman, J.E. Hammer, and B.J. Hobden (2010), Textural studies of vesicles in volcanic rocks: An integrated methodology, Journal of Volcanology and Geothermal Research, 190, 271-289, doi:10.1016/j.jvolcgeores. 2009.12.003.

Steffke, A.M., and A.J.L. Harris (2011), A review of algorithms for detecting volcanic hot spots in satellite infrared data, Bulletin of Volcanology, 73, 1109-1137, doi:10.1007/s00445-011-0487-7.

Thouret, J., A. Gupta, G. Lube, S.C. Liew, S.J. Cronin, and Surono (2010), The 2006 pyroclastic deposits of Merapi Volcano, java, Indonesia: High-spatial resolution IKONOS images and complementary ground based observations, Remote Sensing of Environment, 114, 1949-1967, doi:10.1016/j.rse.2010.03.016.

Tramutoli, V. (1998), Robust AVHRR Technique (RAT) for environmental monitoring: theory and applications, in Earth Surface Remote Sensing II, SPIE, edited by G. Cecchi and E. Zilloli, 3496:101-113.

Vallance, J.W., L. Seibert, W.I. Rose, J.R. Giron, and N.G. Bank (1995), Edifice collapse and related hazards in Guatemala, Journal of Volcanology and Geothermal Research, 66, 337-355, doi:10.1016/0377-0273(94)00076-S.

Wadge, G. (1978), Effusion rate and the shape of aa lava flow fields on Mount Etna, Geology, 6, 503-506, doi:10.1130/0091-7613(1978)6<503:ERATSO>2.0.CO;2.

Wadge, G. (1981), The variation of magma discharge during basaltic eruptions, Journal of Volcanology and Geothermal Research, 11, 139-168, doi:10.1016/03770273(81)90020-2.

Walker, G.P.L. (1973), Lengths of lava flows, Philosophical Transactions of the Royal Society, London, 274, 107-118.

White, S.M., J.A. Crisp, and F.J. Spera (2006), Long-term volumetric eruption rates and magma budgets, Geochemistry Geophysics Geosystems, 7, Q03010, doi:10.1029/ $2005 \mathrm{GC} 001002$. 
Wright, R., and E. Pilger (2008), Satellite observations reveal little inter-annual variability in the radiant flux from the Mount Erebus lava lake, Journal of Volcanology and Geothermal Research, 177, 687-694, doi:10.1016/j.jvolgeores.2008.03.005.

Wright, R., S. Blake, A.J.L. Harris, and D.A. Rothery (2001), A simple explanation for the space-based calculation of lava eruption rates, Earth and Planetary Science Letters, 192, 223-233. doi:10.1016/S0012-821X(01)00443-5.

Wright, R., L. Flynn, H. Garbeil, A.J.L. Harris, and E. Pilger (2002), Automated volcanic eruption detection using MODIS, Remote Sensing of Environment, 82, 135-155, doi:10.1016/S0034-4257(02)00030-5.

Wright, R., H. Garbeil, and A.J.L. Harris (2008), Using infrared satellite data to drive a thermo-rheological/stochastic lava flow emplacement model: A method for nearreal-time volcanic hazard assessment, Geophysical Research Letters, 35, L19307, doi:10.1029/2008GL035228.

Wunderman, R.L., and W.I. Rose (1984), Amatitlán, an actively resurging cauldron 10 $\mathrm{km}$ south of Guatemala City, Journal of Geophysical Research, 89, 8525-8539, doi:10.1029/JB089iB10p08525. 


\section{Appendices}

\section{Appendix A: Examples of MODIS and GOES Hot Spots}

Figure 7.1: These images are representative of the variation in quality of hot spots encountered during this investigation. Pacaya is located in the center red square in each image. The magnified image on the left is the MIR band and the magnified image on the right is the LIR band. In some images, volcanic activity at neighboring volcano Fuego (red cicle west of Pacaya) is observed. Note that the MODIS images have been georectified.

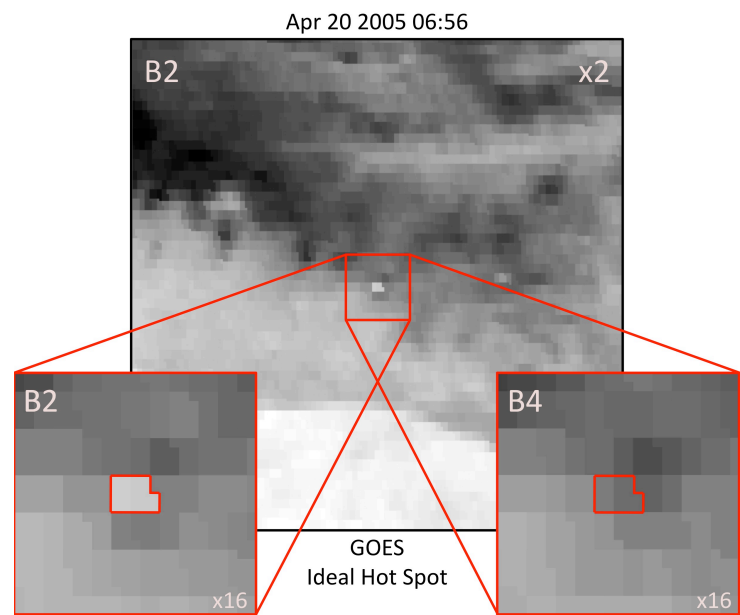

a. Ideal GOES hot spot, which is significantly duller than a MODIS hot spot.

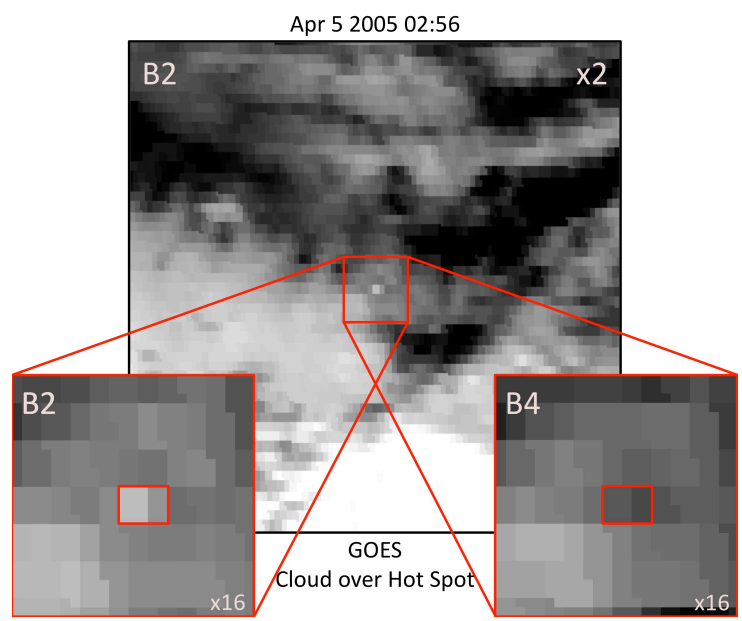

c. Slight cloud cover around Pacaya. Note the very dull appearance of the hot spot.

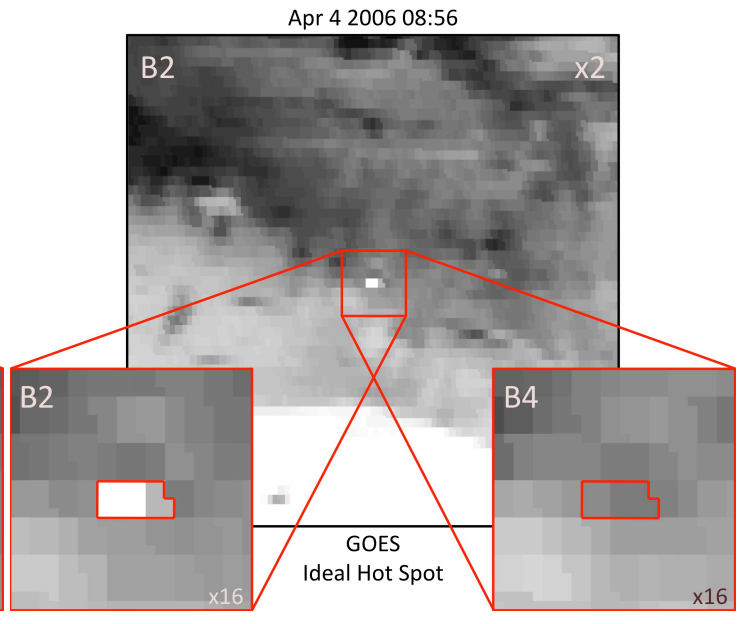

b. Very bright hot spot. No noticeable increase in radiance in band 4 .

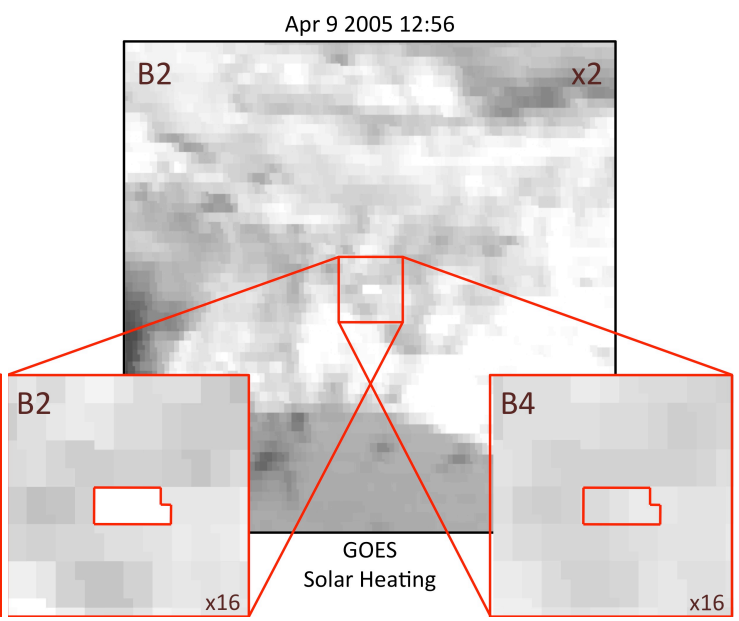

d. Image exhibiting solar heating, but with a hot spot still evidence. 

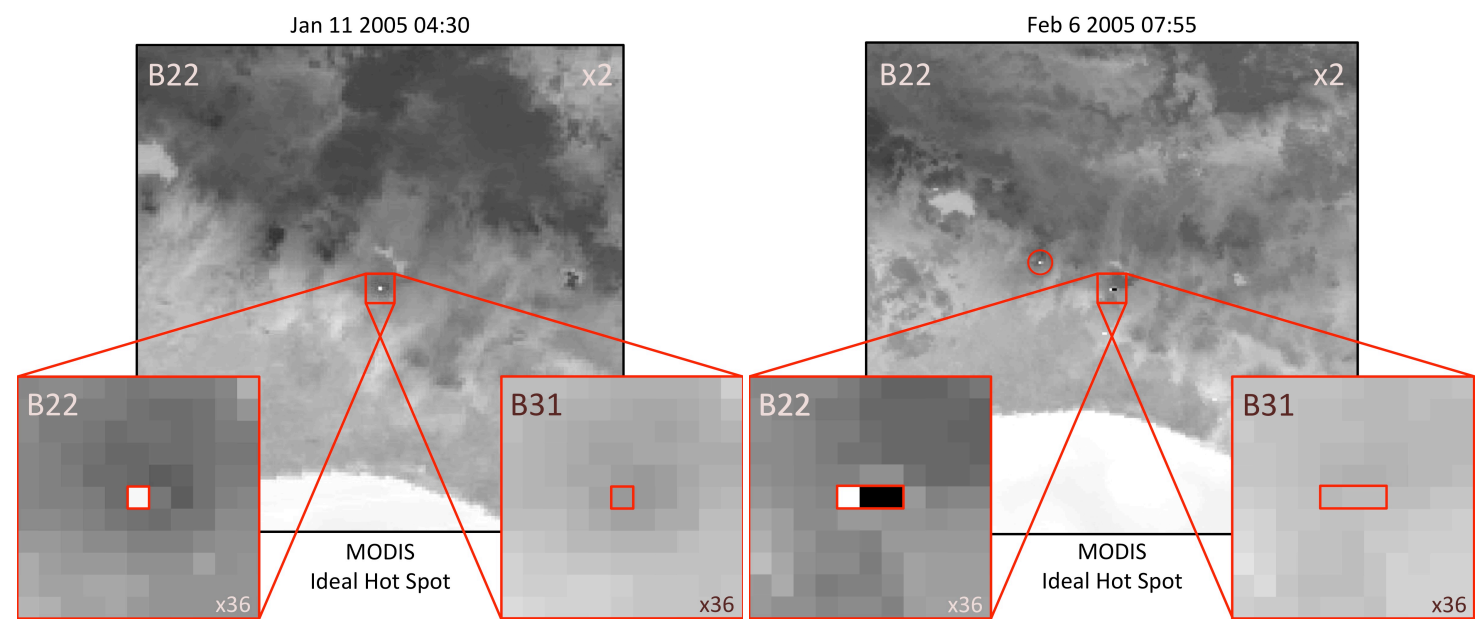

e. Ideal MODIS hot spot. Note there is no increase in radiance in band 31 .

f. Ideal MODIS hot spot, with two saturated pixels (these still appear in the band 22 image).
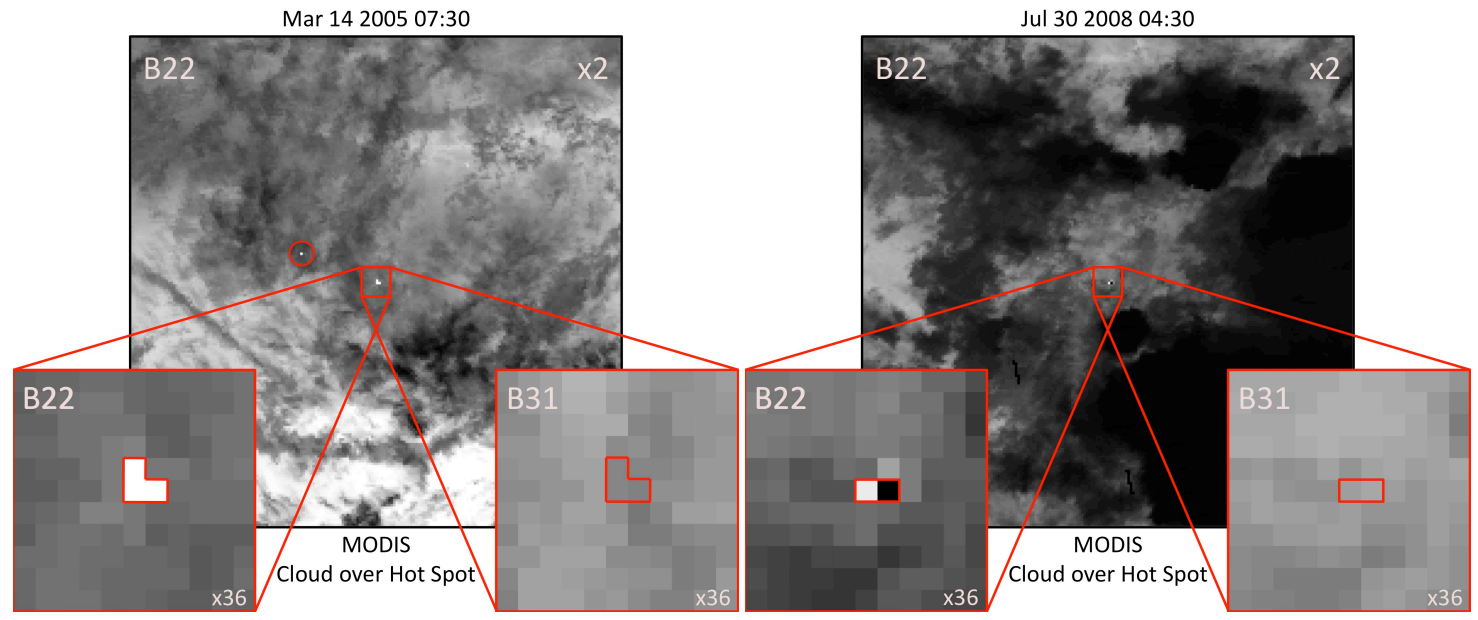

g. Hot spot with moderate cloud cover. Though the hotspot is bright, it is unsuitable for use.

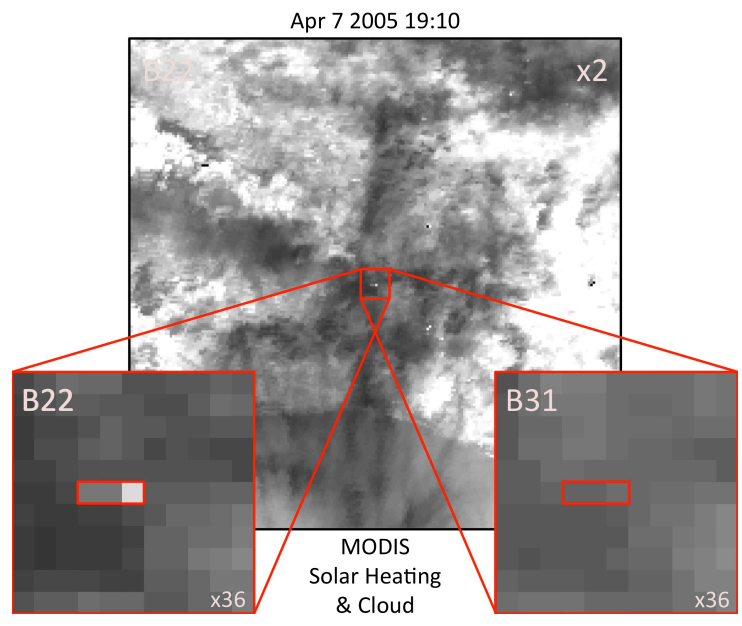

h. Heavy cloud coverage. Note that saturated pixel, which make the hot spot harder to see.

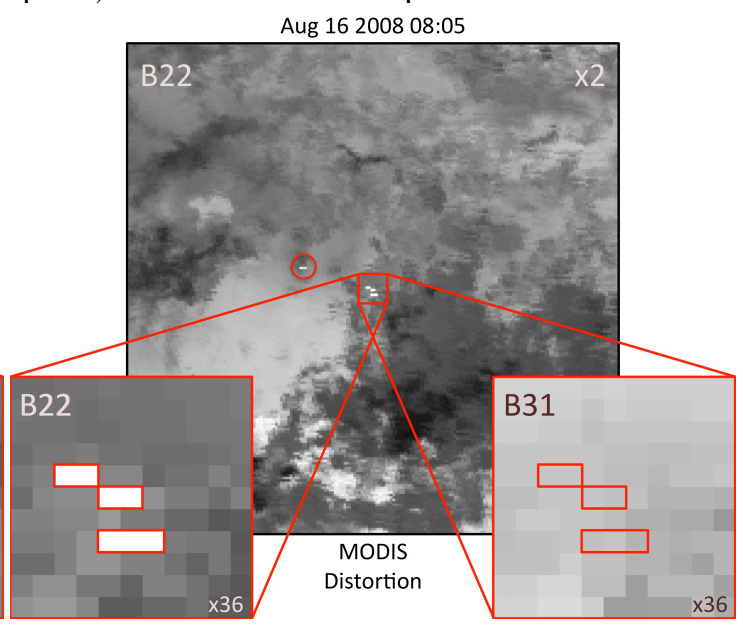

i. Solar heating with a thin layer of cloud over the hot spot.

j. Distorted hot spot at the edge of an image. 


\section{Appendix B: Calculation of MODIS Pixel Area}

MODIS pixel area is a function of the sensor scan angle and the pixel's position in the image. The scan angle $(S)$, in radians, is given by

$$
S=\frac{x-\frac{p}{2}}{H}=\frac{x-\frac{1353}{2}}{705}
$$

where $x, p$, and $H$ are the scan line number (or x-coordinate) of the pixel in the image, number of pixels in the across-track dimension (1353), and sensor altitude (705 $\mathrm{km})$. The zenith angle $(Z)$, in radians, is then given by

$$
Z=\arcsin (1.111) \cdot \sin (S)
$$

The along-track length $\left(L_{A l}\right)$ of the pixel is given by

$$
L_{A l}=A \cdot 9 \frac{\sin (Z-S)}{\sin S}
$$

where $A$ is the length of that side at nadir (i.e. $1 \mathrm{~km})$. The across-track length $\left(L_{A c}\right)$ of the pixel is given by

$$
L_{A c}=\frac{L_{A l}}{\cos (Z)}
$$

Finally, the area $A_{\text {pixel }}$ of the pixel is given by

$$
A_{\text {pixel }}=L_{A l} \cdot L_{A c}
$$




\section{Appendix C: Major Element Compositions of Pacaya's Lavas and}

\section{Calculated Densities}

DRE densities $\left(\mathrm{g} / \mathrm{cm}^{3}\right)$ were calculated following Bottinga and Weill [1970] for all published lava chemical composition from the modern eruptive subphase. Chemical compositions for samples collecting for this investigation are shown in Table 3.1. The average value of $2.678 \mathrm{~g} / \mathrm{cm}^{3}$ was used as the initial input for the TADR model. The average density calculated from the specific flows investigated here $\left(2.723 \mathrm{~g} / \mathrm{cm}^{3}\right)$ was used in determine TADR via method \#2 (Table 3.1). Each sample is labeled Prehistoric (Pre), Historic (His), or Modern (Mod).

Table 7.1

Major element chemical compositions (weight \%) from Eggers [1971].

\begin{tabular}{|c|c|c|c|c|c|c|c|c|}
\hline $\begin{array}{l}\text { Sample } \\
\text { Age }\end{array}$ & $\begin{array}{l}\mathbf{1 7 2} \\
\text { Pre }\end{array}$ & $\begin{array}{l}\mathbf{1 4 5} \\
\text { Pre }\end{array}$ & $\begin{array}{l}\mathbf{1 4 7} \\
\text { Pre }\end{array}$ & $\begin{array}{l}\mathbf{1 7 5} \\
\text { Pre }\end{array}$ & $\begin{array}{l}\mathbf{1 4 6} \\
\text { Pre }\end{array}$ & $\begin{array}{l}\mathbf{1 8 1} \\
\text { Pre }\end{array}$ & $\begin{array}{l}148 \\
\text { Pre }\end{array}$ & $\begin{array}{l}165 \\
\text { Pre }\end{array}$ \\
\hline $\mathrm{Si}_{2} \mathrm{O}_{2}$ & 48.8 & 48.8 & 49.4 & 49.5 & 50.3 & 50.7 & 51.3 & 51.6 \\
\hline $\mathrm{Al}_{2} \mathrm{O}_{2}$ & 20.1 & 20 & 21.2 & 19.3 & 20.8 & 19.2 & 20.3 & 20.1 \\
\hline $\mathrm{Fe}_{2} \mathrm{O}_{3}$ & 3.3 & 5.3 & 2.6 & 2.5 & 2.2 & 4.3 & 3.2 & 6.1 \\
\hline $\mathrm{FeO}$ & 6.5 & 4.2 & 7 & 7.3 & 6.1 & 5.8 & 5.1 & 3 \\
\hline $\mathrm{MgO}$ & 3.8 & 3.7 & 3.6 & 3.5 & 2.6 & 3.2 & 2.7 & 2.9 \\
\hline $\mathrm{CaO}$ & 11.5 & 10.6 & 11 & 10 & 10.5 & 10.5 & 10.4 & 11.4 \\
\hline $\mathrm{Na}_{2} \mathrm{O}$ & 3.2 & 3.3 & 3.3 & 3.3 & 3.6 & 3.4 & 3.7 & 3.2 \\
\hline $\mathrm{K}_{2} \mathrm{O}$ & 0.7 & 0.7 & 0.7 & 0.8 & 0.9 & 1 & 0.8 & 0.7 \\
\hline Totals & 99.4 & 98 & 100.4 & 97.7 & 98.4 & 99.9 & 98.8 & 100.2 \\
\hline $\begin{array}{l}\text { Sample } \\
\text { Age }\end{array}$ & $\begin{array}{l}\mathbf{1 7 1} \\
\text { His }\end{array}$ & $\begin{array}{l}\mathbf{1 4 4} \\
\text { His }\end{array}$ & $\begin{array}{l}\mathbf{1 3 5} \\
\text { His }\end{array}$ & $\begin{array}{l}\mathbf{1 1 7} \\
\text { His }\end{array}$ & $\begin{array}{l}177 \\
\text { Mod }\end{array}$ & $\begin{array}{l}\mathbf{1 7 0} \\
\text { Mod }\end{array}$ & $\begin{array}{l}176 \\
\text { Mod }\end{array}$ & $\begin{array}{l}\mathbf{1 8 0} \\
\text { Mod }\end{array}$ \\
\hline $\mathrm{Si}_{2} \mathrm{O}_{2}$ & 50.2 & 50.3 & 50.9 & 51.8 & 49.4 & 49.5 & 49.6 & 49.6 \\
\hline $\mathrm{Al}_{2} \mathrm{O}_{2}$ & 18.5 & 18.3 & 18.9 & 16.6 & 19.8 & 19.5 & 18.6 & 19.7 \\
\hline $\mathrm{Fe}_{2} \mathrm{O}_{3}$ & 1.9 & 3.6 & 2.9 & 3.4 & 2.2 & 3.3 & 2.8 & 3.7 \\
\hline $\mathrm{FeO}$ & 7.8 & 7 & 7.3 & 8.7 & 7.4 & 7.3 & 7.8 & 6.4 \\
\hline $\mathrm{MgO}$ & 4.2 & 4 & 4.2 & 4.1 & 3.3 & 3.8 & 4.2 & 3.7 \\
\hline $\mathrm{CaO}$ & 10 & 9.9 & 10.1 & 8.5 & 10 & 9.7 & 0.8 & 9.7 \\
\hline $\mathrm{Na}_{2} \mathrm{O}$ & 3.6 & 3.5 & 3.6 & 4.1 & 3.6 & 3.6 & 3.6 & 3.6 \\
\hline $\mathrm{K}_{2} \mathrm{O}$ & 0.8 & 0.9 & 0.8 & 1.1 & 0.8 & 0.9 & 0.9 & 0.9 \\
\hline $\begin{array}{l}\text { Totals } \\
\text { Density }\end{array}$ & 98.6 & 99.2 & 100.4 & 100.3 & $\begin{array}{l}98 \\
2.639\end{array}$ & $\begin{array}{l}99.1 \\
2.662\end{array}$ & $\begin{array}{l}98.8 \\
2.661\end{array}$ & $\begin{array}{l}98.8 \\
2.656\end{array}$ \\
\hline
\end{tabular}


Table 7.1 continued

\begin{tabular}{|c|c|c|c|}
\hline $\begin{array}{l}\text { Sample } \\
\text { Age }\end{array}$ & $\begin{array}{l}179 \\
\text { Mod }\end{array}$ & $\begin{array}{l}169 \\
\text { Mod }\end{array}$ & $\begin{array}{l}77 \\
\text { Mod }\end{array}$ \\
\hline $\mathrm{Si}_{2} \mathrm{O}_{2}$ & 50.7 & 51.1 & 52.8 \\
\hline $\mathrm{Al}_{2} \mathrm{O}_{2}$ & 19 & 19.1 & 17.8 \\
\hline $\mathrm{Fe}_{2} \mathrm{O}_{3}$ & 3.1 & 2.5 & 4.4 \\
\hline $\mathrm{FeO}$ & 6.6 & 7.6 & 5.4 \\
\hline $\mathrm{MgO}$ & 3.7 & 3.7 & 3.7 \\
\hline $\mathrm{CaO}$ & 9.7 & 9.9 & 9.9 \\
\hline $\mathrm{Na}_{2} \mathrm{O}$ & 3.6 & 3.7 & 3.6 \\
\hline $\mathrm{K}_{2} \mathrm{O}$ & 0.9 & 0.9 & 0.9 \\
\hline Totals & 98.6 & 99.8 & 100 \\
\hline Density & 2.640 & 2.641 & 2.641 \\
\hline
\end{tabular}

Table 7.2

Major element chemical compositions (weight \%) from Bardinzteff $\boldsymbol{\&}$

Deniel [1992].

\begin{tabular}{lllllll}
\hline $\begin{array}{l}\text { Sample } \\
\text { Age }\end{array}$ & $\begin{array}{l}\text { G7H } \\
\text { Pre }\end{array}$ & $\begin{array}{l}\text { G7F } \\
\text { Pre }\end{array}$ & $\begin{array}{l}\text { G6M } \\
\text { His }\end{array}$ & $\begin{array}{l}\text { G5V } \\
\text { His }\end{array}$ & $\begin{array}{l}\text { G6B } \\
\text { His }\end{array}$ & $\begin{array}{l}\text { GBI } \\
\text { Mod }\end{array}$ \\
\hline $\mathrm{Si}_{2} \mathrm{O}_{2}$ & 50.8 & 51.65 & 53.04 & 52.7 & 52.16 & 50.07 \\
$\mathrm{Al}_{2} \mathrm{O}_{2}$ & 17.87 & 18.61 & 16.95 & 19.53 & 17.85 & 19.22 \\
$\mathrm{Fe}_{2} \mathrm{O}_{3}$ & 4.22 & 2.79 & 2.8 & 3.87 & 4.68 & 3.35 \\
$\mathrm{FeO}$ & 5.78 & 6.92 & 8.22 & 4.95 & 5.51 & 6.43 \\
$\mathrm{MgO}$ & 5.68 & 4.54 & 4.08 & 2.8 & 4.64 & 4.53 \\
$\mathrm{CaO}$ & 9.47 & 9.42 & 8.13 & 9.56 & 8.98 & 9.73 \\
$\mathrm{Na} 2 \mathrm{O}$ & 2.99 & 3.22 & 3.73 & 3.89 & 3.74 & 3.66 \\
$\mathrm{~K}_{2} \mathrm{O}$ & 0.84 & 0.83 & 1.06 & 0.99 & 0.83 & 0.87 \\
Totals & $\mathbf{9 9 . 7 6}$ & $\mathbf{9 9 . 8 9}$ & $\mathbf{1 0 0 . 5}$ & $\mathbf{1 0 0 . 0 6}$ & $\mathbf{1 0 0 . 3 3}$ & $\mathbf{9 9 . 5 6}$ \\
Density & & & & & & $\mathbf{2 . 6 5 2}$ \\
\hline
\end{tabular}


Table 7.3

Major element chemical compositions (weight \%) from Matías [2009].

\begin{tabular}{|c|c|c|c|c|c|c|c|c|}
\hline $\begin{array}{l}\text { Sample } \\
\text { Age }\end{array}$ & $\begin{array}{l}27 \\
M o d\end{array}$ & $\begin{array}{l}\mathbf{2 8} \\
M o d\end{array}$ & $\begin{array}{l}\mathbf{3 0} \\
\text { Mod }\end{array}$ & $\begin{array}{l}14 \\
\text { Mod }\end{array}$ & $\begin{array}{l}13 \\
\text { Mod }\end{array}$ & $\begin{array}{l}12 \\
M o d\end{array}$ & Mod & $\begin{array}{l}7 \\
\operatorname{Mod}\end{array}$ \\
\hline $\mathrm{Si}_{2} \mathrm{O}_{2}$ & 50.5 & 50.1 & 50.3 & 51.1 & 51.1 & 50.8 & 50.2 & 50.9 \\
\hline $\mathrm{Al}_{2} \mathrm{O}_{2}$ & 20.3 & 19 & 20.6 & 17.9 & 18.6 & 18.1 & 18 & 18.3 \\
\hline $\mathrm{Fe}_{2} \mathrm{O}_{3}$ & 9.3 & 9.5 & 9 & 10.8 & 10 & 10.3 & 10.8 & 10.5 \\
\hline $\mathrm{MgO}$ & 3.21 & 3 & 3.08 & 4.09 & 3.7 & 4.08 & 4.43 & 4.15 \\
\hline $\mathrm{CaO}$ & 10.24 & 9.56 & 10.35 & 8.71 & 9.29 & 8.99 & 9.19 & 9.15 \\
\hline $\mathrm{Na}_{2} \mathrm{O}$ & 3.42 & 4.08 & 3.45 & 3.7 & 3.72 & 3.61 & 3.54 & 3.57 \\
\hline $\mathrm{K}_{2} \mathrm{O}$ & 0.79 & 0.98 & 0.79 & 1.05 & 0.96 & 0.97 & 0.93 & 0.97 \\
\hline Totals & 99.25 & 97.86 & 99.06 & 99.16 & 99.03 & 98.5 & 98.75 & 99.21 \\
\hline Density & 2.681 & 2.676 & 2.675 & 2.703 & 2.687 & 2.696 & 2.715 & 2.702 \\
\hline $\begin{array}{l}\text { Sample } \\
\text { Age }\end{array}$ & $\begin{array}{l}1 \\
\text { Mod }\end{array}$ & $\begin{array}{l}\mathbf{1 0} \\
M o d\end{array}$ & $\begin{array}{l}15 \\
\text { Mod }\end{array}$ & $\begin{array}{l}\mathbf{2 3} \\
\text { Mod }\end{array}$ & & & & \\
\hline $\mathrm{Si}_{2} \mathrm{O}_{2}$ & 50.6 & 50.5 & 51.4 & 51.1 & & & & \\
\hline $\mathrm{Al}_{2} \mathrm{O}_{2}$ & 18.2 & 18.1 & 18.2 & 19.8 & & & & \\
\hline $\mathrm{Fe}_{2} \mathrm{O}_{3}$ & 10.6 & 10.8 & 10.3 & 8.9 & & & & \\
\hline $\mathrm{MgO}$ & 4.23 & 4.52 & 3.83 & 3.37 & & & & \\
\hline $\mathrm{CaO}$ & 9.18 & 9.17 & 9.07 & 9.61 & & & & \\
\hline $\mathrm{Na}_{2} \mathrm{O}$ & 3.57 & 3.52 & 3.7 & 3.8 & & & & \\
\hline $\mathrm{K}_{2} \mathrm{O}$ & 0.95 & 0.92 & 1.02 & 0.88 & & & & \\
\hline Totals & 98.99 & 99.18 & 99.19 & 98.85 & & & & \\
\hline Density & 2.707 & 2.714 & 2.691 & 2.663 & & & & \\
\hline
\end{tabular}

Average density for modern lavas: $2.678 \mathrm{~g} / \mathrm{cm}^{3}$. 


\section{Appendix D: Calendars Representing Satellite Data Coverage}

Figure 7.2: These calendars represent satellite data coverage for seven flows. In each cell, the top and bottom numbers are the number of usable MODIS and GOES images. respectivelv. for that dav.

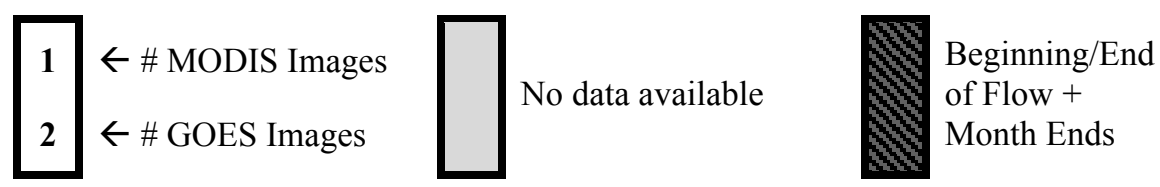

23 Dec 2004 - 17 Aug 2005

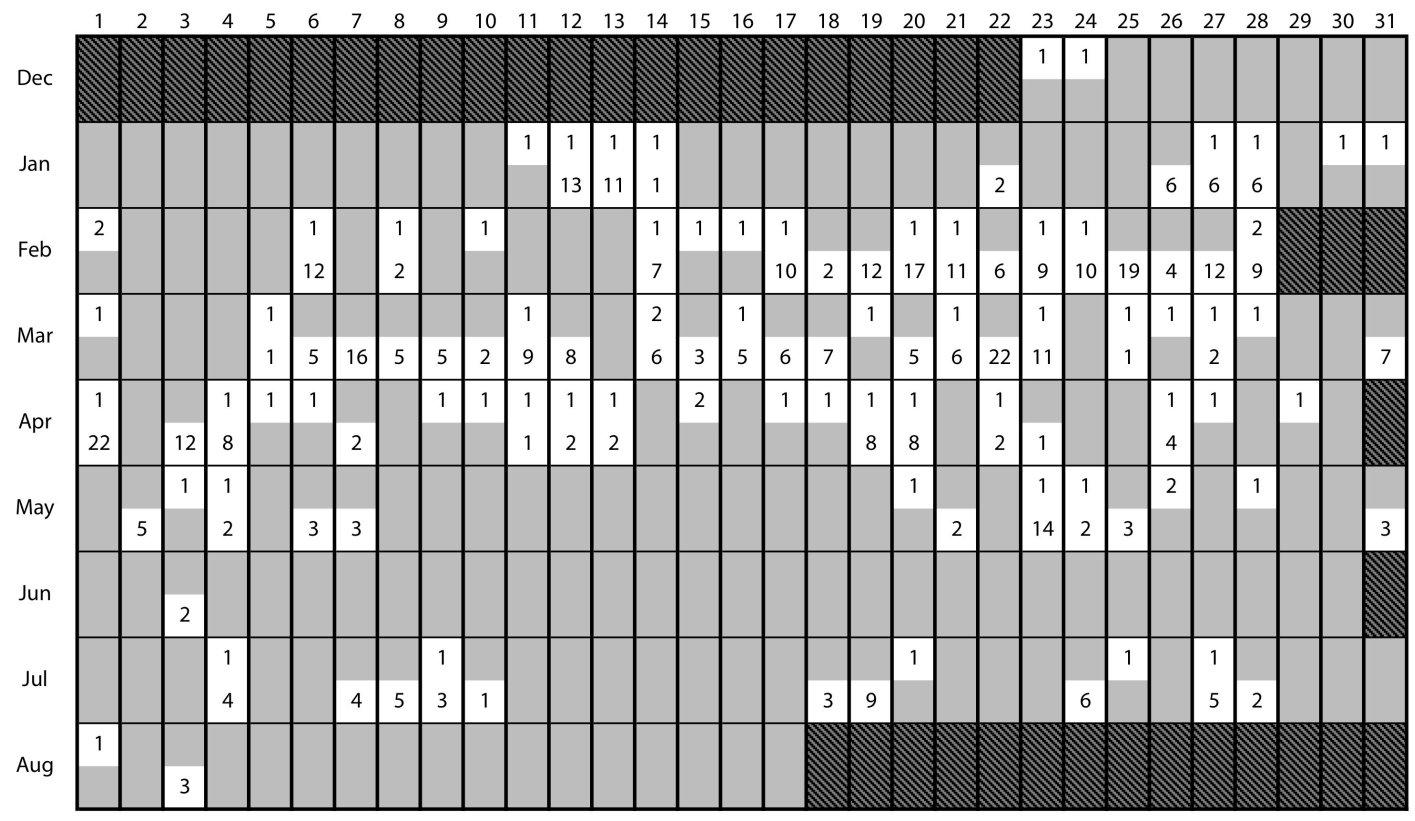

May 82005 - May 152005

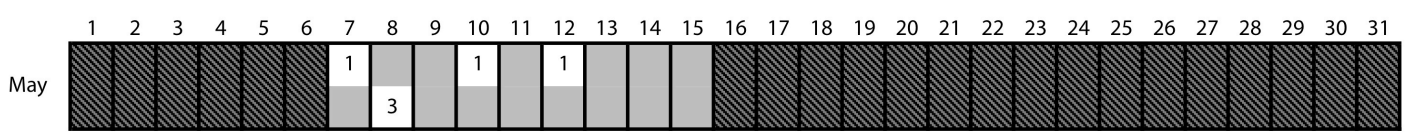

Apr 42006 - Apr 72006

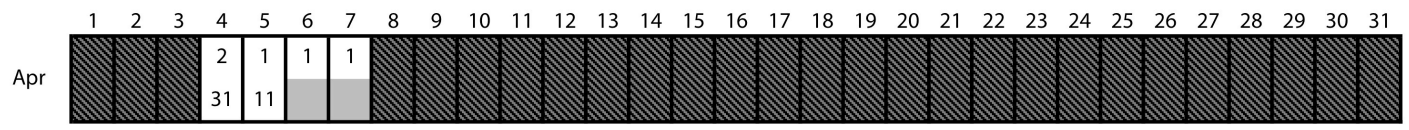




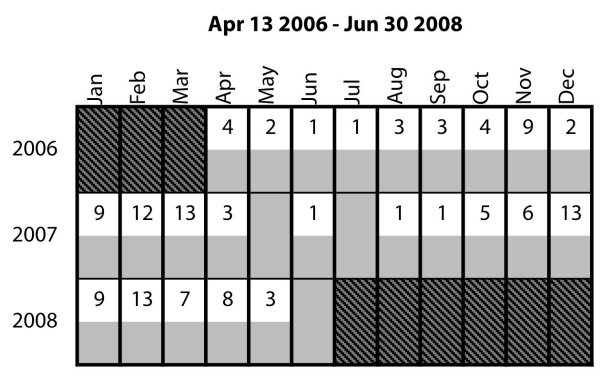

Jul 232008 - Feb 182009

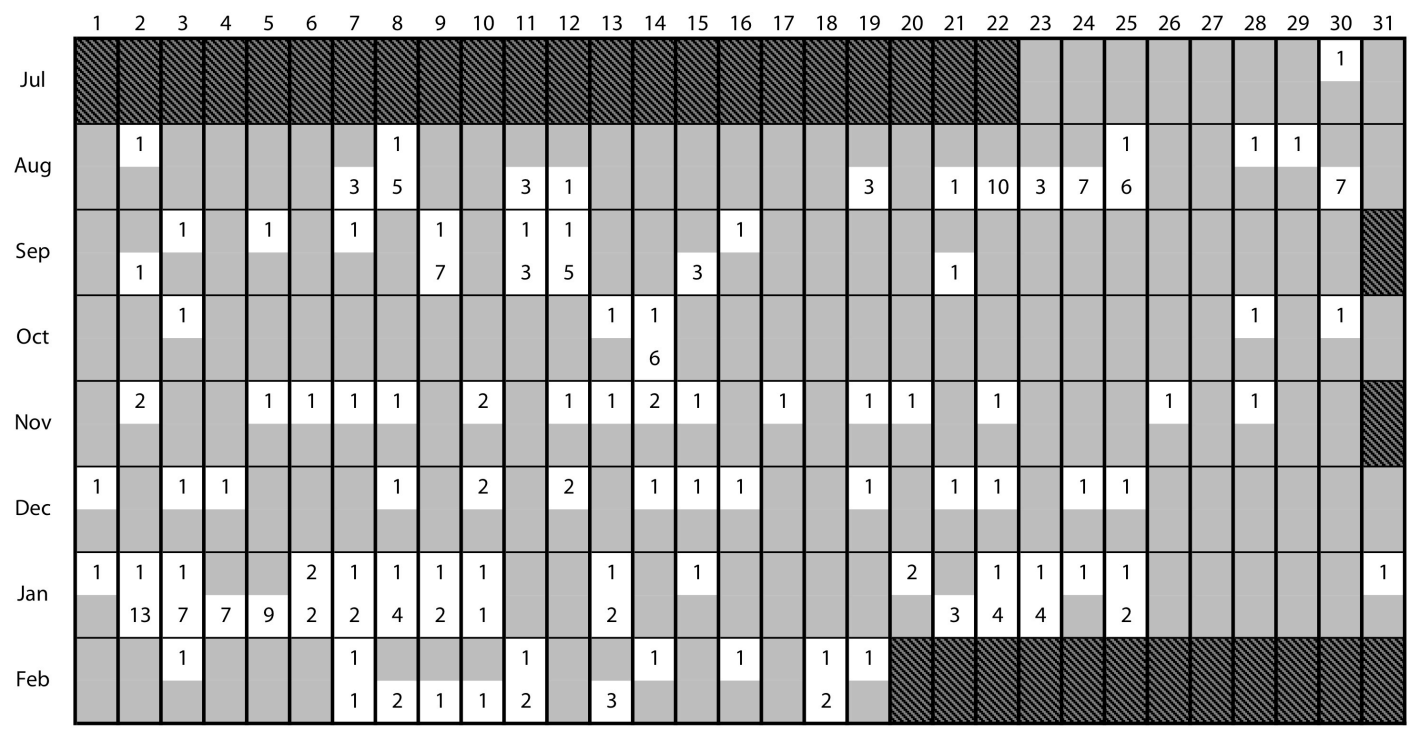

Jan 242009 - Jan 302009

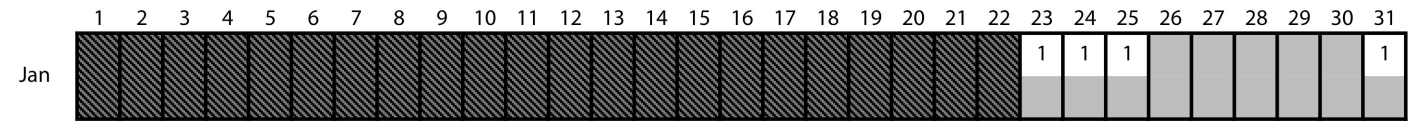

May 272010 - Jun 302010

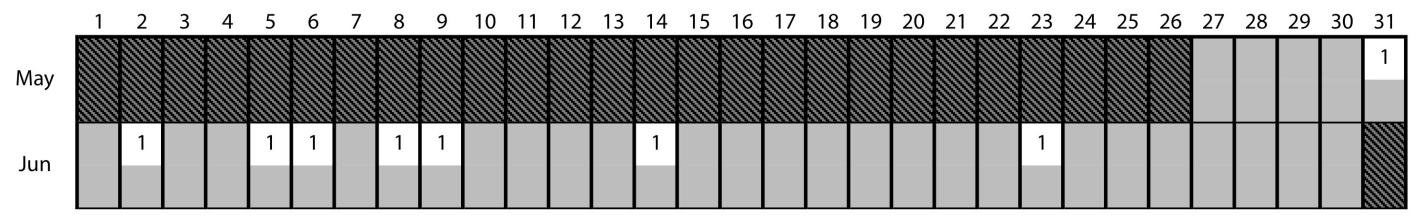




\section{Appendix E: TADR and Cumulative Volume Time Series Calculated via Method 2}
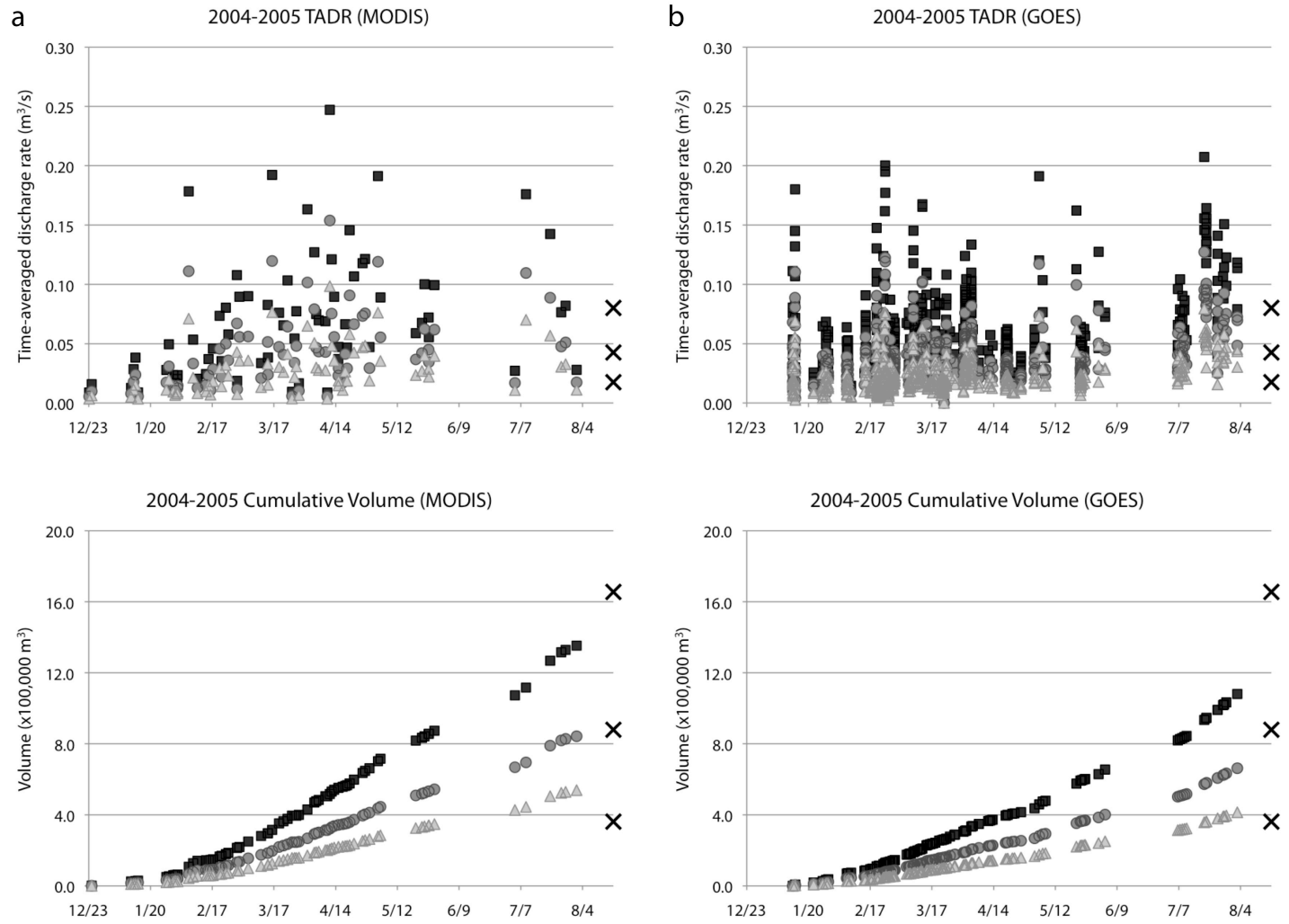

\section{Legend}

$250^{\circ} \mathrm{C}$ Model $\bigcirc 350^{\circ} \mathrm{C}$ Model $\triangle 600^{\circ} \mathrm{C}$ Model

Figure 7.3: Time-averaged discharge rate and cumulative volume time series for each of the five flows using Method 2 (calculation of conversion factor). GOES data was only available during three of these (2004-2005; April 2006; and 20082009). 
C
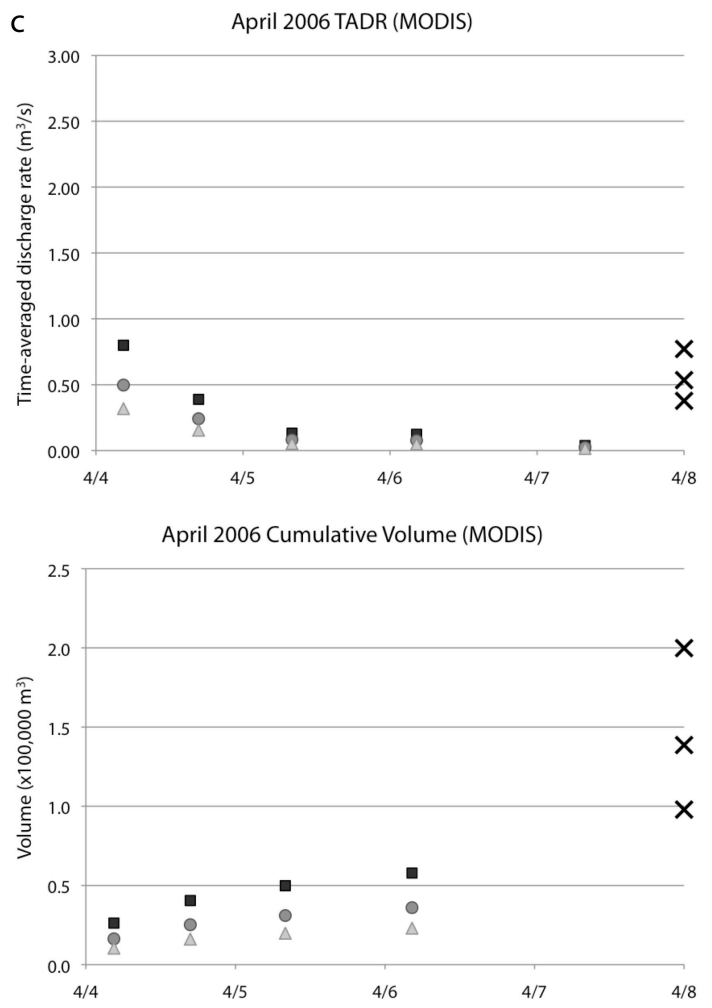

e
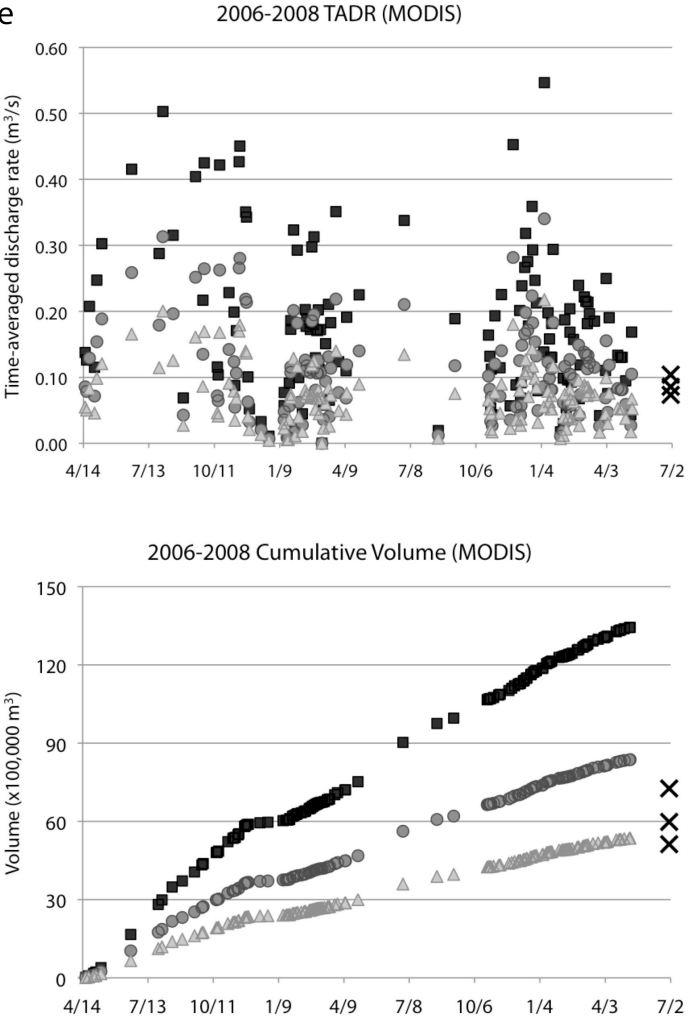

d April 2006 TADR (GOES)

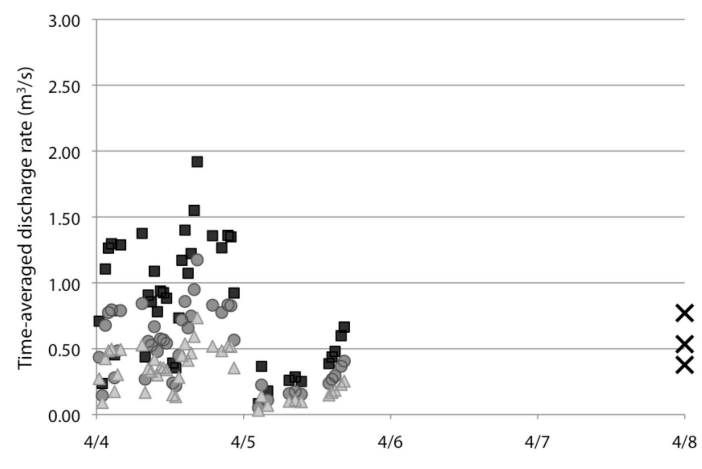

April 2006 Cumulative Volume (GOES)

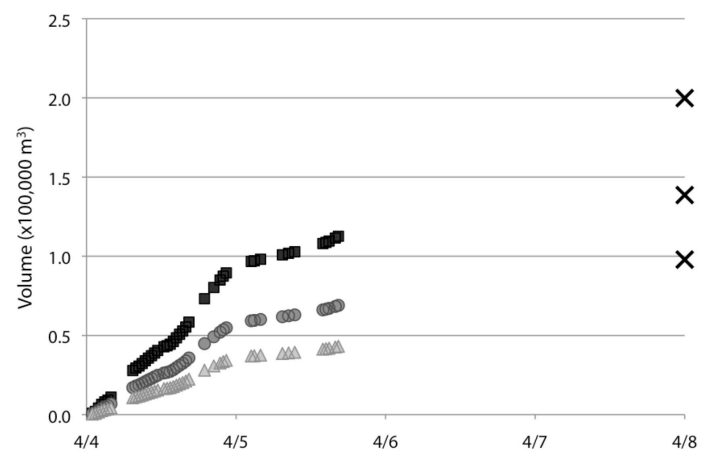

Figure 7.3: Continued...

\section{Legend}

$250^{\circ} \mathrm{C}$ Model $\bigcirc 350^{\circ} \mathrm{C}$ Model $\triangle 600^{\circ} \mathrm{C}$ Mode 

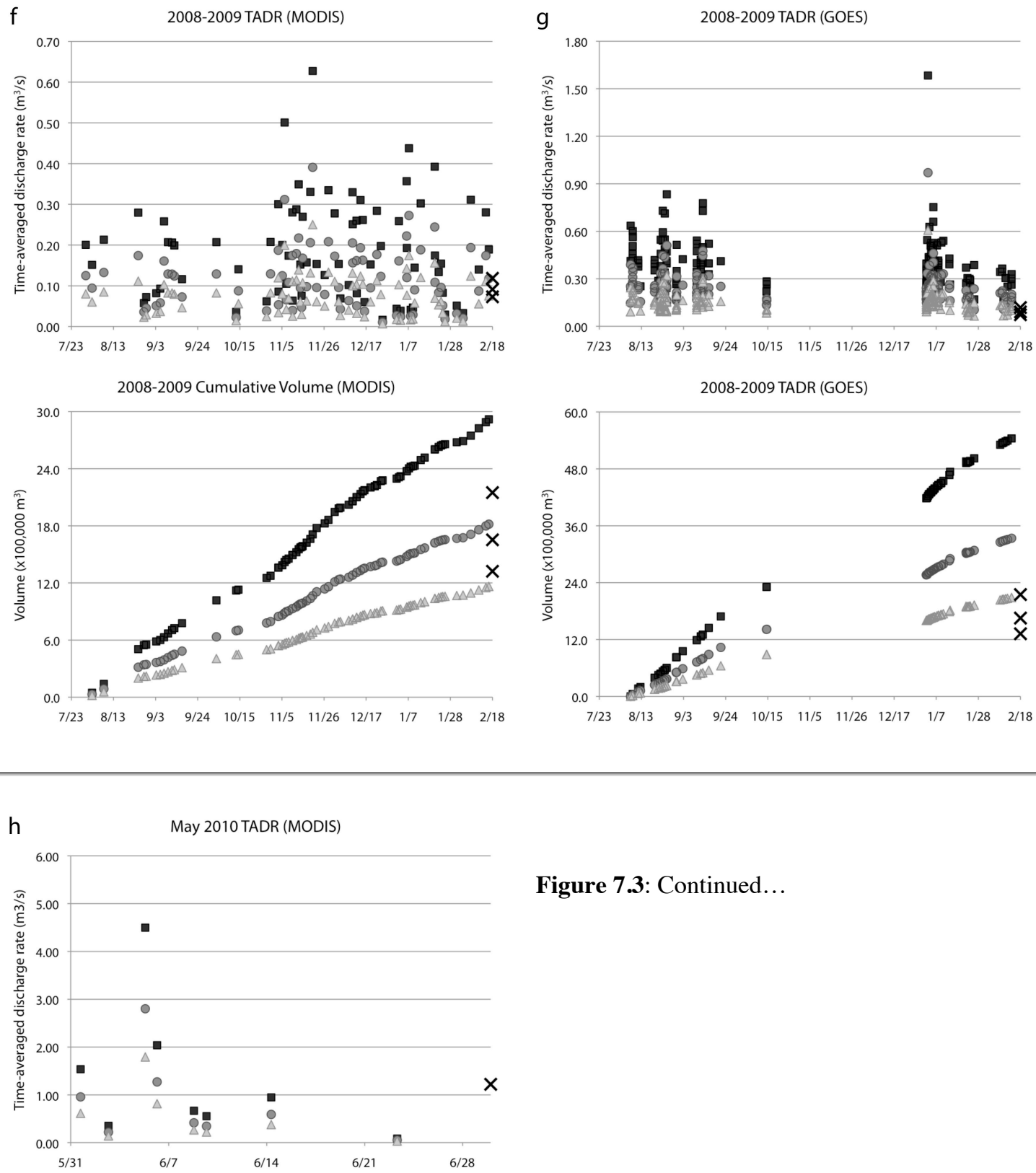

Figure 7.3: Continued...

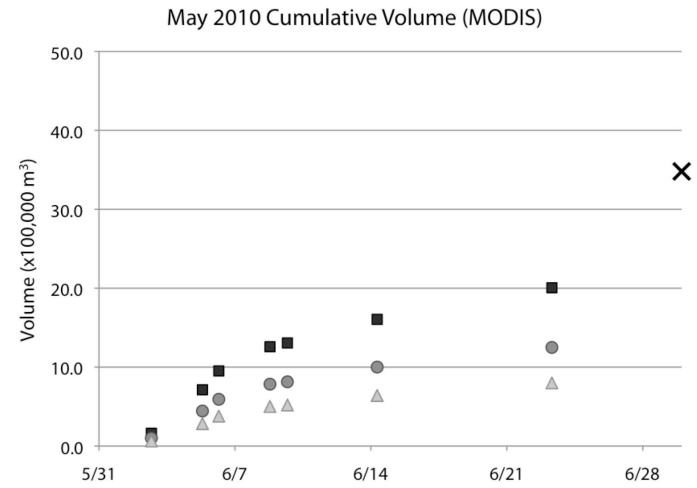

\section{Legend}

$250^{\circ} \mathrm{C}$ Model $\bigcirc 350^{\circ} \mathrm{C}$ Model $\triangle 600^{\circ} \mathrm{C}$ Model 